JOSÉ MANUEL

SANTOS PEREIRA
OTIMIZAÇÃO COMPUTACIONAL DE BIOADSORVENTES PARA A REMOÇÃO DE FÁRMACOS DA ÁGUA

COMPUTATIONAL OPTIMIZATION OF BIOADSORBENTS FOR THE REMOVAL OF PHARMACEUTICALS FROM WATER 


FÁRMACOS DA ÁGUA

\section{COMPUTATIONAL OPTIMIZATION OF BIO- ADSORBENTS FOR THE REMOVAL OF PHARMACEUTICALS FROM WATER}

Dissertação apresentada à Universidade de Aveiro para cumprimento dos requisitos necessários à obtenção do grau de Mestre em Biotecnologia Industrial e Ambiental, realizada sob a orientação científica do Doutor Sérgio Miguel Fernandes dos Santos, Investigador do Departamento de Química da Universidade de Aveiro, e da Doutora Vânia Maria Amaro Calisto, Estagiária de Pós-doutoramento do Departamento de Química da Universidade de Aveiro. 



\section{o júri}

presidente

Doutora Mara Guadalupe Freire Martins

Investigadora Coordenadora do Departamento de Química da Universidade de Aveiro

Doutor Jorge Manuel Campos Marques

Professor Auxiliar do Departamento de Química/Faculdade de Ciências e Tecnologia da Universidade de Coimbra

Doutor Sérgio Miguel Fernandes dos Santos

Investigador Auxiliar do Departamento de Química da Universidade de Aveiro 


contribuíram não só para ao desenvolvimento desta tese de mestrado como também para o meu próprio desenvolvimento pessoal ao longo deste ano.

Um agradecimento especial aos meus orientadores Sérgio e Vânia pela paciência e ajuda incansável. 

palavras-chave

resumo
Adsorção; Carvões Ativados; Fármacos; Tratamento de água; Sustentabilidade; Química Computacional, Dinâmica Molecular, Monte Carlo;

Os fármacos estão entre os contaminantes aquáticos mais persistentes, resistindo aos processos convencionais aplicados nas estações de tratamento de águas residuais (ETAR) e, muitos deles, representam uma ameaça séria para organismos não-alvo e para o meio ambiente. Neste contexto, a adsorção a carvões ativados (CA) é uma das mais promissoras metodologias para a remoção de fármacos da água dada a sua versatilidade e alta eficiência de remoção. Contudo, os CAs implicam custos elevados. A lama primária da resultante do tratamento de efluentes da indústria papeleira foi anteriormente apresentada como uma potencial fonte de carbono alternativa e barata para a produção de CA por pirólise.

A química computacional pode ser uma ferramenta valiosa na elucidação de alguns aspetos do mecanismo molecular de adsorção de poluentes orgânicos a CAs. No presente trabalho, é proposta a utilização de lama primária da indústria papeleira para a produção carvões (não)ativados. Os diferentes materiais foram caracterizados por um conjunto de técnicas experimentais, e os dados adquiridos usados na formulação de um modelo computacional válido, na tentativa de reproduzir a variabilidade do CA em termos de composição elementar, grupos funcionais e porosidade. O modelo desenvolvido foi usado na obtenção de informação pertinente através de técnicas de dinâmica molecular/Monte Carlo que possibilite o melhoramento do CA inicial,

Os resultados adquiridos em simulações Monte Carlo sugerem que CAs com teores de oxigénio superiores apresentam valores de área superficial mais elevados, e, consequentemente, capacidades máximas de adsorção superiores. A presença de iões positivos no meio de adsorção apresenta-se como um fator cooperativo para a adsorção de SMX, dada a formação de complexos $\mathrm{CA}-\mathrm{Na}^{+-}$ SMX em dupla camada e estabilização de conformações abertas, tal como demonstrado através de simulações de dinâmica molecular. 

keywords

abstract
Adsorption; Activated carbons; Imerging contaminants; Water treatment; Sustainability; Computational chemistry; Molecular dynamics, Monte Carlo

Pharmaceutically active ingredients are amongst the most persistent wastewater contaminants, resisting to wastewater treatment plants (WWTP) conventional processes, and some of them are proved to pose serious threats to organisms and the environment. In this context, adsorption by activated carbons (AC) is one of the most promising methodologies for the removal of pharmaceuticals from water due to its versatility and high removal efficiency. However, ACs are expensive and therefore now widely applied. Primary sludge from paper mills has been previously appointed as a potential cheap and renewable source of carbon for activated carbon production by pyrolysis.

Computational chemistry may help shed some light unto the molecular mechanisms underlying the adsorption of organic pollutants in ACs. In this work, it is proposed the usage of primary paper mill sludge in the production of (non)activated carbons. The different materials were characterized by a set of techniques and the gathered data was used in the formulation of a validated model in an attempt to reproduce the elemental composition, functional group variability and porosity. The developed model was used in order to collect relevant information through molecular dynamics/Monte Carlo techniques, enabling the improvement of the initial AC material.

The obtained data in Monte Carlo simulations suggest that AC with higher oxygen levels present greater values of surface are, and consequently superior maximum capacity values. The presence of positive ions in the adsorption medium presents itself as a cooperative factor for SMX adsorption, given the formation of $\mathrm{AC}-\mathrm{Na}^{+}-\mathrm{SMX}$ complexes and the estabilization of open configurations, such as demonstrated in molecular dynamics simulations. 



\section{Index}

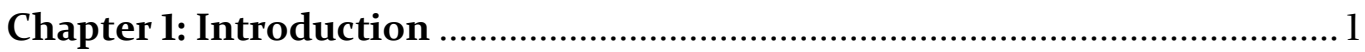

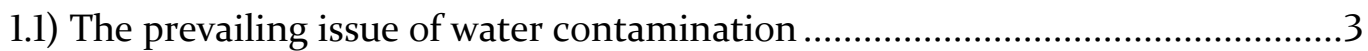

1.2) Activated Carbons: a solution to pharmaceutical contamination of water ..... 8

1.3) Harnessing the potential of paper mill primary sludge as feedstock for activated carbon production 13

1.4) Computational chemistry as a powerful tool to understand adsorption mechanisms 16

1.5) Present work objectives 19

Chapter 2: Materials and methods 21

2.1) Production of carbon materials .23

2.2) Characterization of carbon materials 24

2.2.1) Point of zero charge (PZC) determination. 24

2.2.2) Fourier transform infrared spectroscopy with attenuated total reflectance (FTIR-ATR). 24

2.2.3) Transmission electron microscopy (TEM) 24

2.2.4) Scanning electron microscopy (SEM) and Energy-dispersive X-ray spectroscopy (EDS)

2.2.5) Total organic carbon (TOC) content. .25

2.2.6) Proximate and ultimate analysis .....................................................25

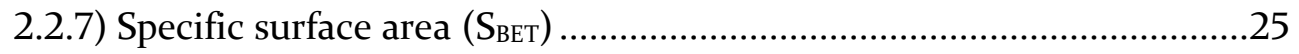

2.2.8) X-Ray Photoelectron Spectroscopy (XPS) .......................................... 26

2.3) Computational modelling approaches .........................................................27

2.3.1) Carbon model development ..............................................................27

2.3.2) Pharmaceutical molecules parametrization.......................................... 29

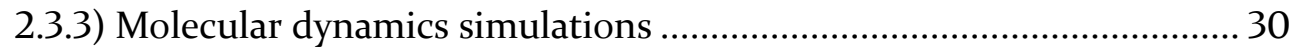

2.3.4) Monte Carlo adsorption essays .......................................................... 31 
Chapter 3: Results and discussion . .33

3.1) Carbon materials production 35

3.2) Carbon materials characterization .36

3.2.1) Fourier transform infrared spectroscopy with attenuated total reflectance (FTIR-ATR) . .36

3.2.2) Point of zero charge (PZC) determination ...........................................37

3.2.3) Transmission electron microscopy (TEM) ...........................................38

3.2.4) Scanning electron microscopy (SEM) and Energy-dispersive X-ray

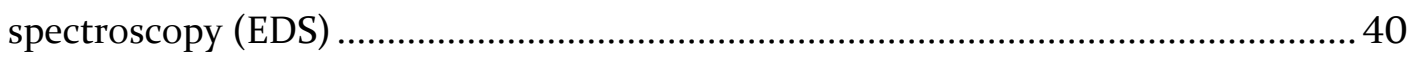

3.2.5) Total organic carbon (TOC) content .................................................... 42

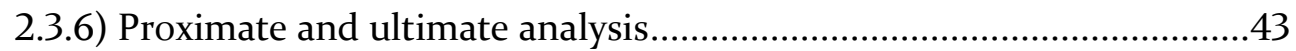

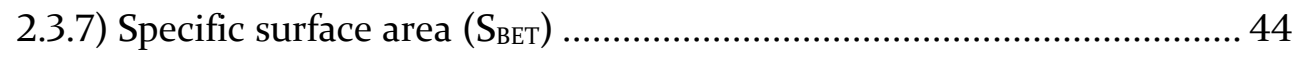

2.3.8) X-Ray Photoelectron Spectroscopy (XPS) ...................................... 46

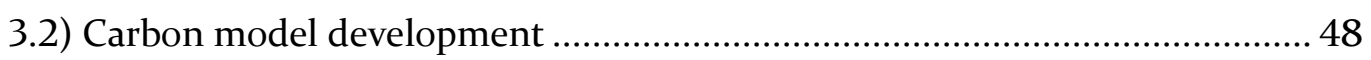

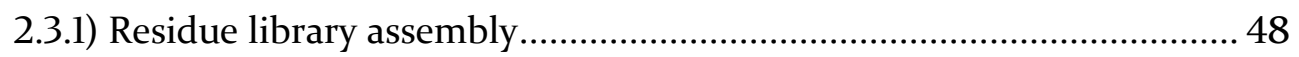

2.3.2) Carbon model production and characterization................................ 50

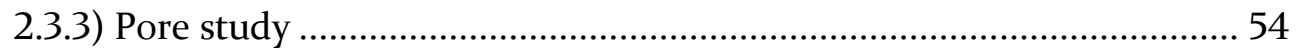

2.3.4) Dipole moment visualization..............................................................55

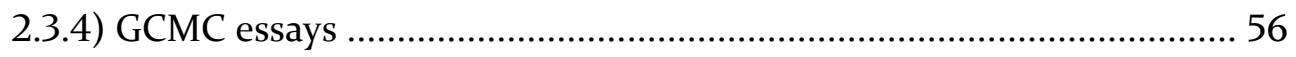

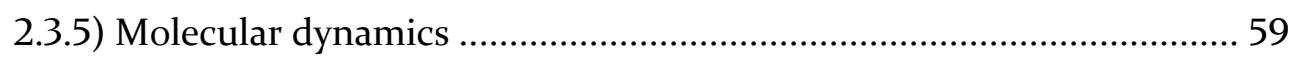

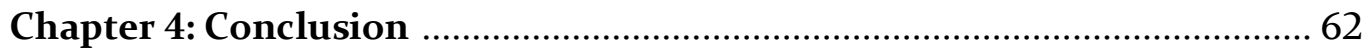

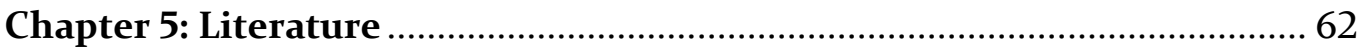




\section{Nomenclature and abbreviations glossary}

AC

APBS

$\mathrm{C}$

CA

CBZ

D

DFT

EDS

EQS

FTIR-ATR

GAC

GAFF

GCMC

IC

LINCS

$\mathrm{MC}$

MD

OC

PA

PAC

PBC

$\mathrm{P}_{\mathrm{C}}$

PS

PZC

RESP

$\mathrm{S}_{\mathrm{BET}}$

SC

SEM

SMX

TC

$\mathrm{T}_{\mathrm{C}}$
Activated carbon

Adaptive Poisson-Botlzmann Solver

Competitive adsorption

Chemical activation

Carbamazepine

Average pore diameter

Density Functional Theory

Energy-dispersive X-ray spectroscopy

Environmental Quality Standards

Attenuated total reflection Fourier-transform infrared spectroscopy

Granular activated carbon

Generalized Amber Force Field

Grand Canonical Monte Carlo

Inorganic carbon

Linear constraint solver

Monte Carlo

Molecular Dynamics

Organic carbon

Physical activation

Powdered activated carbon

Periodic boundary conditions

Critic pressure

Primary sludge

Point of zero charge

Restrained electrostatic potential

Surface area

Single component adsorption

Scanning electron microscopy

Sulfamethoxazole

Total carbon

Critic temperature 


$\begin{array}{ll}\text { TEM } & \text { Transmission electron microscopy } \\ \text { TGA } & \text { Thermogravimetric analysis } \\ \text { TOC } & \text { Total organic carbon } \\ \text { TP } & \text { Transformation product } \\ V_{P} & \text { Total pore volume } \\ \text { VPC } & \text { Virtual porous carbon } \\ \omega & \text { Acentric factor } \\ W_{0} & \text { Total micropore volume } \\ \text { WWTP } & \text { Wastewater treatment plant } \\ \text { XPS } & \text { X-Ray photoelectron spectroscopy }\end{array}$

\section{Illustration index}

Fig. 1. Main routes of pharmaceutical contamination of the environment .........................3

Fig. 2. Sulfamethoxazole and carbamazepine structural changes based on $\mathrm{pH}$............... 6

Fig. 3. Standard activated carbon production methods .................................................. 10

Fig. 4. Main forms of activated carbons distribution ...................................................... 11

Fig. 5. Schematic representation of primary sludge origin ............................................ 14

Fig. 6. Activated carbon model examples ....................................................................... 17

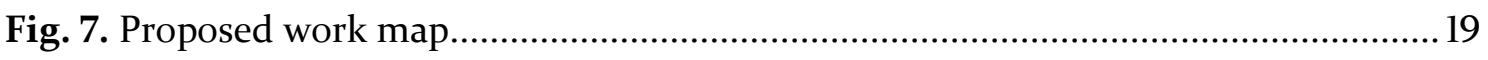

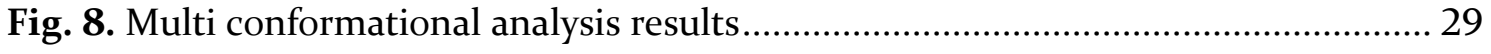

Fig. 9. System preparation for molecular dynamics simulations ................................... 30

Fig. 10. Production step yield $\%(\mathrm{~m} / \mathrm{m})$ for different carbon material samples .................35

Fig. 11. FTIR-ATR spectra of the precursor and different carbon materials ......................37

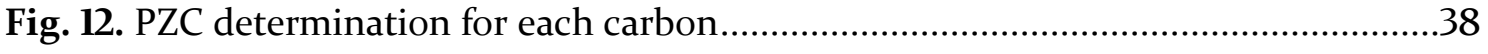

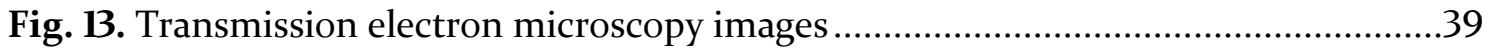

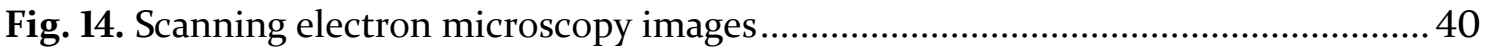

Fig. 15. Energy-dispersive X-ray spectroscopy spectra .................................................... 41

Fig. 16. OC and IC content in PS and the produced carbon materials ............................ 42

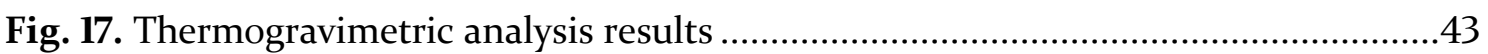


Fig. 18. Elemental analysis of PS and produced carbon materials 44

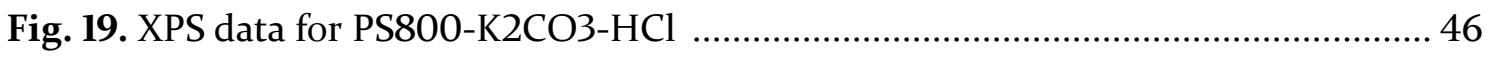

Fig. 20. Schematic representation of the proposed functional groups ........................... 47

Fig. 21. Non-minimized residue example from one of the created libraries .................... 49

Fig. 22. Non-minimized residues from different libraries .............................................. 49

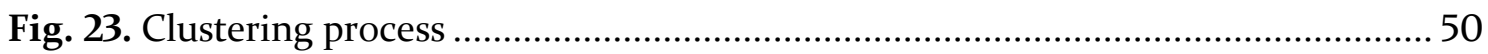

Fig. 24. Visual representation of different instances of the proposed AC model ............ 51

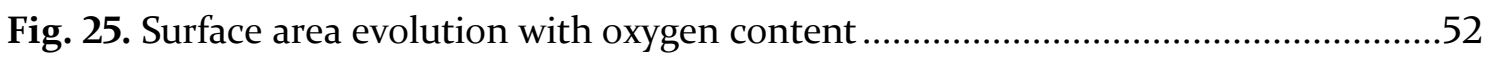

Fig. 26. Elemental and functional content comparison ...............................................52

Fig. 27. Micropore structures in the proposed models .................................................... 54

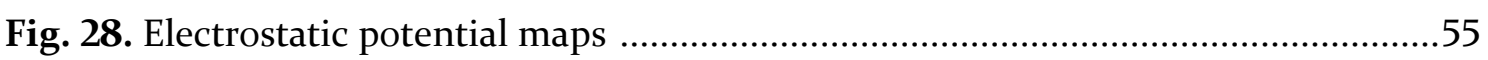

Fig. 29. Electrostatic potential map of the resulting AC model .......................................55

Fig. 30. GCMC adsorption results for different AC models ............................................ 56

Fig. 31. Adsorption capacity and surface area evolution ................................................57

Fig. 32. GCMC adsorption results for different $\mathrm{AC}$ models (in presence of $\mathrm{Na}^{+}$) ............. 58

Fig. 33. Adsorption capacity and surface area evolution (in presence of $\mathrm{Na}^{+}$) ................. 59

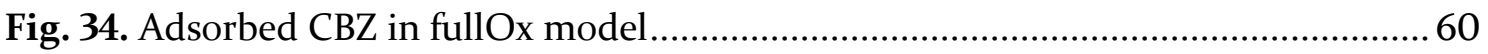

Fig. 35. Different configurations of SMX on a single microcrystallite .............................60

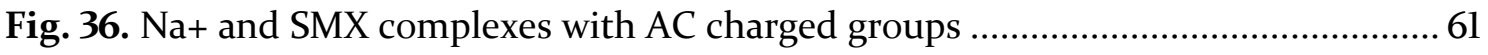

Fig. 37. Competitive adsorption interaction between SMX and CBZ ............................... 61

\section{Table index}

Table 1. Characteristics of pharmaceutical compounds studied ..........................................5

Table 2. Carbamazepine and Sulfamethoxazole concentrations in WWTP ........................

Table 3. Water treatment processes efficacy in pharmaceutical removal........................... 8

Table 4. Alternative renewable sources of cellulosic precursors.......................................... 13

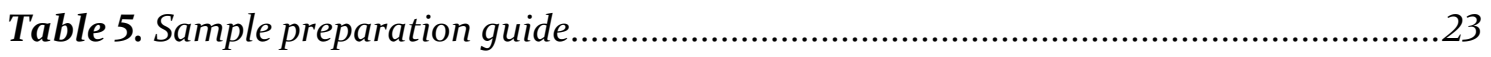

Table 6. Critical properties and acentric factors calculated ............................................. 31

Table 7 - Textural parameters of characterized carbon materials........................................45

Table 8. Characterization of the different models ............................................................53 



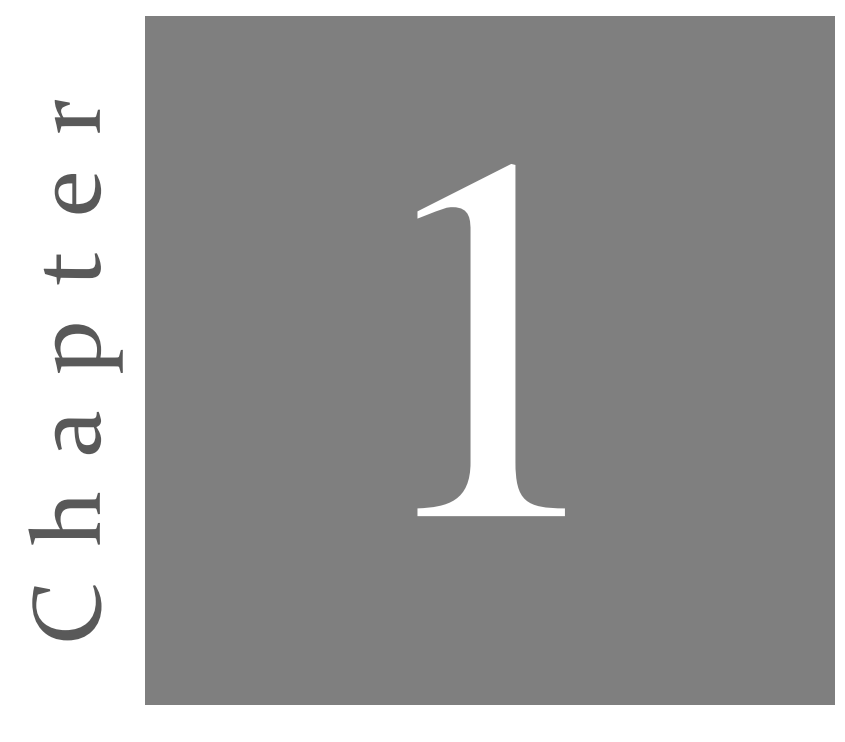

\section{Introduction}

"The leaves, by themselves, are no more than trivial fluttering decoration. It is the trunk and limbs that give the tree its grandeur and the leaves themselves their meaning. There is not a discovery in science, however revolutionary, however sparkling with insight, that does not arise out of what went before. 'If I have seen further than other men,' said Isaac Newton, 'it is because I have stood on the shoulders of giants."

- Isaac Asimov, Adding a Dimension: Seventeen Essays on the History of Science, 1964 


\section{1) The prevailing issue of water contamination}

Both humans and animals have greatly benefited from the last century advances in medicine. However, the consistent increase in drug production, consumption and disregarded disposal poses severe threats to human health and non-target organisms and is a serious cause of environmental damage $(1,2)$. This steady increase in consumption during the last decades can be ascribed to several factors, such as the discovery of new drugs, increase in population and industrialization levels, demographic ageing and expiration of patents resulting in an increase of low-cost generics production (3). As an example, China's pharmaceutical compound production has tripled from 2003 to 2011, accounting for over $20 \%$ of the total global production (4), and global consumption rates of antibiotics has increased by over $30 \%$ in the last decade (5).

Over 200 pharmaceutically active compounds have been identified in the environment, with concentrations ranging from a few nanograms per liter to a thousand micrograms per liter $(3,6)$. Such pharmaceuticals, mainly antibiotics, painkillers, vascular drugs and antidepressants (7), find their way into the ecosystem through several routes, as described in Fig. 1 (8).

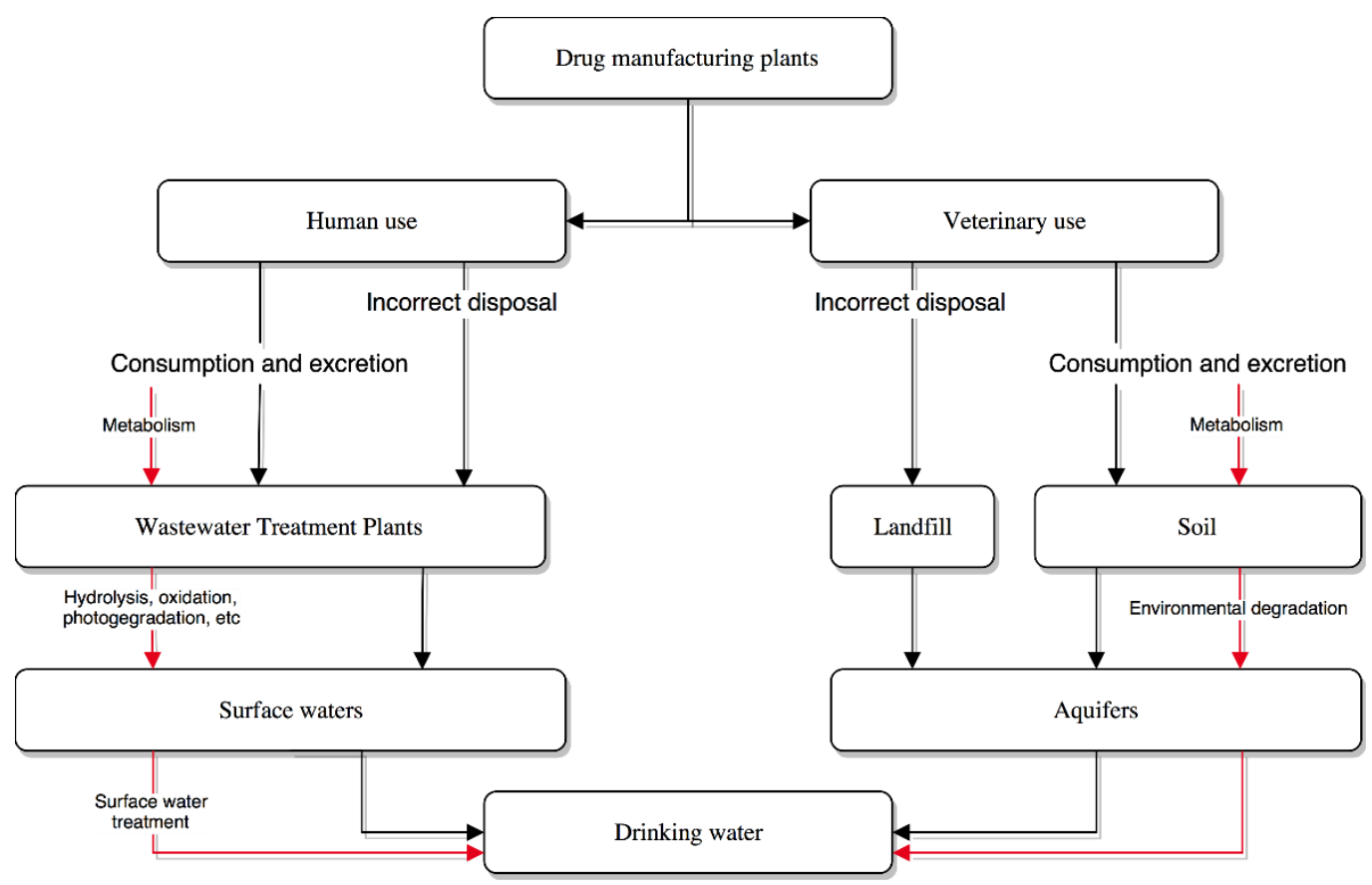

Fig. 1. Main routes of pharmaceutical contamination of the environment. Pharmaceutical transformation products origin and propagation routes are schematically represented in red. 
Wastewater treatment plants (WWTP) receive contaminated effluents from drug manufacturing plants and municipal sewage systems. After administration, pharmaceuticals are metabolized and excreted by the treated organism. While human used pharmaceuticals often find their way to a WWTP, pharmaceuticals used in veterinary applications such as with domestic pets and livestock are directly delivered to the soil where, through infiltration, are lead to aquifers and groundwater systems. Also, aquaculture derived residues are delivered directly to the water. Incorrect disposal of pharmaceuticals also contributes to the contamination of aquifers, directly or through landfill leakage, even though the major cause for environmental contamination resides on WWTP effluent discharges $(9,10)$. It has been reported that about $64 \%$ of these emerging contaminants are only partially removed (<50\%), while up to $9 \%$ are not removed at all by the standard treatment processes in WWTPs (11).

Furthermore, pharmaceutical transformation products (TPs) are produced by a variety of processes (12):

- Metabolism - as an example, $26 \%$ of the administrated ibuprofen, a common pharmaceutical used in inflammatory diseases, pain, dysmenorrhea, or fever, is excreted in the form of hydroxy-ibuprofen, a TP generally considered more toxic to the aquatic life forms than the parent compound $(5,13)$;

- Wastewater treatment processes (such as hydrolysis, oxidation, photodegradation, among others);

- Digestion by microbial activity and other natural processes in the environment;

- Treatment processes for surface water.

Some TPs have been identified as being more ecotoxic than the parent compound, or as having synergetic and additive effects while in mixture (14). This is the case of acridine, a photodegradation product of carbamazepine (CBZ) regarded as mutagenic and carcinogenic (15).

Even though the concentration of therapeutic compounds in the water supply are below the minimum levels for human consumption concern in terms of an acute response, the presence of this type of pollutants still pose a series of risks (16-18): 
- Environmental damage to non-target organisms;

- Biomagnification through the food-chain;

- Long-term/sub-therapeutic exposure to both individual compounds and mixtures;

- Release of antibiotics to the ecosystem acts as a selection force that can lead to the development of antibiotic resistant pathogens;

- Different dose sensitivity in the young, elderly or pregnant are not studied.

For this reasons, some pharmaceutical compounds are now regarded as priority substances in the field of water policy according to European directives (19). Within the scope of the present work, sulfamethoxazole (SMX) and CBZ, two pharmaceutical compounds frequently found in the environment (20-22), are proposed as target active agents for adsorption, whose details are expressed in Table 1 (23-27).

Table 1. Characteristics of pharmaceutical compounds studied

\begin{tabular}{rll}
\hline & SMX & CBZ \\
\hline Chemical formula & $\mathrm{C}_{10} \mathrm{H}_{11} \mathrm{~N}_{3} \mathrm{O}_{3} \mathrm{~S}$ & $\mathrm{C}_{15} \mathrm{H}_{12} \mathrm{~N}_{2} \mathrm{O}$ \\
Molecular weight $\left(\mathrm{g} \mathrm{mol}^{-1}\right)$ & 253.3 & 236.3 \\
Water solubility $\left(\mathrm{mg} \mathrm{L}^{-1}\right)$ & $610\left(37^{\circ} \mathrm{C}\right) ;<100\left(20^{\circ} \mathrm{C}\right)$ & $17.7\left(25^{\circ} \mathrm{C}\right)$ \\
Hydrogen bond acceptor & 4 & 1 \\
Hydrogen bond donor & 2 & 1 \\
Polar surface area $(\AA)$ & 98.22 & 46.33 \\
VdW volume $\left(\AA^{3}\right)$ & 204.70 & 210.15 \\
Number of rings & 2 & 3 \\
pKa & $1.97 ; 6.16$ & $2.3 ; 13.9$ \\
& Acute: 2.7 & Acute: 2000 \\
EQS $\left(\mu \mathrm{Lg} \mathrm{L}^{-1}\right)$ & Chronic: 0.6 & Chronic: 2 \\
& &
\end{tabular}

${ }^{\mathrm{a}}$ Environmental quality standards 
The structure of both pharmaceuticals is schematically represented in Fig. 2, as well as structural changes based on $\mathrm{pH}$ of the medium. An overview of CBZ and SMX concetrations in effluents of various WWTPs can be found in Table 2 (28-36).
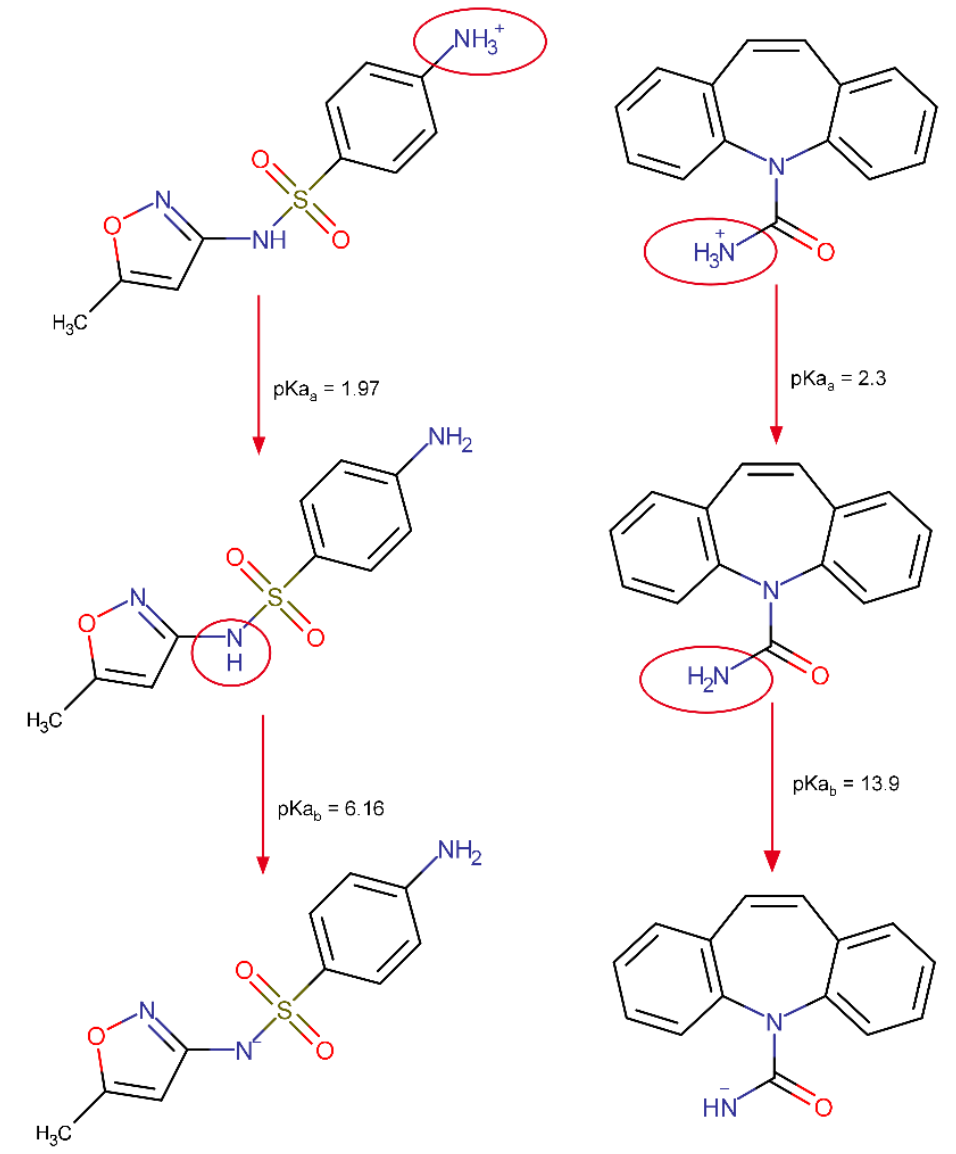

Fig. 2. Sulfamethoxazole (left) and carbamazepine (right) structural changes based on pH. Red circles highlight the structural group who suffered deprotonation with the $\mathrm{pH}$ increase.

SMX is an antibiotic extensively used in the control of human or animal urinary, respiratory and gastrointestinal infections, and it is estimated that $10 \%$ to $30 \%$ is excreted by urine in the original active form $(37,38)$. It is highly persistent to biological degradation in common wastewater treatment processes: maximum concentrations of $4.46 \mu \mathrm{g} \mathrm{L}^{-1}$ (Germany) have been measured in WWTP effluents, over double of the environmental quality standards (EQS) proposed by Oekotoxzentrum (2016) for chronic effects (24). In the case of SMX, bacterial resistance dissemination is a major concern, and therefore additional cautionary measures should be taken, in order to improve the removal rate of this antibiotic from water, especially considering that some of its metabolites are more ecologically toxic than the parent compound (39). 
Table 2. Carbamazepine and Sulfamethoxazole concentrations in WWTP effluents around the world

\begin{tabular}{ccc} 
Country & \multicolumn{2}{c}{ WWTP effluent $\left(\mathrm{ng} \mathrm{L}^{-1}\right)$} \\
\cline { 2 - 3 } Germany & $<6300$ & SMX \\
France & $980-1200$ & $300-2460$ \\
Belgium & $<1200$ & $70-90$ \\
Italy & $300-500$ & - \\
Spain & $<1290$ & $10-30$ \\
Greece & 1030 & - \\
Norway & $<3400$ & $<200$ \\
Sweden & $<1180$ & $79-2200$ \\
USA & $110-190$ & $10-76$ \\
Japan & $18-86$ & $<50$ \\
UK & $230-1060$ & - \\
\hline & & \\
\hline
\end{tabular}

CBZ is generally applied on the treatment of seizures, neuropathic pain, and second-line medication of bipolar disorders and some cases of schizophrenia (40). As one of the most frequently detected pharmaceutical in wastewater (41), this compound is highly recalcitrant to standard wastewater treatments, and poses serious risks to the environment and human health (42-44). It has been detected in WWTP effluents with maximum concentrations as high as $6.30 \mu \mathrm{g} \mathrm{L}^{-1}$ (Germany), over triple the EQS for chronic effects $\left(2 \mu \mathrm{g} \mathrm{L}^{-1}\right)$ proposed (24). In previous studies, it has been shown that some photodegradation products of CBZ (acridine and acridone) are even more toxic than the parent compound (45).

For these reasons, removal of SMX and CBZ from water without the risk of developing dangerous degradation products becomes imperative. 


\section{2) Activated Carbons: a solution to pharmaceutical contamination of water}

Currently, wastewater treatments consist mainly of two classes of methods: on one hand, conventional methods, such as flocculation, filtration and biodegradation, are mainly ineffective on the removal of persistent organic compounds. On the other hand, chlorination, oxidation by ozone and ion exchange resins are examples of advanced methods that although having better efficiencies for the removal of pharmaceuticals, may generate transformation products that are even more dangerous to the environment and are generally more expensive to employ in standard WWTPs $(26,46)$. In this context, over the last decade, some research has been undertaken in order to quantify the efficiency of pharmaceutical removal by standard and advanced water treatment processes currently employed, as stated in Table 3.

Table 3. Water treatment processes efficacy in pharmaceutical removal - adapted from (47-49)

\begin{tabular}{|c|c|c|c|c|c|}
\hline & Process & $\operatorname{Min}(\%)$ & & $\operatorname{ax}(\%)$ & \\
\hline \multirow{4}{*}{ 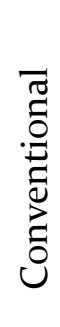 } & Anaerobic activated sludge & $17 \beta$-Estradiol & 0 & Estrone (El) & 79 \\
\hline & Mixed activated sludge & Bezafibrate & 19 & Caffeine & 100 \\
\hline & Aerobic activated sludge & Carbamazepine & 9 & Salicylic acid & 97 \\
\hline & Coagulation & Ibuprofen & $<20$ & Diclofenac & 60 \\
\hline \multirow{7}{*}{ 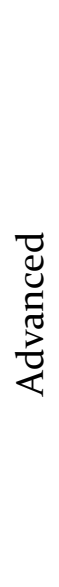 } & Ultrafiltration & Caffeine & 2 & Estrone (El) & 98 \\
\hline & Nanofiltration & Acetaminophen & 18 & Sulfamethoxazole & 98.5 \\
\hline & Reverse Osmosis & Carbamazepine & 65 & Ketoprofen & 99 \\
\hline & UV & Acetaminophen & 1 & Antipyrine & 100 \\
\hline & Photolysis (254 nm) & Naproxen & 29 & Diclofenac & 100 \\
\hline & Ozonation & Ethynylestradiol & 80 & Ketoprofen & 96 \\
\hline & Activated carbons & Cephalexin & 57 & Tetracycline & 100 \\
\hline
\end{tabular}


As for conventional processes, coagulation treatments were mostly ineffective in pharmaceutical removal. Although activated sludge processes can achieve significant removal rates ( $79 \%$ to $100 \%$ of maximum removal), these values can vary immensely due to factors such as tank temperature, hydraulic retention time and sludge age, among others. This unpredictability of results can pose a liability. Furthermore, the optimization of such factors for removal of therapeutic compounds may lead to lower removal rates of other contaminants, such as pathogenic microbial agents, and therefore priority guidelines should not be overridden (17).

Advanced wastewater treatments such as membrane filtration or ozonation allow higher removal rates of pharmaceuticals from wastewater (99\% and $96 \%$ of maximum removal efficiency, respectively), but require an intensive capital investment when compared to standard practices, and therefore are not employed to a meaningful extent. UV treatments, as well as photolysis and ozonation can produce TPs and should be applied with caution. Moreover, ultraviolet radiation presents a fluctuating range of removal rates (1-100\%), and can be, therefore, unreliable in industrial scale applications $(17,50)$.

In this context, adsorption of contaminants by activated carbons $(\mathrm{AC})$ emerges as an optimistic solution, with advantages such as versatile usage and high removal efficiencies and the ability to regenerate and reuse spent adsorbents (51), even though it is still not widely used because of its high-cost (52) and the fact that it doesn't mineralize the contaminants (49). Current estimations place the world's demand for AC around 1.1 million tons per year, and it is expected to grow at a rate of over $10 \%$ per year until at least the 2020's (53). AC are carbon-rich materials with a porous structure, that can be activated by thermal/physical and/or chemical processes in order to increase internal superficial area and therefore, adsorption capacity (54). AC applications vary, including adsorption of industrial pollutants, heavy metals, organic and inorganic compounds, microorganisms, as well as energy storage (55).

Regarding AC production processes, Fig. 3 schematizes two routes to achieve carbonization and activation of precursor materials. Through physical processes, the starting material is firstly carbonized, and then suffers activation under an oxidizing gas flow such as water vapor $\left(\mathrm{H}_{2} \mathrm{O}\right)$, carbon dioxide $\left(\mathrm{CO}_{2}\right)$, or a mixture of both, at high temperatures (800 to $\left.1100{ }^{\circ} \mathrm{C}\right)(56,57)$, whereas in common chemical activation there is carbonization and activation of the initial material simultaneously when impregnated with activating chemical agents at medium-high temperatures $(400-900 \stackrel{\circ}{C})(55,57,58)$. 
The most common activating agents are zinc chlorine $\left(\mathrm{ZnCl}_{2}\right)$, di-hydrogen phosphate $\left(\mathrm{H}_{2} \mathrm{PO}_{4^{-}}\right)$, sodium hydroxide $(\mathrm{NaOH})$, potassium hydroxide $(\mathrm{KOH})$ and potassium carbonate $\left(\mathrm{K}_{2} \mathrm{CO}_{3}\right)$. Chemical activation has shown some benefits over physical processes, such as higher yields, inferior pyrolysis temperatures, and the fact that it generally produces AC with highly developed micro porosity, higher surface area (600 to $2000 \mathrm{~m}^{2}$ $\mathrm{g}^{-1}$ ) and reduced mineral matter content (20). However, chemical activation is commonly more expensive, deals with corrosive substances and requires an extra washing step (59). Although a considerable number of different attributes need to be analyzed in order to fully characterize an $\mathrm{AC}$, the specific surface area $\left(\mathrm{S}_{\mathrm{BET}}\right)$ and average pore diameter $(\mathrm{D})$ are some of the significant influential factors and the most commonly found attributes described in the available literature (21).

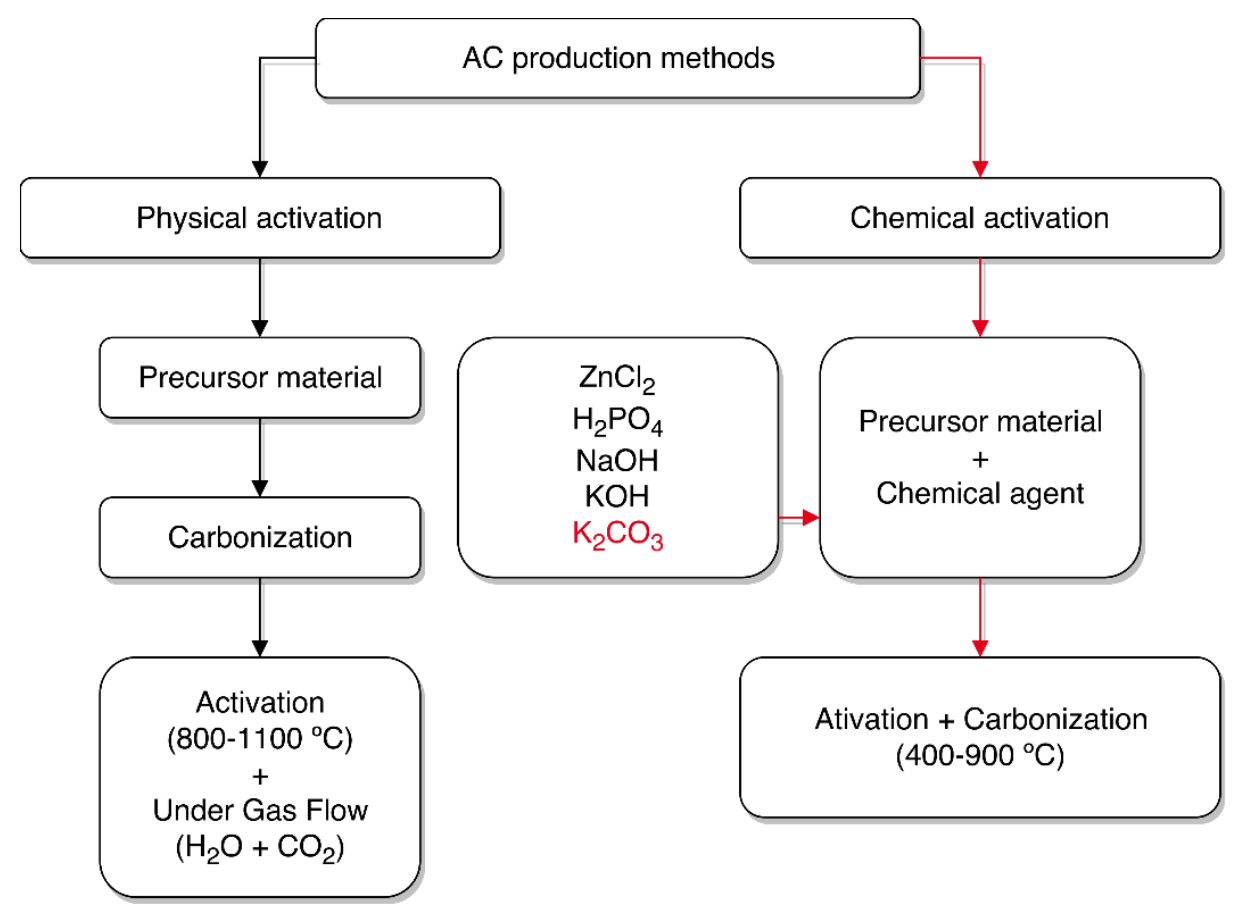

Fig. 3. Standard activated carbon production methods. The proposed method for the present work is illustrated in red.

Washing is often required in order to remove impurities originated by the chemical activation process, usually with water or an acid chemical agent such as hydrochloric acid (HCl) (60). Carbonization using high-power microwaves (1200 W) instead of nitrogen $\left(\mathrm{N}_{2}\right)$ purged muffles has been discussed, with proposed advantages such as shorter process times, lower energy demands and higher yields (53). 
On the subject of activation agent selection, $\mathrm{K}_{2} \mathrm{CO}_{3}$ emerges as a promising choice, based on its environmental advantages, such as avoiding eutrophication problems associated with phosphate use (61) and not being corrosive of hazardous as some alkalimetal hydroxides (62). Also, in previous studies, $\mathrm{K}_{2} \mathrm{CO}_{3}$ activation resulted in $\mathrm{AC}$ with high specific surface areas. For instance, by using industrial pre-treated cork, a $\mathrm{S}_{\mathrm{BET}}$ of $907 \mathrm{~m}^{2} \mathrm{~g}^{-1}$ was achieved (63), when testing AC production from sisal waste a SBET of $1038 \mathrm{~m}^{2} \mathrm{~g}^{-1}$ was obtained (64), cornstalk lignin based AC showed a SBET of $1410 \mathrm{~m}^{2} \mathrm{~g}^{-1}$ (61) and when using chitosan as feedstock, AC showed a $\mathrm{S}_{\text {BET }}$ of $2130 \mathrm{~m}^{2} \mathrm{~g}^{-1}$, although with a larger percentage of mesopores (65). Although the activation method is not thoroughly studied, it is believed that activating agents containing potassium improve the microporous nature of the feedstock material by intercalation of the metal with the carbonaceous structure and acting as a cast during pyrolysis $(62,66,67)$.

Commercially available AC are commonly produced from fossil fuels such as petroleum or bituminous coal and mainly distributed in two forms: powdered activated carbons (PAC) and granular activated carbons (GAC), illustrated in Fig. 4. Both were shown to have consistent removal rates of over $90 \%$ for more than 25 types of pharmaceutical agents. Usually, PAC is continuously fed into the treatment reactors as a new product, while GAC can be regularly regenerated (68). Some other unusual forms of distribution include fibers, cloths, nanotubes or pellets (55). Since AC removal from the reaction medium after adsorption can be troublesome, studies using magnetized AC for magnetic removal were carried, showing promising results (69).
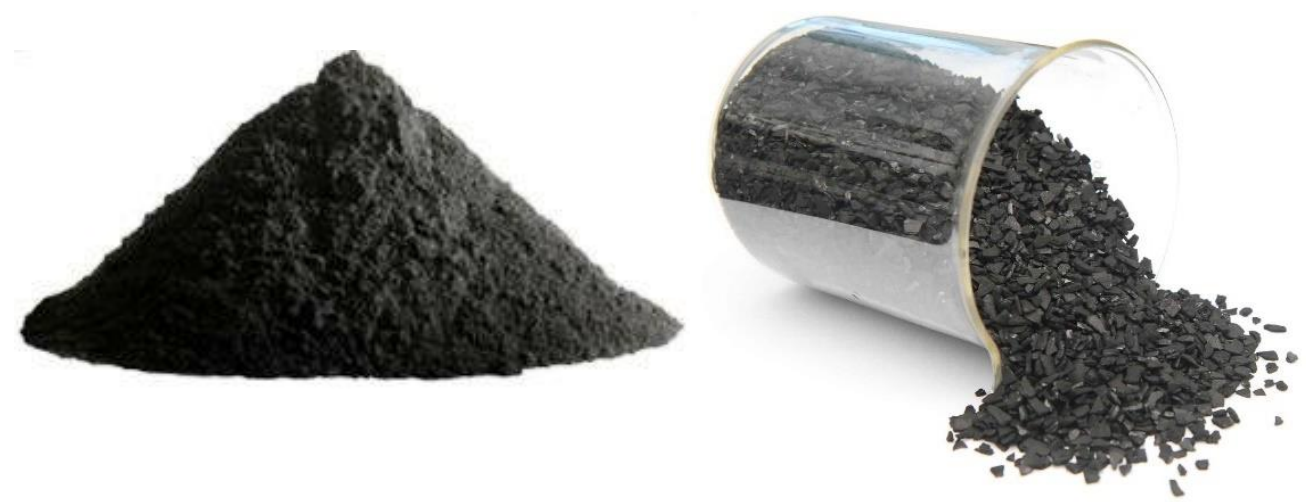

Fig. 4. Main forms of activated carbons distribution: powdered (left) and granular (right) 
Regarding pharmaceuticals adsorption, AC efficiency greatly depends on the target molecule chemistry, given that adsorption is generally governed by hydrophobic/hydrophilic interactions, non-covalent attractions ( $\pi-\pi$ stacking) and electrostatic attraction/repulsion based on the surface functional groups of the carbon. It was previously reported that PAC DETOX 1600, a commercially available AC, presented removal rates of 92\%, 76\% and 73\% towards Triclosan, Metoprolol and Trimethoprim, while only removing $9 \%, 3 \%$ and $1 \%$ of Acetaminophen, Caffeine and Ibuprofen, where the authors point electrostatic interactions, chemical bounding and other non-specific forced as the main agents in the adsorption process. This lower removal rates were improved by combining AC adsorption with ultrafiltration, reaching removal rates of over 90\% towards all pharmaceutical compounds (70).

Given the presence of functional groups on the AC surface, previous works demonstrated the influence of $\mathrm{pH}$ on removal rates of pharmaceuticals and regeneration capacity of AC. Results regarding the adsorption of pramipexole dihydrochloride (PD), a popaminergic antiparkinsonism agent, and dorzolamide (D), an ophthalmic glaucoma agent, using AC derived from potato peels, showed that adsorption was favored by lower $\mathrm{pH}$ (around 2), (61\% maximum removal rate of $\mathrm{PD}$ and 55\% removal rate of $\mathrm{D}$ ), while regeneration of the used $\mathrm{AC}$ was favored by higher $\mathrm{pH}$ (around 10). (71). A different study showed similar results, where the adsorption of ceftazidime was favored at low $\mathrm{pH}$. This effect was attenuated by the impregnation of the AC with metals such as iron, aluminum and copper (4). In opposition, alanine adsorption by commercially available $\mathrm{AC}$ was shown to be favored by basic $\mathrm{pH}$ (above 8) and low content of oxygen (72), revealing that the protuberant adsorption mechanism is dependent on the target molecule chemistry.

Therefore, two main characteristics in the adsorbent are of importance: the superficial area/pore development and surface chemistry (26). 


\section{3) Harnessing the potential of paper mill primary}

\section{sludge as feedstock for activated carbon production}

Currently, AC are primarily derived from fossil fuels hydrocarbons resulting from the heavy fractions of petroleum and coal or expensive lignocellulosic materials, so its use is therefore restricted by cost and availability, as well as environmental concerns regarding particulate matter generation or heavy metal contamination during carbonization processes, as well as extensive exploration of natural resources $(51,56,57)$. As summarized in Table 4, abounding alternative renewable sources of cellulosic precursors have been proposed and studied as alternative precursors for AC production, either by physical activation (PA) or chemical activation (CA).

Table 4. Alternative renewable sources of cellulosic precursors for AC production

\begin{tabular}{|c|c|c|c|c|c|}
\hline Precursor & Activation method & $T(\mathrm{oC})$ & $\mathrm{S}_{\mathrm{BET}}\left(\mathrm{m}^{2} \mathrm{~g}^{-1}\right)$ & $\mathrm{D}(\mathbf{n m})$ & Ref. \\
\hline Coconut shell & $\mathrm{PA}\left(\mathrm{H}_{2} \mathrm{O}\right)$ & 850 & 1493 & 1.57 & (73) \\
\hline Eucalyptus & $\mathrm{PA}\left(\mathrm{CO}_{2}\right)$ & 900 & 1491 & 2.15 & \multirow{2}{*}{ (74) } \\
\hline Wattle & $\mathrm{PA}\left(\mathrm{CO}_{2}\right)$ & 900 & 1000 & 2.16 & \\
\hline Quercus agrifolia & $\mathrm{PA}\left(\mathrm{CO}_{2}\right)$ & 880 & 1197 & 2.17 & $(75)$ \\
\hline Cane sugar bagasse & $\mathrm{CA}\left(\mathrm{HNO}_{3}\right)$ & 900 & 868 & 1.90 & \multirow{2}{*}{ (76) } \\
\hline Sawdust & $\mathrm{CA}\left(\mathrm{HNO}_{3}\right)$ & 900 & 1100 & 2.00 & \\
\hline Olive tree & $\mathrm{CA}\left(\mathrm{H}_{3} \mathrm{PO}_{4}\right)$ & 550 & 904 & 5.30 & $(52)$ \\
\hline Vietnamese jute & $\mathrm{PA}\left(\mathrm{CO}_{2}\right)$ & 950 & 657 & 1.76 & \multirow{2}{*}{$(77)$} \\
\hline Coconut fibers & $\mathrm{PA}\left(\mathrm{CO}_{2}\right)$ & 950 & 534 & 1.78 & \\
\hline Palm seeds & $\mathrm{CA}\left(\mathrm{ZnCl}_{2}\right)+\mathrm{PA}\left(\mathrm{H}_{2} \mathrm{O}\right)$ & 800 & 1291 & 2.43 & (78) \\
\hline Rice husk & $\mathrm{PA}\left(\mathrm{CO}_{2}\right)$ & 500 & 39 & 3.01 & \multirow{6}{*}{$(79)$} \\
\hline Rice husk & $\mathrm{PA}\left(\mathrm{H}_{2} \mathrm{O}\right)$ & 500 & 74 & 2.89 & \\
\hline Macadamia nut shell & $\mathrm{PA}\left(\mathrm{CO}_{2}\right)$ & 500 & 844 & 2.30 & \\
\hline Macadamia nut shell & $\mathrm{PA}\left(\mathrm{H}_{2} \mathrm{O}\right)$ & 500 & 487 & 0.52 & \\
\hline Corncob & $\mathrm{PA}\left(\mathrm{CO}_{2}\right)$ & 500 & 675 & 2.13 & \\
\hline Corncob & $\mathrm{PA}\left(\mathrm{H}_{2} \mathrm{O}\right)$ & 500 & 836 & 2.04 & \\
\hline
\end{tabular}


Regarding average pore diameter (D), it's possible to infer that such values usually prevail between 1.5 and $3.0 \mathrm{~nm}$. IUPAC recommendations define a micropore as being a pore with a diameter of less than $2 \mathrm{~nm}(80)$.

Besides agricultural precursors, some industrial wastes have been studied as potential feedstock for AC production. Primary paper mill sludge (PS) is the result of primary treatment of paper mill effluents, as described in Fig. 5. This material mainly consists of wood fibers and organic matter such as amino acids, polycyclic aromatic hydrocarbons, heterocyclic compounds and organofluoride compounds $(81,82)$.

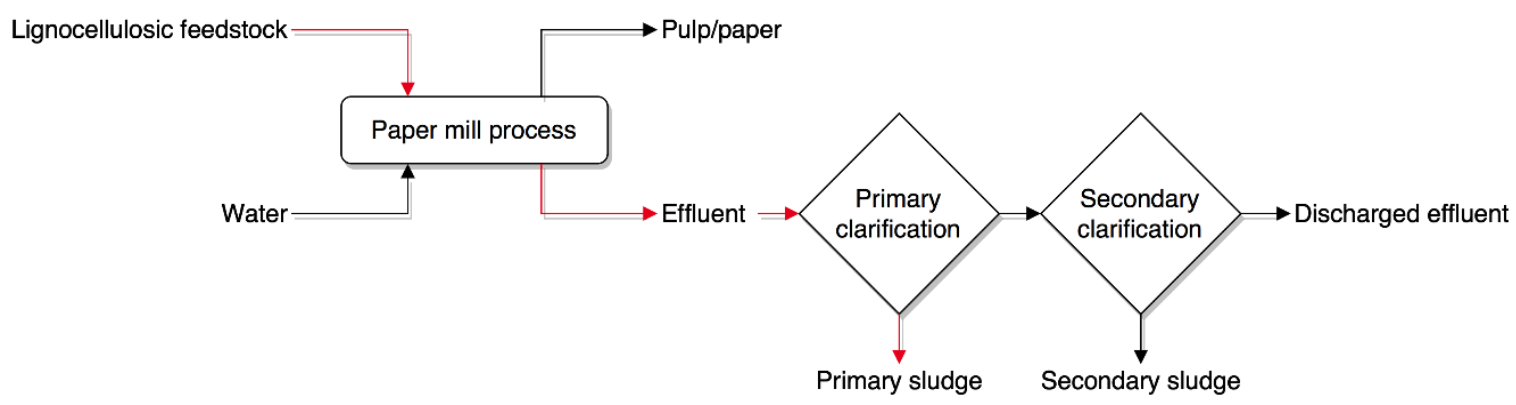

Fig. 5. Schematic representation of primary sludge origin in paper mill effluent treatment processes, highlighted in red

Pulp and paper mills around the globe produce large amounts of PS: USA, Japan, China, Europe and South Africa together produce nearly 30 million tons per year (83). For comparison, in North America, $4 \mathrm{~kg}$ of sludge is produced for every $100 \mathrm{~kg}$ of paper (84). Furthermore, disposal of PS is currently a major issue. Traditionally, it involves landfilling or energy production though incineration/combustion. However, such solutions are rapidly becoming unsustainable based on a number of factors $(81,82,84)$ :

- Water removal from crude PS in order to meet landfill standards, as well as transportation to the landfill, is economically suboptimal;

- Leachate production in landfills constitutes a ground water pollution source;

- Progressively stringent measures have been employed regarding landfill space depletion;

- Given the high water content of untreated PS, energy production is far from ideal due to energy loss to water evaporation; 
- Combustion of PS, if improperly handled, may cause atmospheric pollution due to $\mathrm{NO}_{\mathrm{X}}, \mathrm{SO}_{\mathrm{X}}$ and suspension dust emissions;

Given its abundance and sizable content in carbon, PS has been proposed as a feedstock for AC production (26,46,85-89), after showing interesting results for the production of non-activated carbons, and therefore acting as a starting point for the study of AC production. When compared to commercial ACs, alternative adsorbents generated from PS showed faster adsorption kinetics, comparable $S_{B E T}$ and higher adsorption capacity, especially when considering samples activated with $\mathrm{ZnCl}_{2}$. Another study using PS as a starting point for AC production showed that further biological activation with Pseudomonas putida resulted in an increase from 65\% removal rate of phenol to 97\% (90). These results further substantiate the notion that AC generated from PS material is a versatile and competitive option to common AC. 


\section{4) Computational chemistry as a powerful tool to understand adsorption mechanisms}

Despite being thoroughly studied, the adsorption process at the molecular level in AC remains shrouded and constitutes a point of divergence in the scientific community. For example, disparity in theories regarding the primary adsorption principle exists, where some studies point functional group interactions as the main force guiding molecular adsorption, while others assign it to microporous structure and specific surface areas (77). Therefore, deeper insights into the interactions between adsorbates and the AC are necessary. This would allow the modulation of the AC characteristics in order to increase adsorption capacities and rates or target compound selectivity.

Computational chemistry harnesses the power of generalized and readily available computers use to simulate dynamic aspects of molecular systems (91) by molecular dynamics (MD) and/or Monte Carlo (MC) simulations. Citing Tamar Schlick (92):

"MD is the science of simulating motion of a system of particles according to Newton's classical equations of motion."

In other words, MD allows the study of molecules movement in detail, bridging molecule structure to function. Besides molecular dynamics techniques, MC approaches became a standard practice in adsorption simulations (93). Grand Canonical Monte Carlo (GCMC) is highlighted among the several ensembles proposed. In this technique, the chemical potential, volume and temperature of the system are fixed, leaving the pressure/concentration of the species involved as the sole parameter contributing for the addition/deletion of molecules in the system (94). This ensemble allows for an easy definition of adsorption isotherms and helps to highlight competition effects, such as coadsorption (95).

Several models for AC have been previously proposed as schematically shown in Fig. 6. Structureless models use a continuous surface without isolated atoms (96). Slit pore models assumes an array of semi-infinite and rigid carbon walls at a given distance (pore size) (96). They are often decorated with functional groups to study their influence in a simple manner. Both approaches try to simplify the carbon material surface and often fail 
to account for more complex situations, such as pore architecture or edge effects. Mimetic models try to imitate the synthesis process, through techniques such as Reverse Monte Carlo, template mesoporous structures or quenching (94). This results in more complex models that more closely mimic the structure of real ACs, but often lack experimental characteristics and uniqueness between different instances of the same model, and are computationally expensive to generate (97). Finally, we have the reconstruction models: these models often use data from experimental characterization techniques to build the model of the AC. A common approach is the usage of microcrystallites: graphitic structures with less than $5 \mathrm{~nm}$ in diameter, comprised of stacked carbon layers and based on experimental observations, as to create a virtual porous carbon (VPC) models. The spatial orientation and stacking of this building blocks in 3D space creates pores that give the VPC's their characteristic high surface area (98).

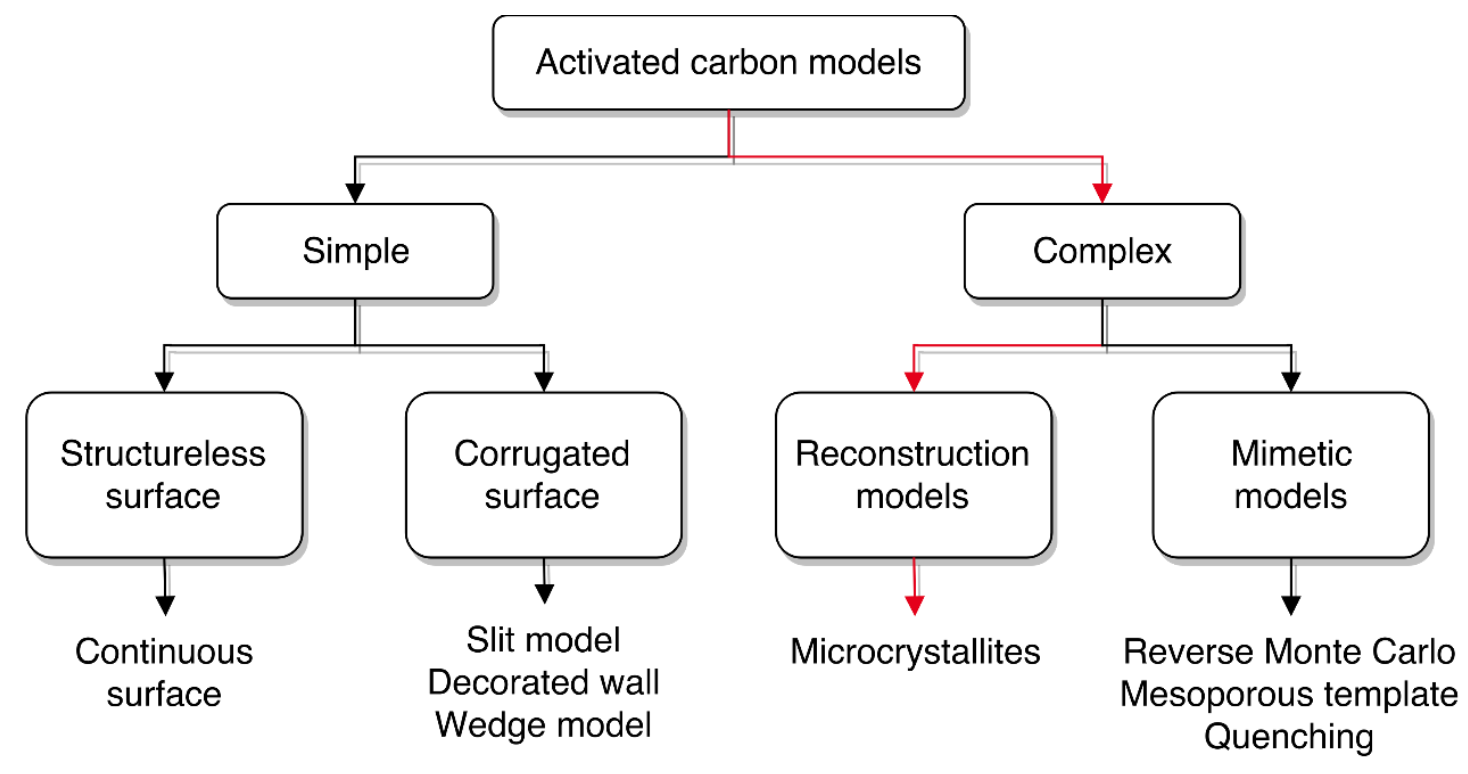

Fig. 6. Activated carbon model examples. The proposed model type for the present work is highlighted in red.

The VPC reconstruction method has been explored in previous works, since the first proposed model by Segarra and Glandt in 1994 (99). For this reason, the VPC models are sometimes referred to as SG models. Platelets with an homogeneous size and nature were used, without explicit atoms described, in a very simple fashion. Several authors upgraded this initial model in order to define more complex behaviors. Some works of interested are highlighted below. 
Liu et al. (100) explored the usage of the VPC reconstruction method in order to study the adsorption of water in AC's, using GCMC. The results show that the created model is in accordance to experimental data in terms of isotherm shape, further validating the VPC model.

Di Biase et al. (101) used simple fullerene-like molecules packed in a simulation box, where the density was tuned in order to achieve the desired surface area of the resulting material. Some platelets were further adorned with hydroxyl (-OH) or carboxyl $(-\mathrm{COOH})$ to study the effect of oxygen concentration and nature. GCMC was then employed to develop adsorption isotherms of $\mathrm{CH}_{4}$ and $\mathrm{CO}_{2}$ in gaseous phase. The results show good agreement with experimental data. Oxygen groups in the carbon surface increased $\mathrm{CO}_{2}$ adsorbance, with the nature of the oxygen groups not being relevant.

Gonciaruk et al. (102) followed a similar strategy, but introduced the use of different types of platelets, with varying sizes. However, the resulting AC model surface area was not explicitly defined, and resulted from natural microcrystallite packaging. This packaging resulted in a porous structure with surface areas between 175 and $500 \mathrm{~m}^{2} \mathrm{~g}^{-1}$. Although these values are lower than expected, the proposed model was not optimized based on any experimental data. GCMC was then used to study $\mathrm{CO}_{2}$ and $\mathrm{CH}_{4}$ adsorption, with appropriate similarity to experimental results.

More recently, Bahamon et al. (95) further explored the usage of VPC models, with the addition of more complex molecules as targets for adsorption (ibuprofen, in this example, is one of the few studies performed with organic contaminants). The used AC model included different sized platelets, defects and oxygenated groups (hydroxyl, pyran, carboxyl and carbonyl). Finally, ibuprofen adsorption from an ibuprofen/water mixture was simulated using GCMC. Results are in general accordance with experimental results available in literature, since the defined model was not optimized in accordance to any specific AC sample in a quantitative manner, being a pure qualitative behavior study. 


\section{5) Present work objectives}

The possibility to adapt the existing computational models in a quantitative manner to a real sample of AC naturally emerges as an interesting development in the field of AC modelling and as a tool for designing improvements in AC production. Such study would allow the modulation of the characteristics of AC to improve adsorption rate, capacity or selectivity towards certain target molecules. This objective requires substantial characterization of real AC sample in terms of surface area, elemental constitution, charge, particle size and functional group composition. Characterization of the feedstock and carbon materials of intermediary steps allow a broader overview of the process.

As previously stated, paper mill PS showed promising results when used as feedstock for AC production, making it a compelling candidate for the present study. The application of AC in water treatment has showed consistency on obtaining good results when it comes to pharmaceutical adsorption from contaminated water systems, therefore CBZ and SMX emerge as interesting adsorption targets. However, questions regarding which properties constitute an efficient adsorbent persist. Therefore, an assortment of computational chemistry strategies is proposed to elucidate molecular behaviors otherwise inaccessible, such as molecular dynamics simulations and GCMC adsorption studies. The development of a unified model which can accurately replicate experimental data is hereby proposed as a step towards a better understanding of the chemistry underlying pharmaceutical adsorption by AC, as schematically represented in Fig. 7.

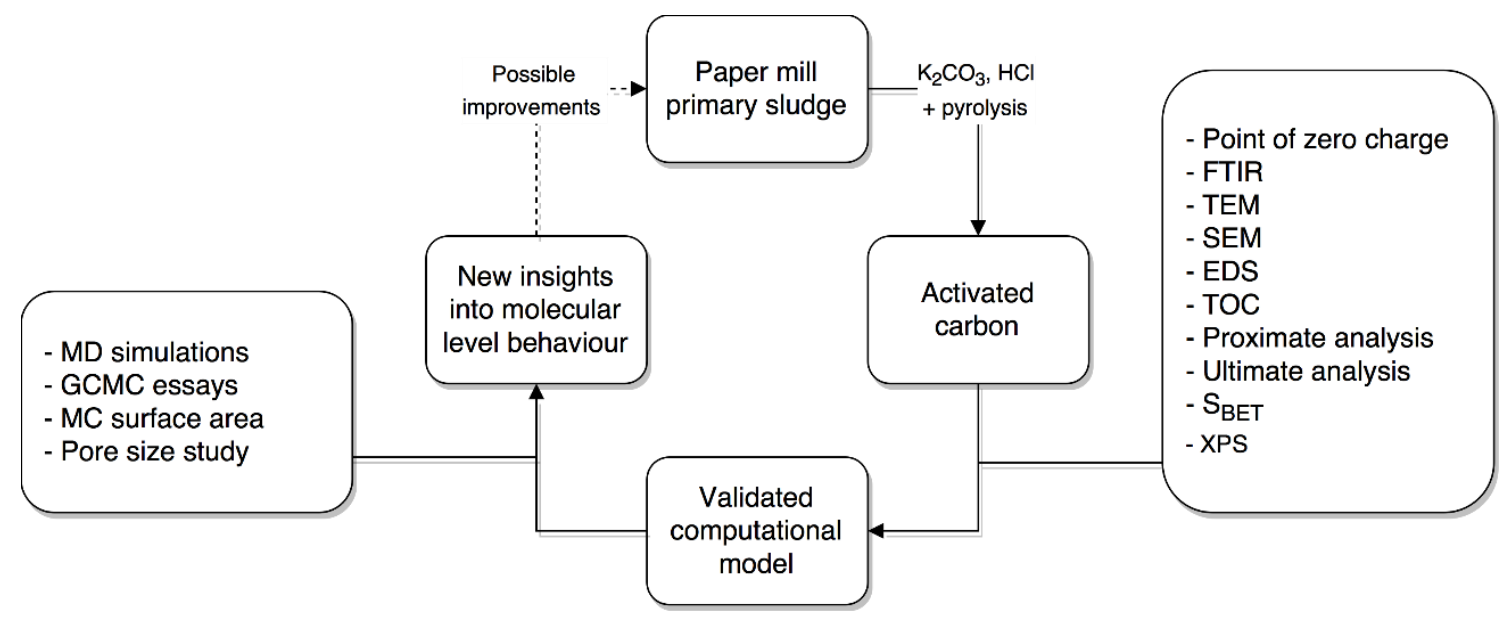

Fig. 7. Proposed work map 
Hence, the objectives of this work are as follows:

- To produce real AC using paper mill PS as feedstock, by chemical activation using $\mathrm{K}_{2} \mathrm{CO}_{3}$ and $\mathrm{HCl}$ washing.

- To fully characterize the AC structure and surface chemistry using a battery of techniques to obtain a set of relevant data:

○ Point of Zero Charge (PZC);

- Fourier transform infrared spectroscopy (FTIR);

- Transmission (TEM) and Surface (SEM) Electron Microscopy;

○ Energy-dispersive X-ray spectroscopy (EDS);

- Total Organic carbon determination (TOC);

- Proximate and ultimate analysis;

- Specific Surface Area $\left(\mathrm{S}_{\mathrm{BET}}\right)$;

○ X-ray photoelectron spectroscopy (XPS).

- To use the gathered experimental data to develop and test a validated model for AC regarding pore distribution, surface area and superficial functional groups;

- To use a validated model for $\mathrm{AC}$ in the interest of obtaining pertinent conclusions regarding molecular behavior in adsorption experiments, resorting to computational chemistry tools:

○ MD simulations;

○ GCMC essays;

○ MC surface area determination and pore size studies.

- To extrapolate the modelled data into factitious models with different characteristics to study the effect of:

○ Oxygen content;

Ion concentration of the aqueous phase. 


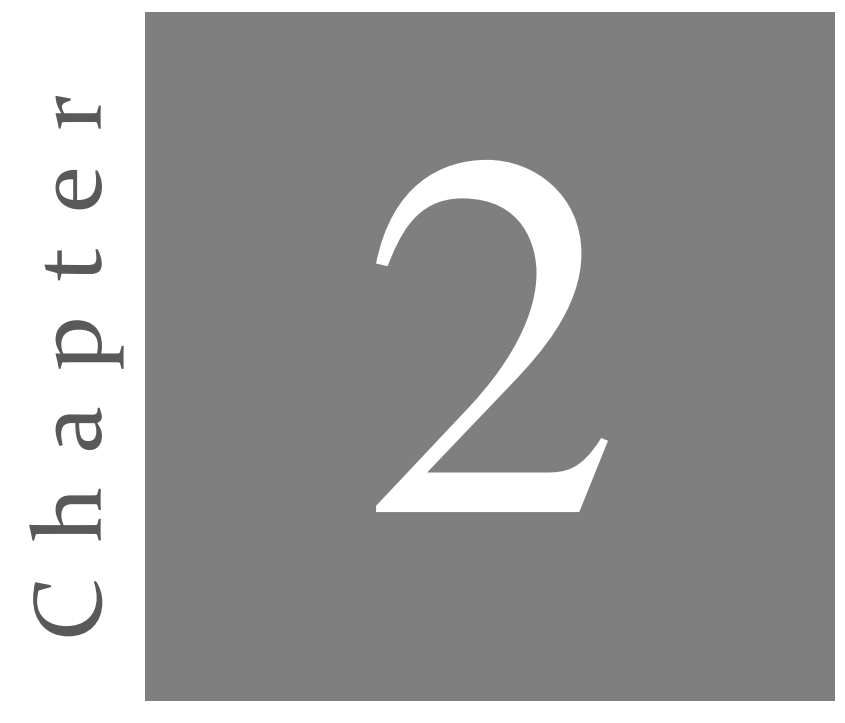

\section{Materials and methods}

"The important thing is not to stop questioning. Curiosity has its own reason for existence. One cannot help but be in awe when he contemplates the mysteries of eternity, of life, of the marvelous structure of reality. It is enough if one tries merely to comprehend a little of this mystery each day."

- Albert Einstein, LIFE Magazine, 2 May 1955 


\section{1) Production of carbon materials}

Three different carbon materials were produced using primary paper mill sludge (PS) as a precursor. The sludge was obtained from a Portuguese factory operating an elemental chlorine free kraft process, using Eucalyptus Globulus. PS was dried at $60{ }^{\circ} \mathrm{C}$ in an oven, for $24 \mathrm{~h}$ and grinded with a blade mill before further treatment. A description of each sample treatment can be found in Table 5 .

ACs were produced by chemical activation with potassium carbonate $\left(\mathrm{K}_{2} \mathrm{CO}_{3}\right)$, in a proportion of 1:1 $(w / w)$. The activating agent solution was prepared with the proportion of $50 \mathrm{~mL}$ of distilled water $\left(\mathrm{H}_{2} \mathrm{O}_{\mathrm{d}}\right)$ to $15 \mathrm{~g}$ of $\mathrm{K}_{2} \mathrm{CO}_{3}$. PS was impregnated during $\mathrm{lh}$ in ultrasounds bath at room temperature. The impregnated PS was left to dry for 7 days on the hotte.

Pyrolysis of PS or impregnated-PS was performed in porcelain crucibles. The pyrolysis was performed in a furnace muffle under inert atmosphere with a nitrogen flow, at $800^{\circ} \mathrm{C}$, heating rate of $10^{\circ} \mathrm{C} \mathrm{min}^{-1}$ and residence time of 150 minutes. Nitrogen flow was maintained during the cooling of the furnace. Samples without further treatment were grinded with a blade mill, and named PS800.

Some samples were subjected to a washing step using $\mathrm{HCl}$ in a proportion of $1.2 \mathrm{~g}$ of carbon material to $40 \mathrm{~mL}$ of $1.2 \mathrm{M} \mathrm{HCl}$ (37\%, Panreac). The carbon material and the washing solution were kept in contact for $\mathrm{lh}$. The resulting slurry was vacuum filtered and washed with distilled water until neutral $\mathrm{pH}$ of the washing leachate was achieved. The samples were then dried for $7 \mathrm{~h}$ in an oven at $105^{\circ} \mathrm{C}$, and subsequently grinded with a blade mill. Such samples were named PS800- $\mathrm{HCl}$ and $\mathrm{PS} 800-\mathrm{K}_{2} \mathrm{CO}_{3}-\mathrm{HCl}$, the latter having suffered chemical activation.

Table 5. Sample preparation guide

\begin{tabular}{rccc}
\hline Samples & Pyrolysis & Washing & Activation \\
\hline PS800 & $\checkmark$ & $\times$ & $\times$ \\
PS800-HCl & $\checkmark$ & $\checkmark$ & $\times$ \\
PS800- $\mathrm{K}_{2} \mathrm{CO}_{3}-\mathrm{HCl}$ & $\checkmark$ & $\checkmark$ & $\checkmark$ \\
\hline
\end{tabular}




\section{2) Characterization of carbon materials}

\subsection{1) Point of zero charge (PZC) determination}

PZC was determined by batch equilibration. $2 \mathrm{mg}$ of each carbon sample were shaken in polypropylene tubes with $10 \mathrm{~mL}$ of $\mathrm{NaCl} 0.1 \mathrm{M}(\geq 99.5 \%$, Fluka) solution, for $12 \mathrm{~h}$ in a overhead shaker at $25^{\circ} \mathrm{C}$, at different $\mathrm{pH}$ values. A total of 11 tubes were used from $\mathrm{pH}$ values ranging from 2 to 12 . Initial $\mathrm{pH}$ values were measured and adjusted using $0.1 \mathrm{M}$ and 0.05 M HCl (37\%, Panreac), and 0.1 M and 0.05 M NaOH (99.3\%, José Manuel Gomes dos Santos, Portugal). The final $\mathrm{pH}$ was measured and the PZC was determined by plotting the $\Delta \mathrm{pH}\left(p H_{f}-p H_{i}\right)$ versus the $\mathrm{pH}_{\mathrm{i}}$. The $\mathrm{PZC}$ is the $\mathrm{pH}$ value at which the curve intersects the $\mathrm{x}$-axis. All carbon samples were subjected to this technique, except PS.

\subsection{2) Fourier transform infrared spectroscopy with attenuated total reflectance (FTIR-ATR) \\ FTIR-ATR spectra were obtained using a Shimadzu-IRaffinity-1 spectroscope, with nitrogen purge. The measurements were recorded in the range of $600-4000 \mathrm{~cm}^{-1}, 4.0$ of resolution, 128 scans and with atmosphere and background correction. All carbon samples, including PS, were subjected to this FTIR-ATR analysis.}

\subsection{3) Transmission electron microscopy (TEM)}

TEM images were obtained using a HR-(EF)TEM JEOL 2200FS microscope at the following magnitudes: 5 000x, 20 000x, 50 000x, 80 000x, 100 000x, 150 000x and 200 000x. All carbon samples were subjected to TEM imaging, except PS. Higher magnitudes of 150 000x and 200 000x were only applied in $\mathrm{PS} 800-\mathrm{K}_{2} \mathrm{CO}_{3}-\mathrm{HCl}$ samples.

2.2.4) Scanning electron microscopy (SEM) and Energy-dispersive X-ray spectroscopy (EDS)

SEM images were obtained at the following magnitudes: 300x, 1 000x, 3 000x, 10 000x, 30 000x and 50 000x, using a Hitachi SU-70. The apparatus was also used to 
perform EDS analysis using a Bruker QUANTAX 400. All carbon samples were subjected SEM imaging and EDS, including PS.

\subsection{5) Total organic carbon (TOC) content}

Total carbon (TC) and inorganic carbon (IC) were determined using a TOC-VCPH Shimadzu analyzer, with a solid sample module SSM-5000A, and the TOC content was obtained by difference. Glucose $\left(\mathrm{C}_{6} \mathrm{H}_{12} \mathrm{O}_{6}, 40 \%\right.$ of carbon) was used as standard to establish and test the calibration curve for TC determination, while sodium carbonate $\left(\mathrm{Na}_{2} \mathrm{CO}_{3}, 11 \%\right.$ of carbon) was used as the standard for IC determination. Carbon content of the materials was determined as the average of 3 replicates. All samples, including PS, were subjected to TOC content determination.

\subsection{6) Proximate and ultimate analysis}

Standard methods to determine the moisture (UNE 32002), volatile matter (UNE 32019) and ash content (UNE 32004) were employed in a LECO TGA-601 automatic analyzer, for proximate analysis. The remaining fraction after ash and volatile matter (at dry basis) was determined to be the fixed carbon content.

Ultimate analysis were performed in a LECO CHNS-932 analyzer, determining the content in carbon $(C)$, hydrogen $(H)$, nitrogen $(N)$ and sulfur $(S)$ in the samples. The difference between the remaining fraction, in dry basis, and the ash percentage was considered to be the oxygen $(O)$ content.

All carbon samples, including PS, were subjected to proximate and ultimate analysis.

\subsection{7) Specific surface area $\left(S_{B E T}\right)$}

Specific surface area $\left(S_{\mathrm{BET}}\right)$ was determined on a Micromeritics ASAP2420 apparatus using the $\mathrm{N}_{2}$ adsorption isotherm at $-196^{\circ} \mathrm{C}$ and Brunauer-Emmett-Teller equation in the relative pressure range 0.01-0.1. Degasification process of the sample was carried overnight. Additionally, average pore width and total pore volume were also determined from the amount of nitrogen adsorbed at a relative pressure of 0.99. All carbon samples were subjected to $\mathrm{S}_{\mathrm{BET}}$ determination, except PS. 


\subsection{8) X-Ray Photoelectron Spectroscopy (XPS)}

Functional group content was determined by XPS analysis. Spectra were acquired in an Ultra High Vacuum system with a base pressure of $2 \times 10^{-10}$ mbar located on TEMA, University of Aveiro. The system is equipped with a hemispherical electron energy analyzer (SPECS Phoibos 150), a delay-line detector and a monochromatic AlK $\alpha$ (1486.74 eV) X-ray source. High resolution spectra were recorded at normal emission take-off angle and with a pass-energy of $20 \mathrm{eV}$, which provides an overall instrumental peak broadening of $0.5 \mathrm{eV}$. Only PS800- $\mathrm{K}_{2} \mathrm{CO}_{3}-\mathrm{HCl}$ sample was targeted for XPS analysis. 


\section{3) Computational modelling approaches}

\subsection{1) Carbon model development}

Carbon models were obtained by clustering carbon microcrystallites into a VPC. The carbon material was considered to be a disordered configuration of platelets of different sizes, decorated with specific functional groups, as an extension of the Segarra and Glandt model (103), and more recently, the Bahamon approach (95). Experimental data was considered in order to mimic the real material characteristics, namely the AC surface area, elemental constitution and functional content, having PS800- $\mathrm{K}_{2} \mathrm{CO}_{3}-\mathrm{HCl}$ as a starting point. The applied strategy and resulting AC models are further discussed in detail in chapter 3.

A great deal of attention was given to automation throughout the present work. A series of Python scripts were developed in order to produce the AC model in a reliable and autonomous way, so that replicas could be easily studied. An online repository version of the developed and used scripts during this work can be found at github.com/JosePereiraUA/carbon/. In this context, the following tasks were programmed in the produced scripts:

- Carbon residue design, with the following options:

- Size and number of carbon layers;

- Functionalization content, where the following functional groups were designed: ethers, carbonyls, carboxyls and edge hydrogens;

- Atom charges determination;

- Functional group hydrogenation in accordance to $\mathrm{pH}$;

- Residue library construction, with variable number of residues;

- Clustering process of residues into AC models, with the following options:

- Atom count limits;

○ Charged ions addition;

- Manipulation of necessary files for both batch MD studies and GCMC essays 
Atomtypes for all molecules used in the present work, including the carbon models, were extracted from Generalized Amber Force Field (GAFF) forcefield (104), and simplified for this model application. For this matter, non-bonded interactions were considered to be Lennard-Jones pairs, with Lorentz-Berthelot combination rules as defined in GAFF forcefield. Lennard-Jones and electrostatics 1-4 interactions were multiplied by a 0.5 and 0.833 factor, respectively.

For functional group' partial charge definition, small sets of carbon rings were manually designed using Avogadro 1.1.1 (105), and the different types of functional groups were added separately. The resulting molecules were optimized by Density Functional Theory (DFT) at the B3LYP/6-31G* level using Gaussian09 (106). The minimized structure was then used in the calculation of the electrostatic potential map, at the HF/6-31G* level, from which Restrained Electrostatic Potential (RESP) partial charges were obtained using Antechamber (107).

The obtained partial charges were used in the developed Python script. A functional group was considered as all the heteroatoms involved, the carbon atom where the functional group is attached to $\left(C_{0}\right)$ and the neighbor carbon atom connected to $C_{0}$. All functional groups had a neutral charge: positive charges were dispersed by $\mathrm{C}_{0}$ and neighbor atoms to keep the sum neutral. 


\subsection{2) Pharmaceutical molecules parametrization}

CBZ and SMX molecules were manually designed on a first approach, using Avogadro 1.1.1, and relaxed using GAFF forcefield and Steepest Descent Algorithm.

The resulting molecules were subject to a multi conformational analysis as follows: the molecules were firstly brought up to $1500 \mathrm{~K}$ in a molecular dynamics simulation in vacuum (translation/rotation around the system center of mass was removed), allowing them to rearrange in conformations with associated energies distinct from the global minimum energy value. Snapshots were gathered every 1 ps, for $2.5 \mathrm{~ns}$, resulting in 2500 different conformations gathered. Each of the resulting frames was minimized, and the resulting conformations were sorted based on the structure energy, where the 20 molecules with the lowest energies were selected for superimposed visualization. As illustrated in Fig. 8, all the resulting conformations were similar.
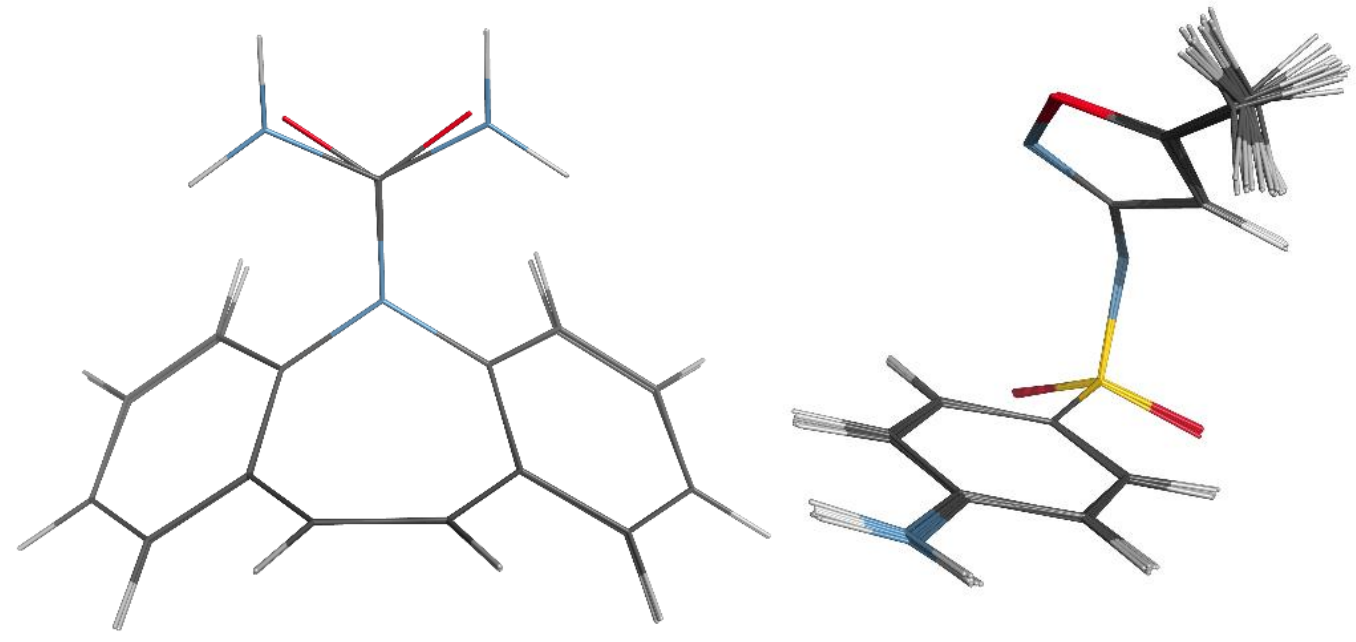

Fig. 8. Multi conformational analysis results (20 conformations aligned): Left - CBZ shows a rotation center; Right - SMX present rotation to some extent on the $\mathrm{CH}_{3}$ group, but adopts a closed conformation on itself

The conformation with the lowest energy was then further optimized by DFT at the B3LYP/6-31G* level, using Gaussian09 software. The eletrostatic potential map was calculated at the HF/6-31G* level, and partial charges for the pharmaceutical molecules were obtained using RESP method on Antechamber. 


\subsection{3) Molecular dynamics simulations}

Molecular dynamics simulations were performed using the GROMACS software (108), in $125 \mathrm{~nm}^{3}$ cubic boxes ( $5 \mathrm{~nm}$ each side) with periodic boundary conditions (PBC)
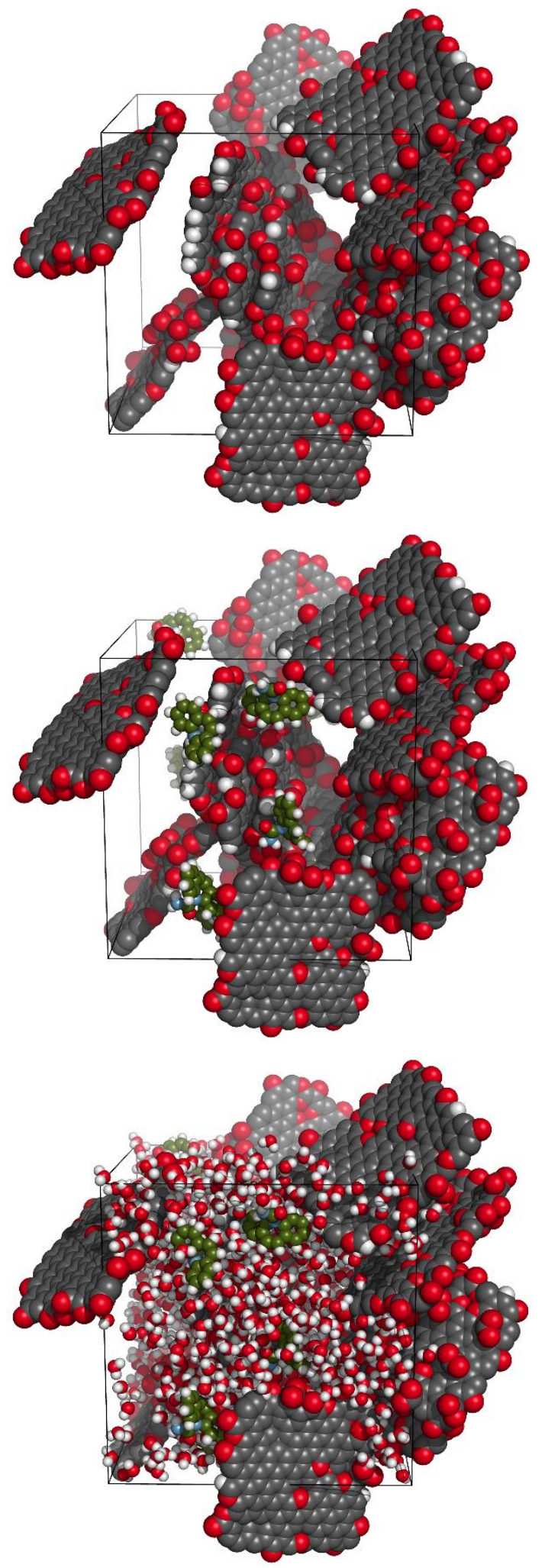

Fig. 9. System preparation for molecular dynamics simulations: Top - Carbon model; Middle Pharmaceutical addition; Bottom - Solvation applied. All simulation stages used: the Verlet cut-off scheme for neighbor searching; particle-mesh Ewald for electrostatics beyond $12 \AA$ cut-off; $12 \AA$ cut-off for van der Waals interactions. Water molecules were modeled according to the TIP3P model (109).

Firstly, pharmaceutical molecules of interest were attempted to be introduced in the system until the requested number was placed or no more available space was identified (100 insertion trials per molecule). Secondly, solvent molecules were added until no more space was free, as described in Fig. 8. Molecular dynamics simulations were split into 5 different stages:

- Solvent relaxation: Position restrictions were imposed to carbon and pharmaceutical molecules, in order for the water molecules to adopt a more natural position. Minimization criteria were: $\mathrm{F}_{\max }<10 \mathrm{~kJ} \mathrm{~mol}^{-1} \mathrm{~nm}^{-1}, 100000$ steps or $\Delta \mathrm{F}$ lower than machine tolerance;

- Minimization: The whole system was energy minimized without restrictions, following the previous criteria;

- Heat equilibration: The simulation was brought up to $300 \mathrm{~K}$, for 1 to $2 \mathrm{~ns}$, using a NoseHoover extended ensemble, and maintained stable towards the end of the stage;

- Pressure equilibration: The simulation box vectors were compressed by a ParrinelloRahman extended-ensemble to equilibrate the system at 1 bar pressure, during 1 to $2 \mathrm{~ns}$. 
- Data gathering: The equilibrated system settings was kept for $10 \mathrm{~ns}$ for data collection, having snapshots collected every 20 ps for further analysis. Linear Constrain Solver (LINCS) algorithm was employed to convert all bonds and angles that involve hydrogen atoms to bond constrains.

\subsection{4) Monte Carlo adsorption essays}

Monte Carlo adsorption essays were carried out in the GCMC ensemble using RASPA 2.0 software (110). Partial pressure values were converted to fugacity using the Peng-Robinson equation of state (111), as stated in Eq. 1.

$$
\begin{aligned}
p=\frac{R T}{V_{m}-b}-\frac{a \alpha}{V_{m}^{2}+2 b V_{m}-b^{2}} & \text { where }: \\
a & =\frac{0.45724 R^{2} T_{C}^{2}}{p_{C}} \\
b & =\frac{0.07780 R T_{C}}{p_{C}} \\
\alpha & =\left(1+k\left(1-T_{R}^{0.5}\right)\right)^{2} \\
k & =0.37464+1.54226 \omega-0.26992 \omega^{2} \\
T_{R} & =\frac{T}{T_{C}}
\end{aligned}
$$

Critical temperature $\left(\mathrm{T}_{\mathrm{C}}\right)$, critical pressure $\left(\mathrm{P}_{\mathrm{C}}\right)$ and acentric factor $(\omega)$ values were extracted from available literature for water and ions. SMX and CBZ critical properties were estimated using Joback method (112), and acentric factors were predicted using Positional Distributive Contribution method (113). The calculated values used in the present work are available in Table 6. GCMC essays were performed for 3000 to 6000 steps (or until equilibrium), at $300 \mathrm{~K}$ and $1 \mathrm{~atm}$. Water was used as solvent in all essays. Partial pressures of the components in the simulation were tuned to reflect the desired concentration of the pharmaceutical molecules in the mixture.

Table 6. Critical properties and acentric factors calculated for the pharmaceutical molecules studied

\begin{tabular}{cccc}
\hline & $\mathbf{T}_{\mathbf{C}}(\mathbf{K})$ & $\mathbf{P}_{\mathbf{C}}(\mathbf{k P a})$ & $\boldsymbol{\omega}$ \\
\hline SMX & 1006.40 & 5175.72 & 0.2389 \\
CBZ & 915.59 & 3325.84 & 0.1456 \\
\hline
\end{tabular}


Simulated concentrations of pharmaceuticals in water were 1, 100 and $1000 \mathrm{ppb}$, as to reflect the values commonly found in literature regarding their concentrations in the environment. Two modes of adsorption were studied: single component and competitive adsorption. In competitive adsorption, the considered pharmaceuticals were in an equimolar mixture. Four types of moves were employed, with equal probability, in the GCMC ensemble: translation, rotation, reinsertion and identity change. Translation and rotation move and orient the molecule in $3 \mathrm{D}$ space; reinsertion moves try to remove or insert a new molecule in the simulation box with equal probability.; identity change moves try to remove one molecule and insert a different one in the same place and with the same orientation. This move was especially useful in competitive adsorption essays.

\subsection{5) Monte Carlo surface area determination}

Geometric surface area of the modelled materials was computed using Monte Carlo, where a probe atom (radius $\sigma=2.958 \AA$ ) was "rolled" over the AC model surface, and the $\mathrm{S}_{\mathrm{BET}}$ was considered as the summation of all non-overlapping probe spheres after $10^{4}$ steps. Additionally, void fraction volumes were also computed using MC. Helium probes were inserted in the $\mathrm{AC}$ model box using Widom particle insertions, and the void fraction was determined to be the empty space divided by the total volume.

\subsection{6) Visualization methods}

Molecular structures were visualized with PyMol (114). Carbon atoms are displayed in dark grey, oxygen atoms in red, hydrogen atoms in light grey, nitrogen atoms in blue and sulphur atoms in yellow. In pharmaceutical molecules, SMX carbon atoms are displayed in light brown and CBZ carbon atoms are displayed in dark green, for clarity.

Macromolecular electrostatic potential maps were obtained with the Adaptive Possion-Boltzman Solver (APBS) plugin for PyMol (115). APBS writes out electrostatic potentials in dimensionless units of $\mathrm{k}_{\mathrm{b}} \mathrm{T}_{\mathrm{c}}{ }^{-1}$ where $\mathrm{k}_{\mathrm{b}}$ is Boltzmann's constant $\left(1.38 \times 10^{-23}\right.$ $\left.\mathrm{J} \mathrm{K}^{-1}\right)$, $\mathrm{T}$ is the temperature $(\mathrm{K})$ and $\mathrm{e}_{\mathrm{c}}$ is the charge of an electron $\left(1.6 \times 10^{-19} \mathrm{C}\right)$.

Pore studies were performed with the aid of MOLE 2.0 software (110), considering only pores with diameters less than $2 \mathrm{~nm}$ (micropores). A $30 \AA$ surface probe was used to find cavities. 


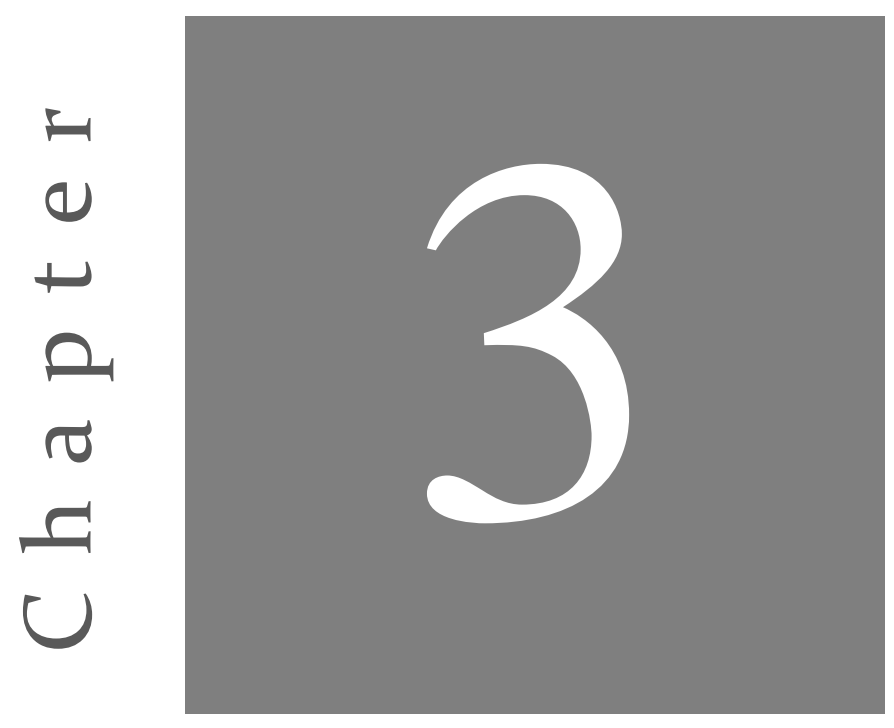

\section{Results and discussion}

"No, you're not going to be able to understand it. ... That is because I don't understand it. Nobody does. Quantum mechanics describes nature as absurd from the point of view of common sense. And yet it fully agrees with experiment. So I hope you can accept nature as She is - absurd.”

- Richard Feynman, The Strange Theory of Light and Matter, 1985 


\section{1) Carbon materials production}

As previously described, 3 carbon materials were prepared for characterization. As illustrated in Fig. 10, production yields were vastly different among samples: PS800 had a production yield of $43.2 \%$. When the carbon material suffered a washing step with $\mathrm{HCl}$, the production yield plummeted to $15.1 \%$. This difference can be attributed to the removal of inorganic material and also inevitable losses of carbon. Furthermore, when the carbon material was activated using $\mathrm{K}_{2} \mathrm{CO}_{3}$, the overall yield of the production step was 3.5\%, as a result of the reaction between the percursor and the activating agent which resulted in an extremely low-density material.

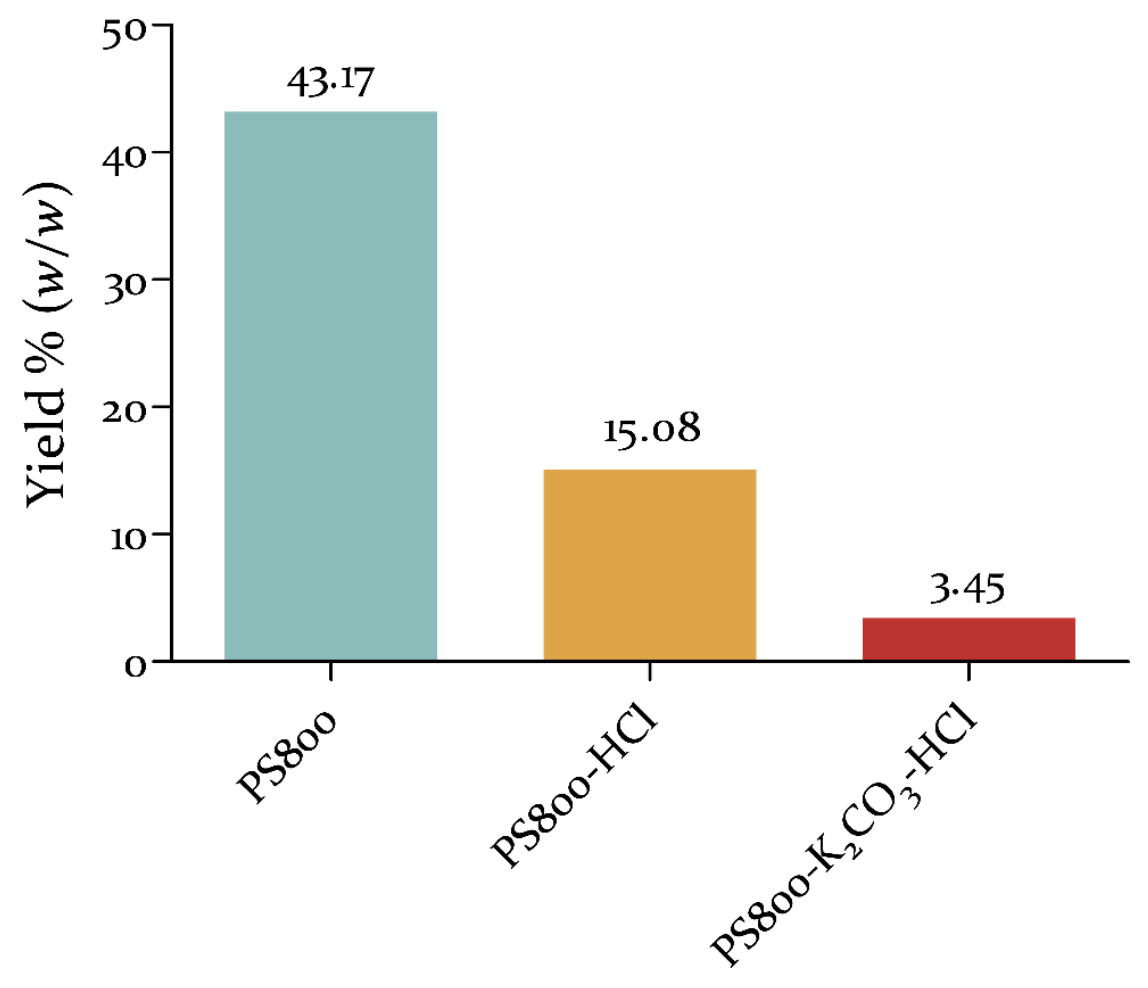

Fig. 10. Production step yield $\%(\mathrm{~m} / \mathrm{m})$ for different carbon material samples 


\section{2) Carbon materials characterization}

\subsection{1) Fourier transform infrared spectroscopy with attenuated total reflectance (FTIR-ATR)}

It has been previously shown that surface chemistry may play a major role in adsorption mechanisms in ACs Therefore, FTIR-ATR was employed as technique to provide insights regarding the functional group contents of the studied samples. Fig. 11 shows the FTIR-ATR spectra obtained for each of the samples characterized. It is possible to distinguish a fingerprint region on the spectra, around wavenumber 500 to $1700 \mathrm{~cm}^{-1}$. Several peaks can be identified, namely:

- The small set of peaks from $500-750 \mathrm{~cm}^{-1}$ are usually acknowledged as signals from in- and out-of-plane vibrations from aromatic ring deformations, while the $1650 \mathrm{~cm}^{-1}$ peak can be attributed to $\mathrm{C}=\mathrm{C}$ stretching in benzene rings;

- The peaks at 1030, 1110 and $1160 \mathrm{~cm}^{-1}$ are recognized as $\mathrm{C}-\mathrm{O}-\mathrm{C}$ stretching vibrations signals;

- The peak around $1350 \mathrm{~cm}^{-1}$ can be related to $\mathrm{C}-\mathrm{H}$ bending vibrations;

- The broad peak at $1440 \mathrm{~cm}^{-1}$, in conjugation with a sharp strong signal at $875 \mathrm{~cm}^{-1}$ is characteristic of carbonate ions;

- Although with smaller intensity, the broad peak at $3300 \mathrm{~cm}^{-1}$, in conjugation with smaller peaks at 2920 and $3640 \mathrm{~cm}^{-1}$ indicates the presence of -OH alcohol or phenol groups;

The identified peaks fade in PS800- $\mathrm{K}_{2} \mathrm{CO}_{3}-\mathrm{HCl}$ sample. Such information can give us a first indication of the surface chemistry of the characterized samples. The gathered data suggests that PS-derived carbon material's functional groups are primarily composed of ethers, phenols, alcohol and C-H groups. It is still possible to observe the disappearance of FTIR-ATR signals related to carbonate ions in materials subjected to $\mathrm{HCl}$ washing, in PS800- $\mathrm{HCl}$ and $\mathrm{PS} 800-\mathrm{K}_{2} \mathrm{CO}_{3}-\mathrm{HCl}$ samples, being expected that formed pores and cavities become unobstructed by these carbonate impurities, increasing the carbon material effectiveness in adsorption experiments. 


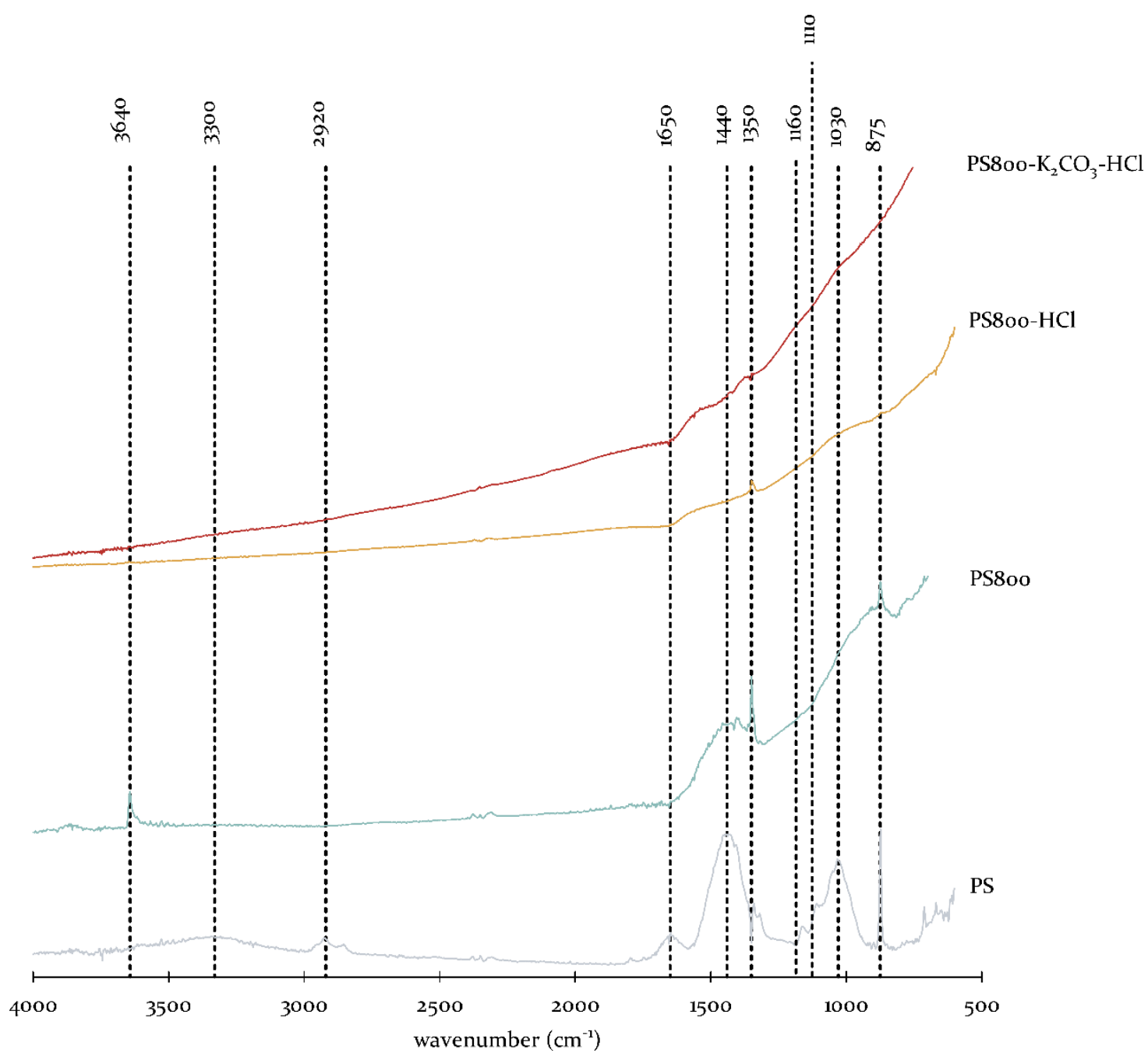

Fig. 11. FTIR-ATR spectra of the precursor and different carbon materials

\subsection{2) Point of zero charge (PZC) determination}

For the PZC determination, tubes with a salt solution, at different $\mathrm{pH}$ values between 2 and $12\left(\mathrm{pH}_{\mathrm{i}}\right)$, were incubated with a carbon material sample. It is expected that the carbon functional groups interact with the medium to provide or receive protons, contributing for a variation in the final $\mathrm{pH}\left(\mathrm{pH}_{\mathrm{f}}\right)$ of the sample. For this reason, the $\mathrm{PZC}$ is defined as the $\mathrm{pH}$ value at which the $\mathrm{pH}$ of the medium is similar to the one on the carbon surface, and therefore there is an insignificant change in $\mathrm{pH}_{\mathrm{f}}$. In Fig. 12, this is shown as the $\mathrm{pH}$ value at which the $\Delta \mathrm{pH}$ is 0 . PZC values of the studied samples are as follow:

- PS800: 11-12

- PS800-HCl: 7-8

- PS800-K2CO3-HCl: 5-6 
Such values pose more of a qualitative

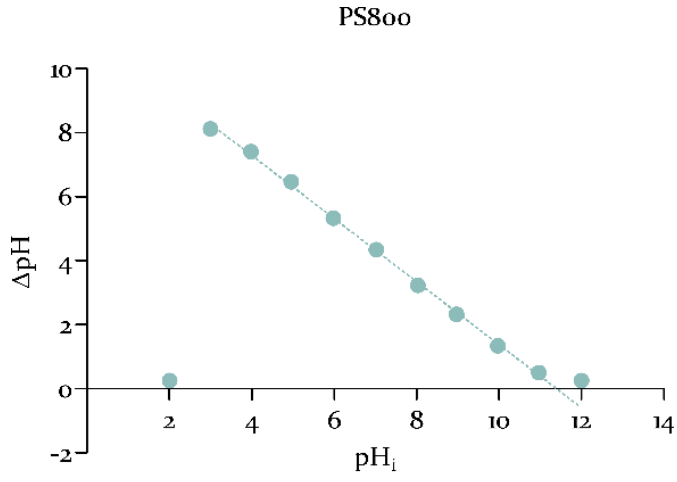
assessment than a quantitative one. Their relevance relies on the notion that, with further treatment, the resulting carbon material becomes more acidic. This can be explained by the removal of carbonates from the feedstock by $\mathrm{HCl}$ washing, further enhanced by the increase in porosity and disorder after chemical activation.

Furthermore, it is possible to observe an apparent buffering capacity to minimum and maximum $\mathrm{pH}$ values (close to 2 and 12). This effect can be interpreted as an artifact caused by the presence of very strong acidic and alkaline solutions, since the salt solution $\mathrm{pH}$ was adjusted with $\mathrm{HCl}$ and sodium hydroxide $(\mathrm{NaOH})$. Small

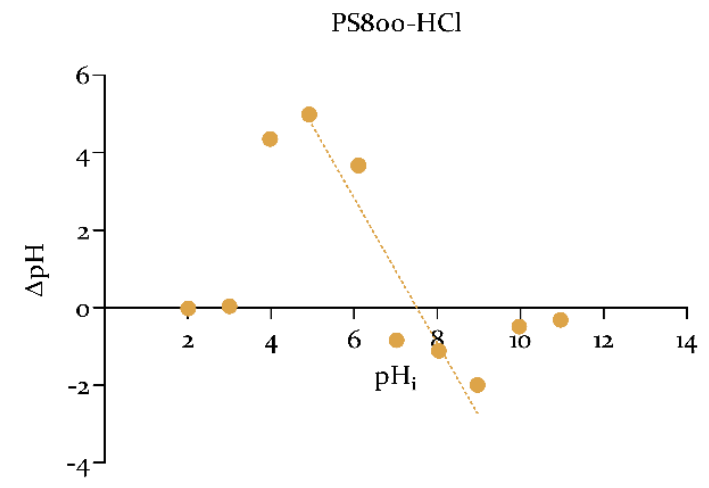
contributions from the carbon functional groups would then pose little to no disturbance towards

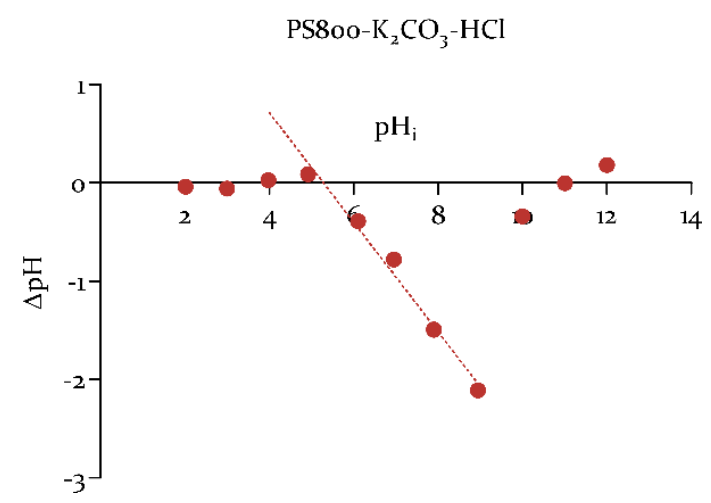

Fig. 12. PZC determination for each carbon

\subsection{3) Transmission electron microscopy (TEM)}

TEM images provide an effective way of visually observing the internal morphology of the carbon materials, namely the carbon sheets that compose them, as illustrated in Fig. 13. For lower amplifications, it is possible to observe the lack of crystalline organization of the samples. In particular, non-activated carbons show a prevalence of amorphous materials, while PS800- $\mathrm{K}_{2} \mathrm{CO}_{3}-\mathrm{HCl}$ samples present a much higher degree of pore and cavity formation. 
PS800

PS800-HCl

PS800- $\mathrm{K}_{2} \mathrm{CO}_{3}-\mathrm{HCl}$
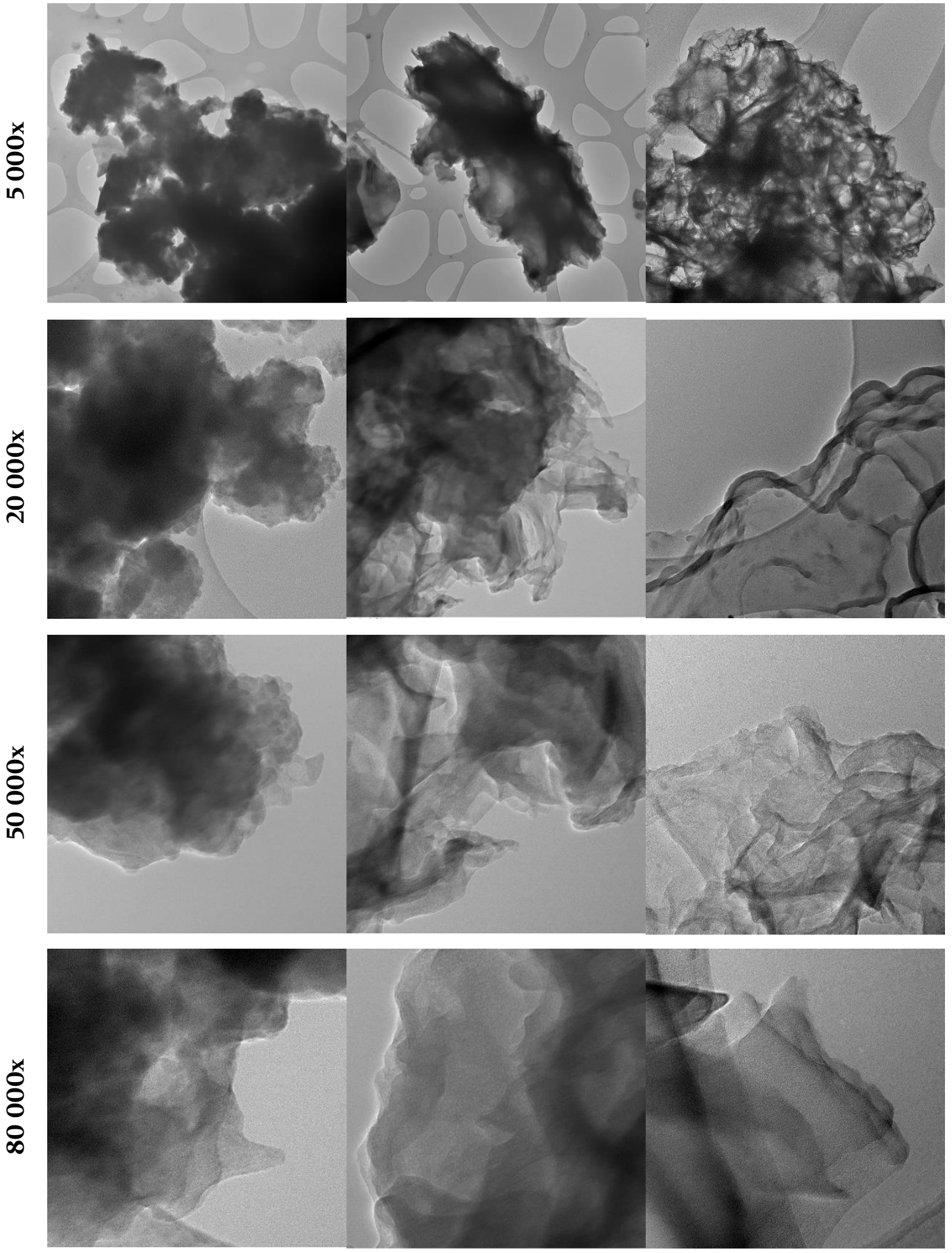

Fig. 13. Transmission electron microscopy images of PS800, $\mathrm{PS} 800-\mathrm{HCl}$ and $\mathrm{PS} 800-\mathrm{K}_{2} \mathrm{CO}_{3}-\mathrm{HCl}$ samples (from left to right), at amplifications of 5 000x, 20 000x, 50 000x and 80 000x (from top to bottom) 
3.2.4) Scanning electron microscopy (SEM) and Energy-dispersive $X$ ray spectroscopy (EDS)

External morphology studies provide important insights into the effects produced by each production step in the textural properties of the materials. SEM images are illustrated in Fig. 14. SEM images of PS clearly show the individual fibers that compose the initial precursor. These fibers appear to be deconstructed after the pyrolysis step, giving rise to a more amorphous and disorganized structure. Impurities deposited on the material surface appear is these figures with a lighter tone, often obstructing cavities. Their prevalence is largely eliminated after the $\mathrm{HCl}$ washing step and it becomes possible to detect the occurrence of some pores.
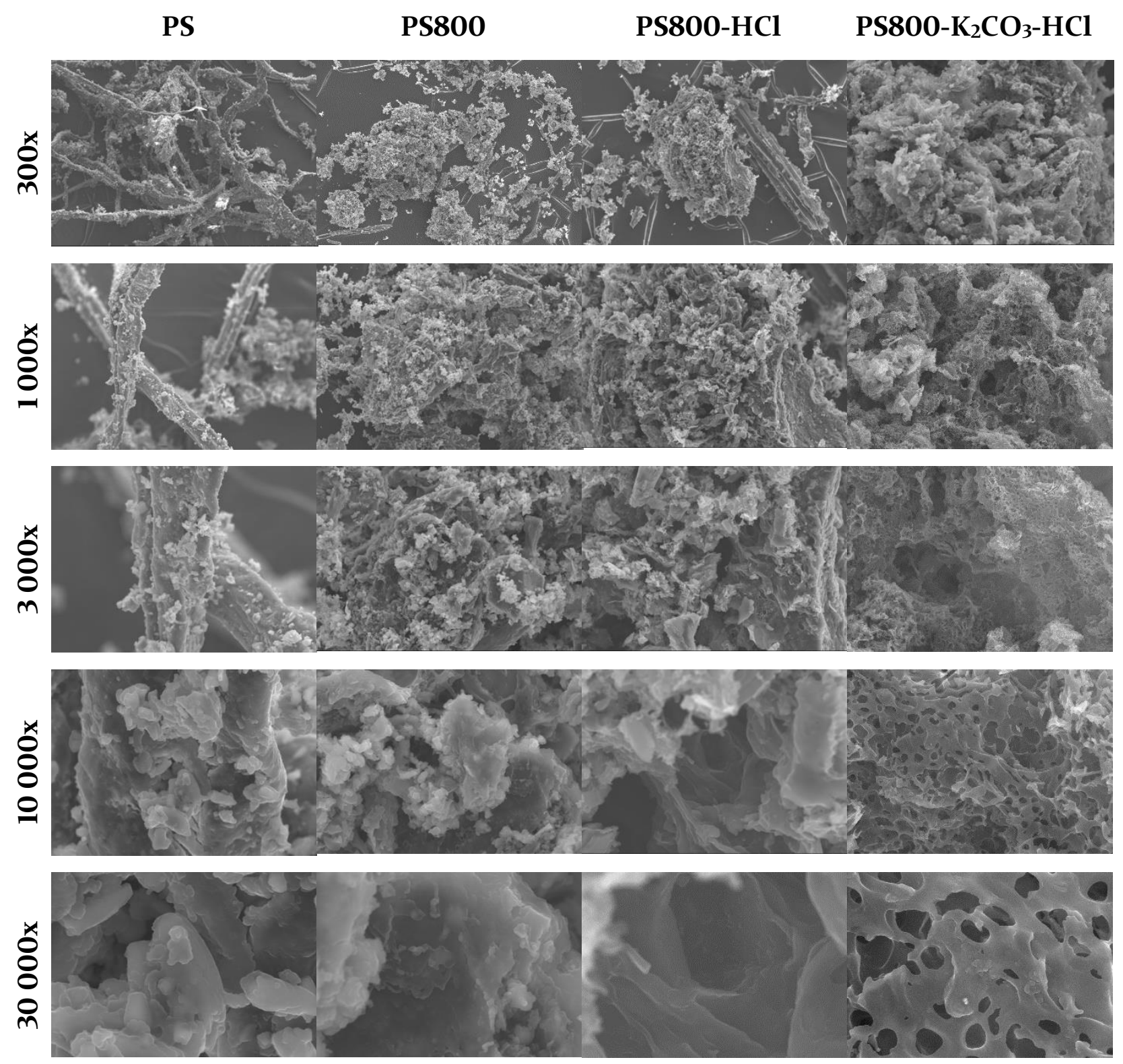

Fig. 14. Scanning electron microscopy images of PS, PS800, $\mathrm{PS} 800-\mathrm{HCl}$ and $\mathrm{PS} 800-\mathrm{K}_{2} \mathrm{CO}_{3}-\mathrm{HCl}$ (from left to right) at 300, 1000x, 3 000x, 10 000x, 30 000x amplifications (from top to bottom) 
With chemical activation, the initial fiber structure becomes unrecognizable. Comparing PS800- $\mathrm{K}_{2} \mathrm{CO}_{3}-\mathrm{HCl}$, at high amplifications, with the non-activated materials, it is possible to observe an extremely pronounced increase in pore content, resulting in a higher surface area.

EDS spectra were also obtained for precursor and carbon materials, in order to have a qualitative assessment of the sample's elemental constitution, as shown in Fig. 15.

PS
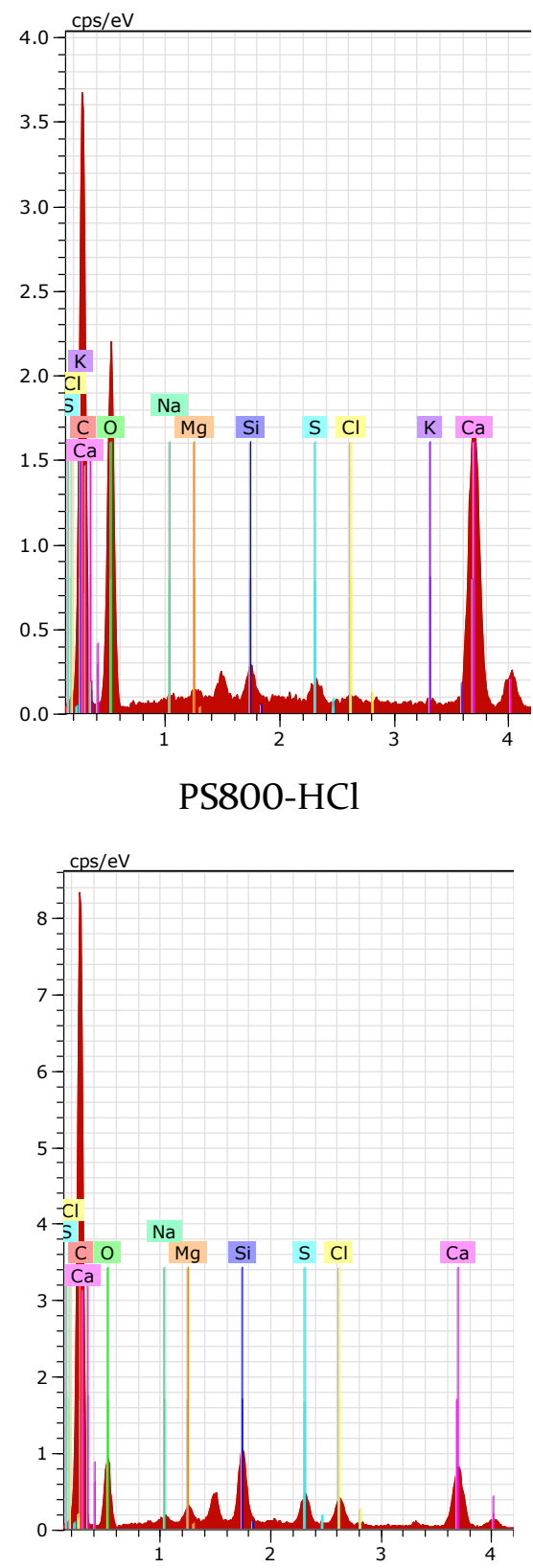

PS800
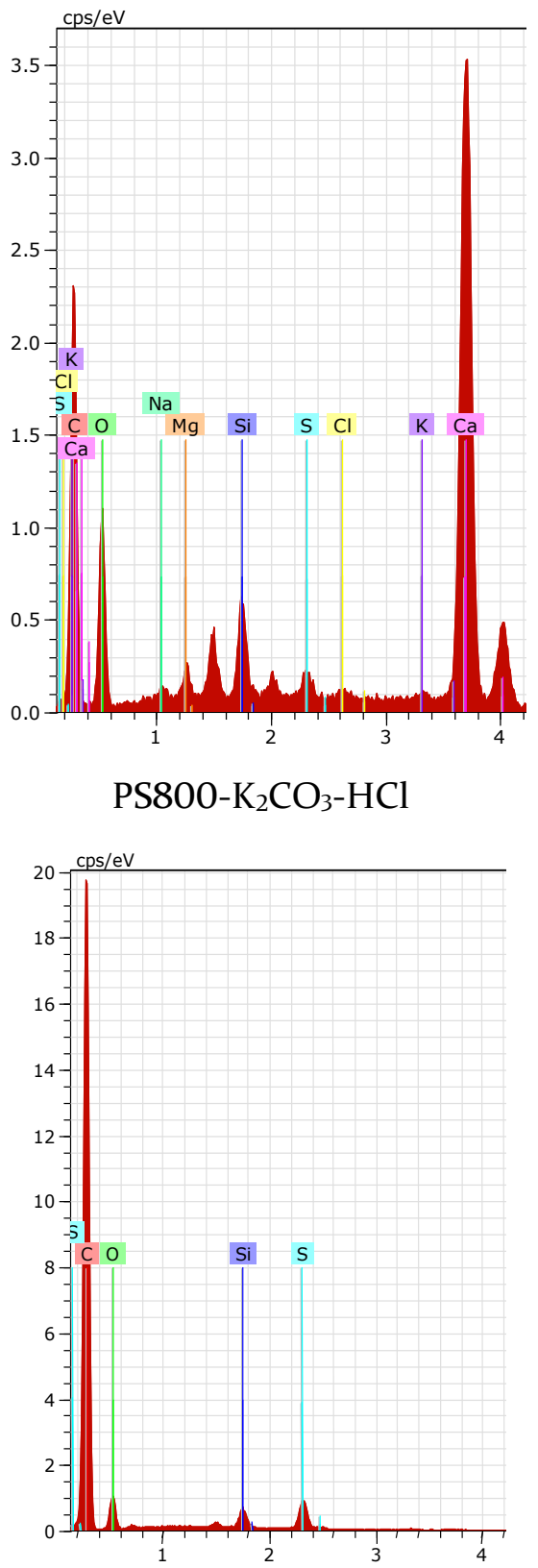

Fig. 15. Energy-dispersive X-ray spectroscopy spectra for PS and produced carbon materials 
EDS spectra data further cements the notion, complementary to FTIR-ATR data, that the precursor impurities are mainly composed of calcium carbonates, given the high abundance of calcium (Ca) in PS. Comparing this with PS800, it is possible to infer that pyrolysis removed much of the volatile carbon matter, reducing the relative abundance of the carbon element in comparison to others. Carbonates removal by $\mathrm{HCl}$ washing is also supported by these data, showing the reduction of Ca peak relative intensity in PS800$\mathrm{HCl}$ sample. Finally, the $\mathrm{PS} 800-\mathrm{K}_{2} \mathrm{CO}_{3}-\mathrm{HCl}$ EDS spectra show that the activation step is mostly responsible for increasing the amount of carbon on the surface, therefore reducing the relative intensity of the other elements peaks.

\subsection{5) Total organic carbon (TOC) content}

Regarding TOC content, the performed analysis suggests that pyrolysis is responsible for the removal of most inorganic carbon (IC), reducing its prevalence from $13.2 \pm 0.2 \%$ of the total carbon in PS to only $0.12 \pm 0.04 \%$ of the total carbon in $\mathrm{PS} 800-\mathrm{K}_{2} \mathrm{CO}_{3}-\mathrm{HCl}$.

The data, illustrated in Fig. 16, also complements previous observations respecting the total content in carbon, by comparing the carbon percentage in PS800 and PS800-HCl. It's possible to infer that the washing step is responsible for removing most of the IC in the carbon material, increasing the relative percentage of total carbon in the sample from $23.2 \pm 0.2$ $\%$ to $58.8 \pm 0.2 \%$. The activation step also results in an increase in carbon percentage, to $66.9 \pm 0.6 \%$.

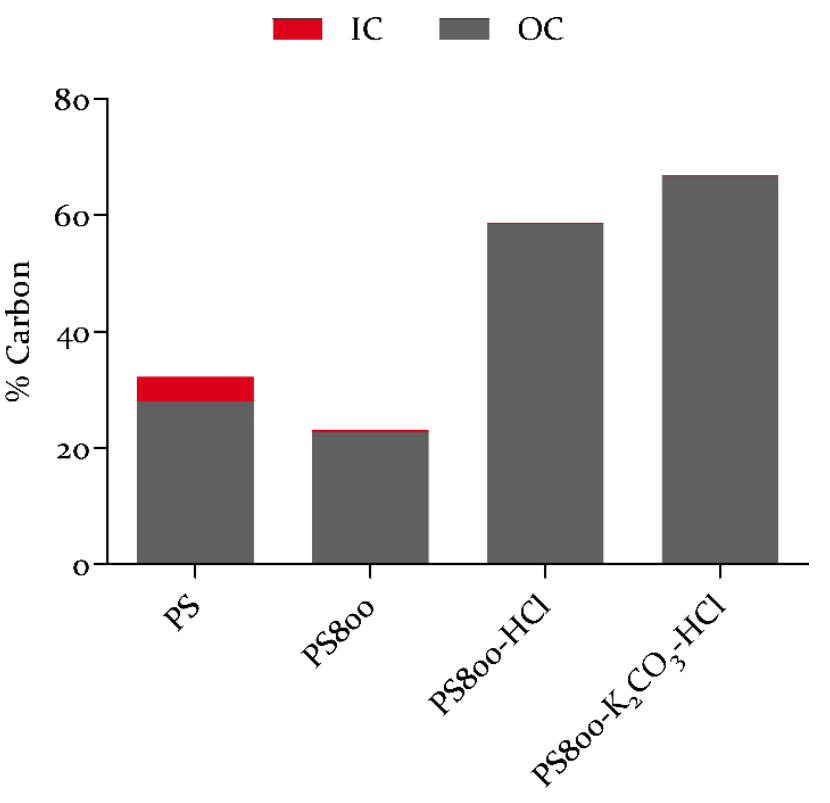

Fig. 16. Organic (OC) and IC content in PS and the produced carbon materials 


\subsection{6) Proximate and ultimate analysis}

Thermogravimetric analysis (TGA) of PS and the produced carbon materials provided relevant insights regarding volatile matter, moisture and mineral content, as illustrated in Fig. 17. Moisture percentage in the precursor was determined to be $4.9 \%$, while decreasing to $2.5 \%$ after pyrolysis, as expected. With further treatment, moisture levels increased to $7.7 \%$ and $16.6 \%$ in PS800-HCl and PS800- $\mathrm{K}_{2} \mathrm{CO}_{3}-\mathrm{HCl}$, respectively. This increase may be caused by an increase in porosity and therefore surface area and adsorption potential of moisture.

At a dry basis, it is possible to observe a relevant decrease in volatile matter after pyrolysis, from $63.9 \%$ to $21.2 \%$. Pyrolysis also resulted in an increase in ash contents, from $28.0 \%$ to $61.7 \%$, while not significantly improving the levels of fixed carbon. $\mathrm{HCl}$ washing was effective in reducing the ash levels from $61.7 \%$ to $23.42 \%$, being this value even lower after activation, 10.75\%. This resulted in a relative increase of fixed carbon, reaching 57.2\% and 63.3\% in PS800- $\mathrm{HCl}$ and PS800$\mathrm{K}_{2} \mathrm{CO}_{3}-\mathrm{HCl}$, respectively. In a general way, fixed carbon and volatile matter contents in each sample follow similar values when compared to TOC analysis data.

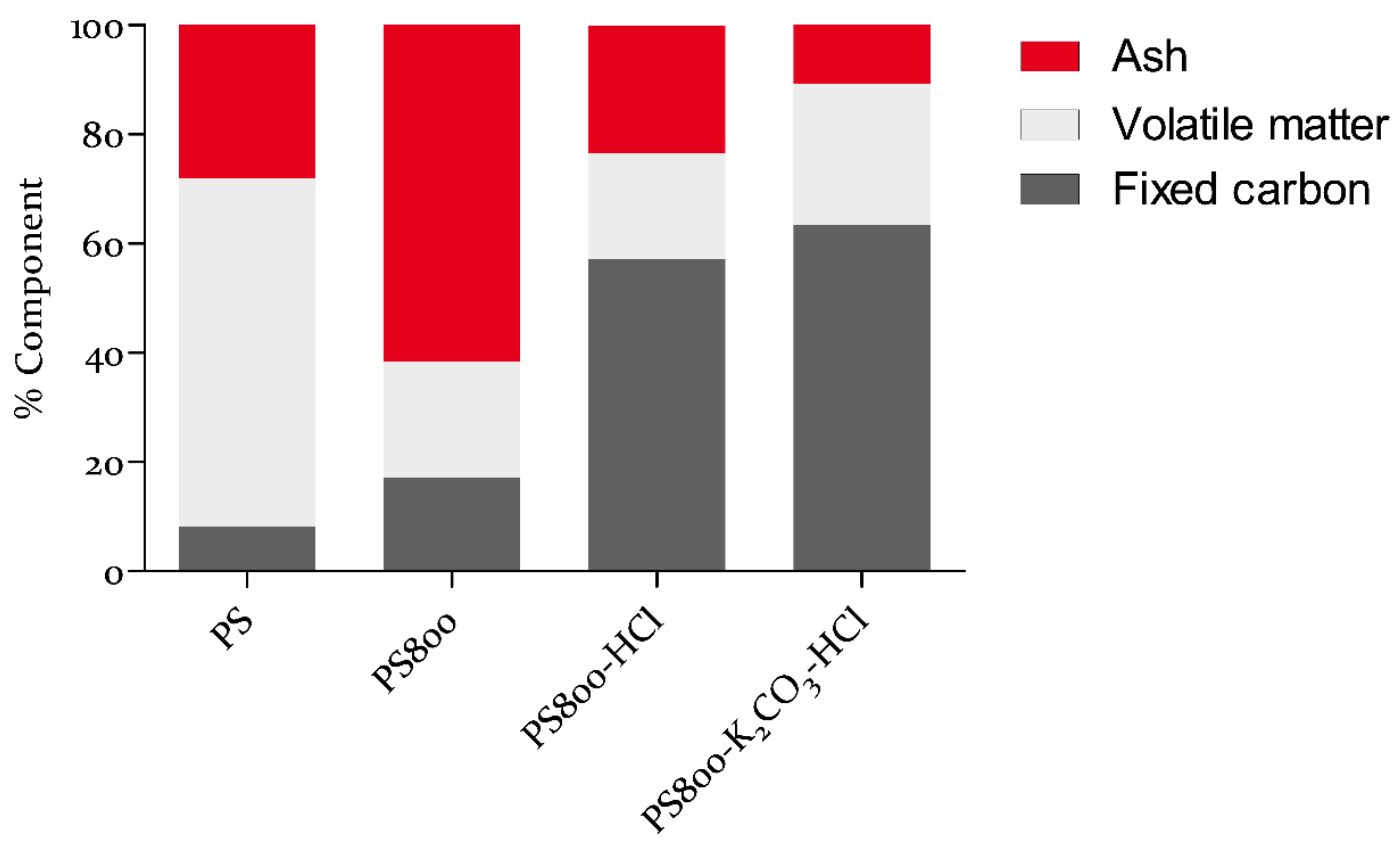

Fig. 17. Thermogravimetric analysis results, displayed in dry basis 
Ultimate analysis was also employed to quantify elemental content for carbon $(C)$, hydrogen $(H)$, sulfur $(S)$, nitrogen $(N)$ and oxygen $(O)$, as described in Fig. 18.
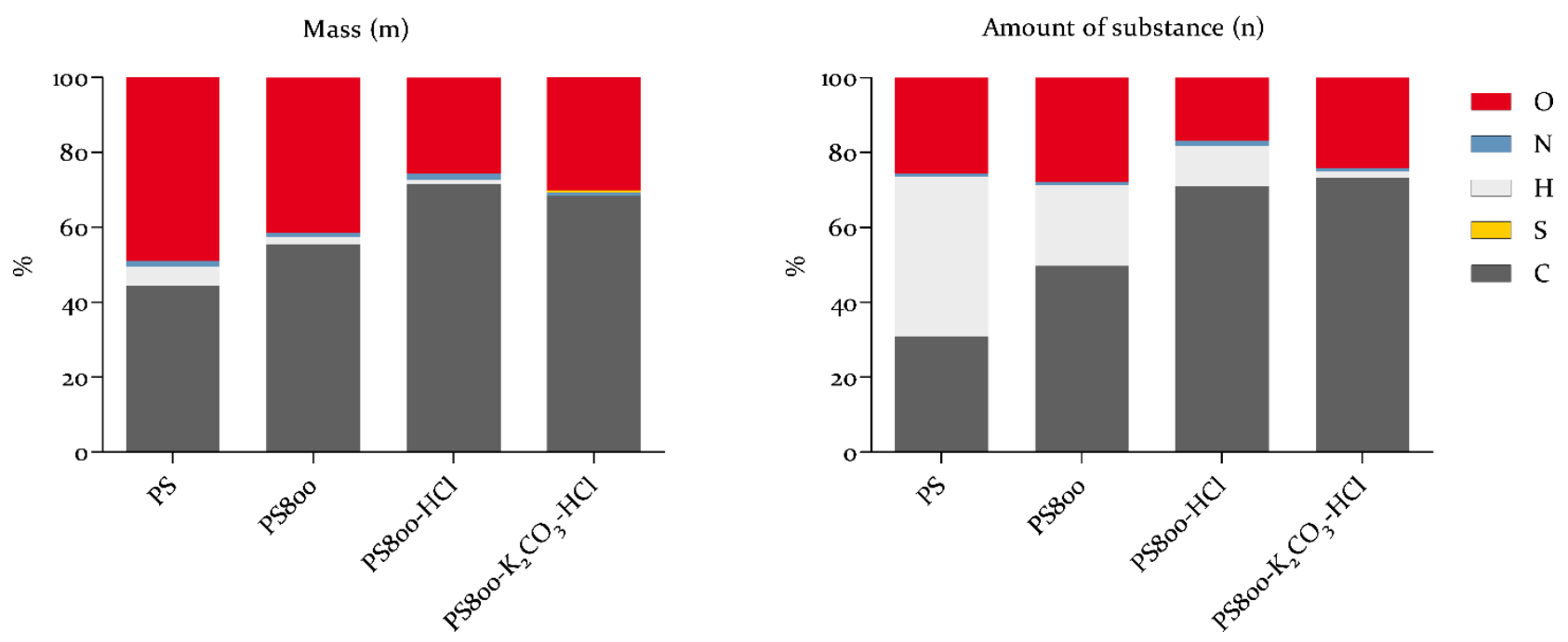

Fig. 18. Elemental analysis of PS and produced carbon materials, in dry and ash free basis, for mass and amount of substance percentages (Oxygen content was determined by difference)

Gathered data agrees with previous characterization techniques, showing the prevalence of mostly carbon, oxygen and hydrogen in the samples. It is possible to infer that volatile matter released during pyrolysis is mostly constituted by oxygen and hydrogen. With a relatively high percentage of oxygen $(24.3 \%$ in $n)$, PS800- $\mathrm{K}_{2} \mathrm{CO}_{3}-\mathrm{HCl}$ raises questions regarding the importance of the existence of heteroatoms in adsorption processes. Finally, it is considered that sulphur and nitrogen appear in only trace percentages on the activated carbon $(0.032 \pm 0.01 \%$ and $0.62 \pm 0.04 \%$ in $n$, respectively), and therefore have a limited contribution in modulating adsorption processes.

\subsection{7) Specific surface area $\left(S_{\mathrm{BET}}\right)$}

As stated in Table 7, several textural parameters were obtained for each of the produced carbon materials. It is possible to observe the activating effect of potassium carbonate on the carbon material, increasing the $S_{B E T}$ from $248 \mathrm{~m}^{2} \mathrm{~g}^{-1}$ to $1586 \mathrm{~m}^{2} \mathrm{~g}^{-1}$. This value places the produced activated carbon in the present work on pair with available commercial products. By comparison, the commercially available AC PULSORB has a $S_{B E T}$ of $1109 \mathrm{~m} 2 \mathrm{~g} \mathrm{-1}(87)$ and the PAC DETOX 1600 has a $S_{B E T}$ of 1550-1600 m2 g -1 (70). Furthermore, chemical activation also had a profound repercussion on micropore content. 
It is possible to infer that micropores have a much higher incidence on the activated sample, contributing in a larger scale for the increase of total pore volume $\left(V_{P}\right)$. According to IUPAC (80), micropores are defined as having a pore diameter of less than 2 $\mathrm{nm}$. This places the average pore on $\mathrm{PS} 800-\mathrm{K}_{2} \mathrm{CO}_{3}-\mathrm{HCl}$ sample on the threshold of microporosity, with an average size of $2.93 \mathrm{~nm}$.

Table 7. Textural parameters of characterized carbon materials

\begin{tabular}{rllll}
\hline Sample & $\boldsymbol{S}_{\boldsymbol{B E T}}\left(\mathbf{m}^{2} \mathbf{g}^{-1}\right)$ & $\boldsymbol{W}_{\boldsymbol{O}}\left(\mathbf{c m}^{3} \mathbf{g}^{-1}\right)$ & $\boldsymbol{V}_{\boldsymbol{P}}\left(\mathbf{c m}^{3} \mathbf{g}^{-1}\right)$ & $\boldsymbol{D}(\mathbf{n m})$ \\
\hline PS800 & 79 & 0.029 & 0.049 & 5.59 \\
PS800-HCl & 248 & 0.081 & 0.154 & 4.97 \\
PS800-K2CO3-HCl & 1586 & 0.268 & 0.839 & 2.93
\end{tabular}

$S_{B E T}$ - BET surface area

$W_{O}$ - Micropore volume

$V_{P}$ - Total pore volume

$D$ - Average pore diameter 


\subsection{8) X-Ray Photoelectron Spectroscopy (XPS)}

$\mathrm{C}$ is

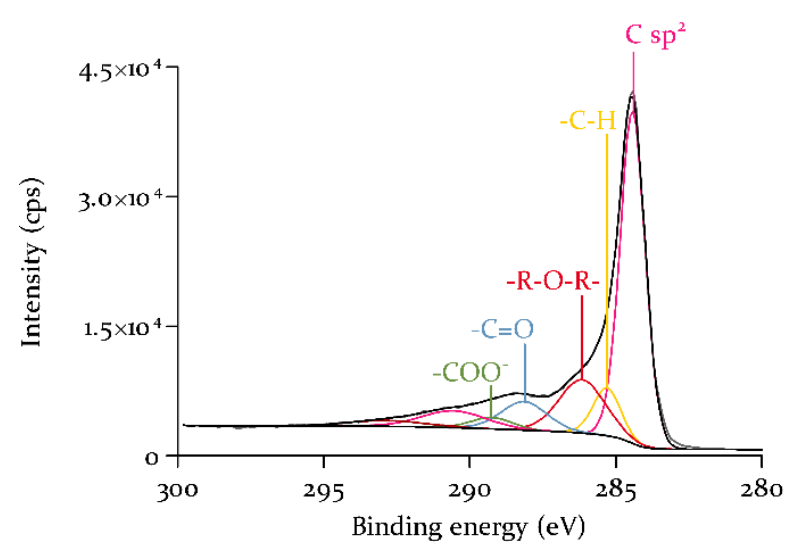

$\mathrm{O}$ is
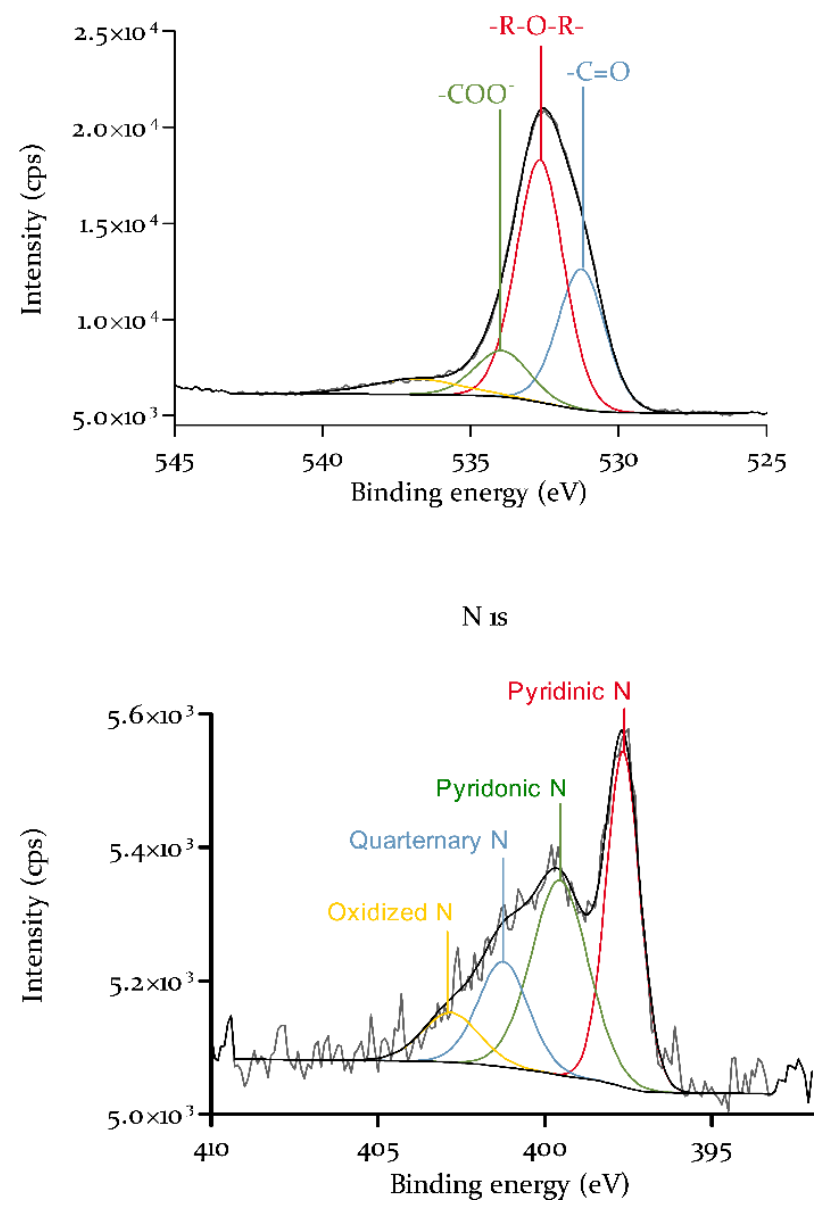

Fig. 19. XPS data for PS800-K2CO3-HCl. Experimental data are shown in grey, fitting data in black and each of the proposed components in color.
XPS data was collected for carbon $(\mathrm{C})$, oxygen $(\mathrm{O})$ and nitrogen $(\mathrm{N})$ peaks, for the produced AC. The proposed fitting of the experimental data is shown in Fig. 19, and a schematic model for the considered functional groups is illustrated in Fig. 20. Being a surface characterization technique with a depth of analysis up to $10 \mathrm{~nm}$, it allows us to have an unprecedented look into the surface chemistry of the activated carbon. From the $\mathrm{C}$ ls spectra it is possible to verify that most of the carbon layers are composed of $\mathrm{sp}^{2}$ carbon, with some functionalization level of - $\mathrm{CH}$ (8.5\%), ethers (15.9\%), carboxylic (2.9\%) and carbonyl (8.4\%) groups. These results are in accordance with FTIR data, and the $\mathrm{O}$ ls spectra. Other effects such as $\pi-\pi$ transition and plasmon bands were considered to better fit the tail of the $C$ ls spectra, and adsorbed water in the $\mathrm{O}$ ls spectra, who follow the same order in abundancy. Although in trace quantities, N-based functional groups were possible to be quantified: mostly pyridonic (37.3\%) and pyridinic groups $(36.2 \%)$. 


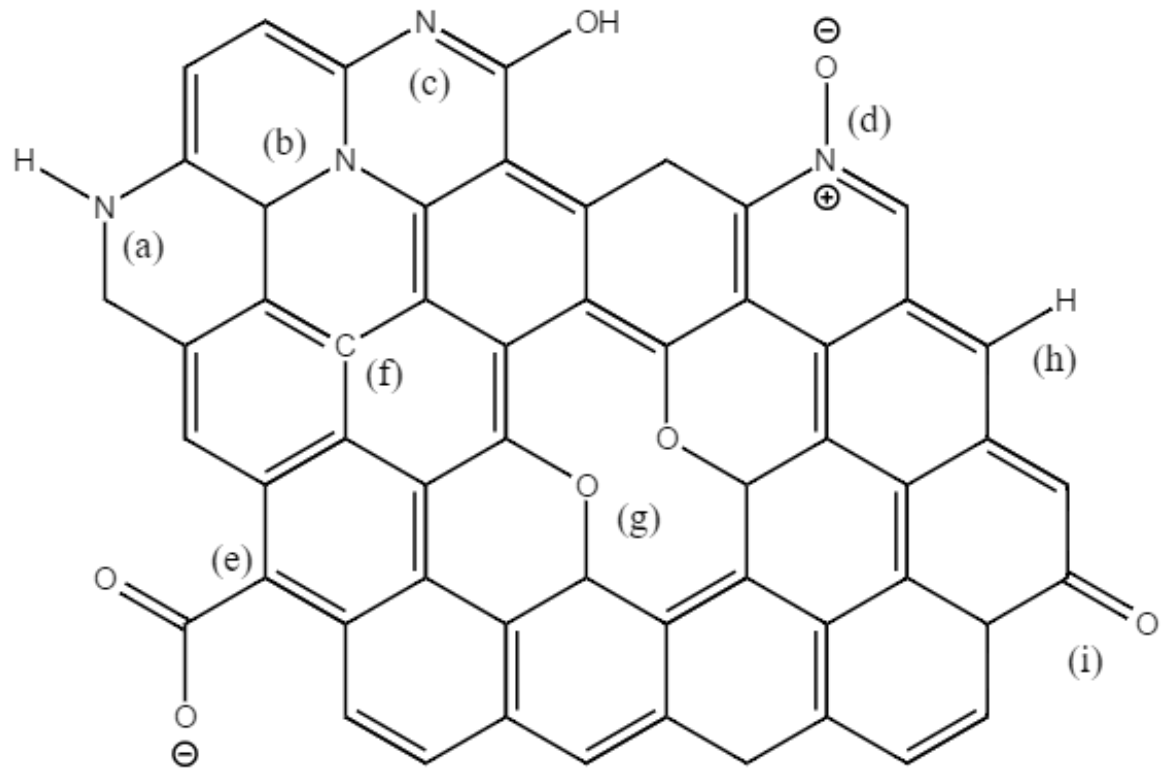

Fig. 20. Schematic representation of the proposed functional groups present in PS800-K2CO3-HCl, based on XPS data. (a) Pyrrolic N; (b) Quaternary N; (c) Pyridonic N; (d) Oxidized N; (e) Carboxylic group; (f) sp $^{2}$ carbon; (g) Ether; (h) - $\mathrm{CH}$; (i) Carbonyl group

The complete characterization of the precursor and carbon samples provided, therefore, a starting point for the development of the proposed computational model, in order to mimic not only the qualitative aspects of the samples, such as types of elements or functional groups, but the quantitative amounts of the referred characteristics. This abstraction requires, nonetheless, a certain level of approximation and assumptions in the interest of obtaining pertinent data in a reasonable time window. In the next section the development of the activated carbon model will be further explored. 


\section{2) Carbon model development}

\subsection{1) Residue library assembly}

As referred in section 2, AC models were obtained by clustering carbon microcrystallites into a VPC. The carbon material was considered to be a disordered configuration of platelets of different sizes, decorated with specific functional groups, as an extension of the Segarra and Glandt model (103), and more recently, the Bahamon approach (95). Only experimental data relative to $\mathrm{PS} 800-\mathrm{K}_{2} \mathrm{CO}_{3}-\mathrm{HCl}$ was considered for the assembly of the AC model.

Several residue libraries were produced through a collection of Python scripts developed for this purpose. The proposed libraries are composed of microcrystallites of different sizes and thickness: as a starting point, an average length and width of $20 \AA$, and 1 to 4 parallel graphite-like layers with 3.14 Å gap were considered, as described by Rosalind E. Franklin (116). These values were intended to be tuned in order to mimic real characteristics of the AC in the VPC model, but, interestingly, such default values resulted in models having good accordance with the desired characteristics, namely the surface area.

The microcrystallite layers were then enhanced with different functional groups to reflect the experimental characterization of the real AC. The considered functional groups were: carboxyls, carbonyls, $\mathrm{C}-\mathrm{H}$ terminations, 2-ring and 3 ring-ether crowns and ether terminations. Carboxyl protonation was performed in accordance with the $\mathrm{pH}$ of the desired simulation, having a negative charge for $\mathrm{pH}$ values below the modeled carbon $\mathrm{PZC}$, and vice-versa. All the simulations were performed at $\mathrm{pH}$ 7. Since the AC sample PZC is around 5, all carboxyls were, consequently, deprotonated and bearing a negative charge. Edge carbons were often left without hydrogen atoms attached to keep aromaticity after carboxyl and carbonyl groups were added. An example residue is represented in Fig. 21. Basic groups were ignored in this particular model, given their low presence in the experimental sample.

A random Gaussian distribution was employed in the input experimental values to generate small variances in the different residues of each library, in an effort to better reproduce the real heterogeneity of the carbon materials. Therefore, all values obtained 
are the median of several slightly different models. Each library was composed of at least 100 different residue microcrystallites.

(c)

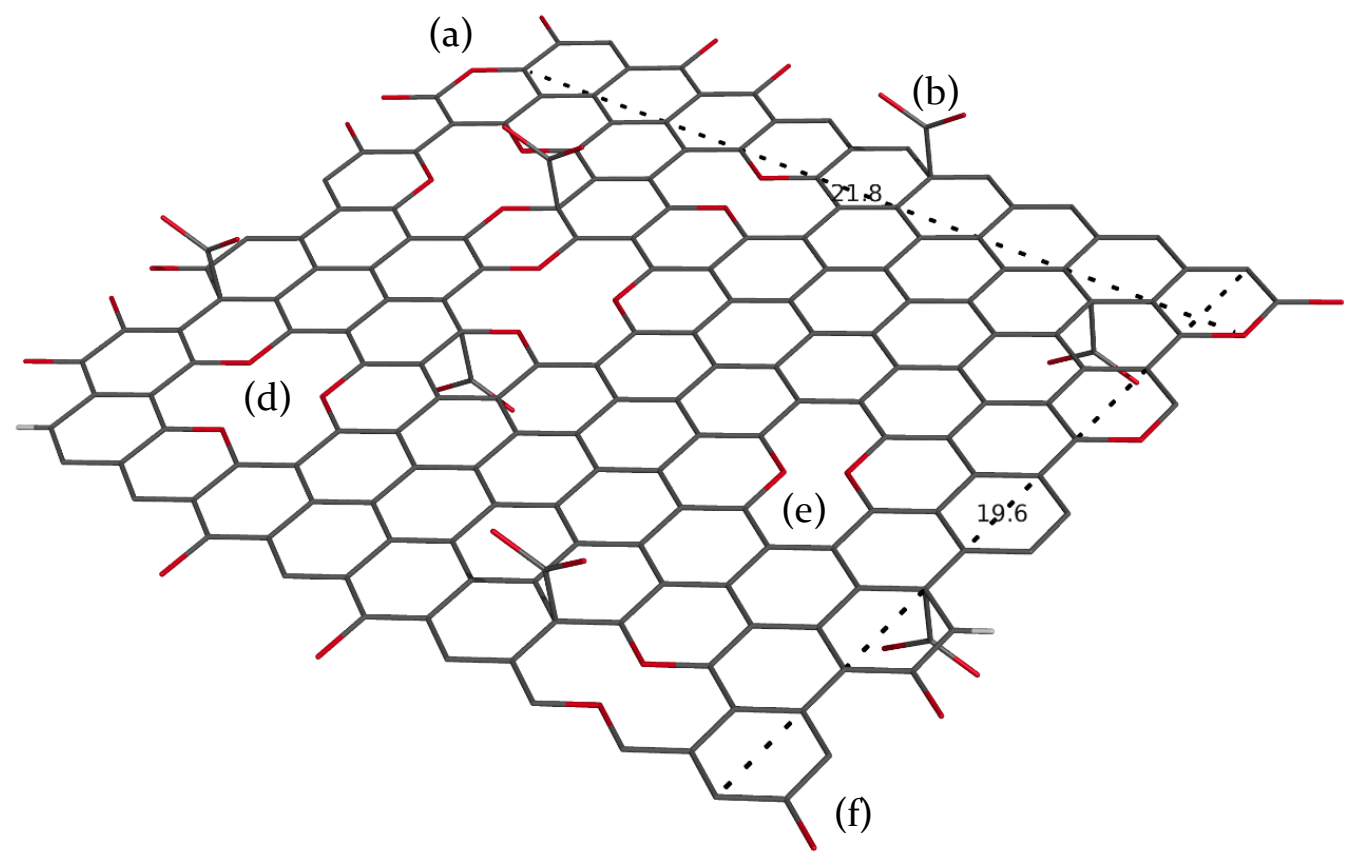

Fig. 21. Non-minimized residue example from one of the created libraries. Width and length distances are displayed by a dashed line $(\mathrm{x}=21.8 \AA \AA, \mathrm{y}=19.6 \AA)$. Functional groups are labeled: (a) - edge ether; (b) - carboxyl; (c) - edge hydrogen; (d) - 3-sided ether crown; (e) - 2-sided ether crown; (f) - carbonyl

A total of 3 residue libraries were created, allowing for the study of oxygen influence in carbon clustering and adsorption of pharmaceuticals: fullOx, which mimics experimental values of oxygen content to the best possible extent $(\approx 24 \%)$; $\operatorname{minOx}$, compromising residues with very few oxygen atoms $(\approx 2 \%)$; and maxOx, comprised of microcrystallites very rich in oxygen atoms $(\approx 35 \%)$. An example residue of each described library is represented in Fig. 22.
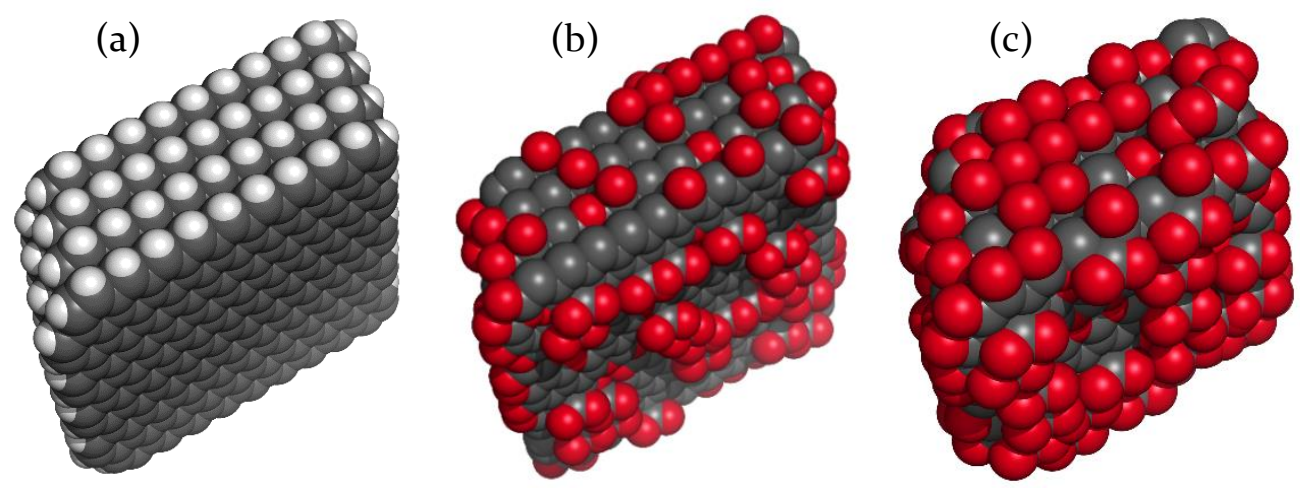

Fig. 22. Non-minimized residues from different libraries: (a) - minOx; (b) - fullOx; (c) - maxOx 


\subsection{2) Carbon model production and characterization}

The previously described platelets were used for the formation of carbon models through carbon clustering processes. A random number of residues was arbitrarily placed inside a cubic simulation box with a volume of $125 \mathrm{~nm}^{2}$ and the carbon atom count limit was placed at 3000 atoms per simulation, in order to keep the complexity of the system and the clustering time as low as possible, without compromising the relevance of the obtained results. The maximum number of insertion attempts of new residues tuned to ensure that all available space was occupied, and the void fraction of the box was only modulated by the size of the residues. The system was then left to minimize through molecular dynamics simulation in vacuum. Simulations were performed in the NVT ensemble (no pressure coupling); translation/rotation around the system center of mass were removed in all simulations. The proposed residue clustering process, illustrated in Fig. 23, was composed of 3 distinct stages:

- Minimization: The system was initially relaxed. Minimization criteria were: $F_{\max }$ $<10 \mathrm{~kJ} \mathrm{~mol}^{-1} \mathrm{~nm}^{-1}, 100000$ steps or $\Delta \mathrm{F}$ lower than machine tolerance;

- Heating: The system was brought up to $300 \mathrm{~K}$, allowing the molecules to adopt higher energy conformations and cluster together during 1 to 2 ns.

- Stabilization: The carbon model were left to stabilize at $300 \mathrm{~K}$ for 1 to $2 \mathrm{~ns}$, for data gathering (every 1000 steps) and pore development. The LINCS algorithm was applied to convert all bonds and angles that involve hydrogen atoms to bond constrains.
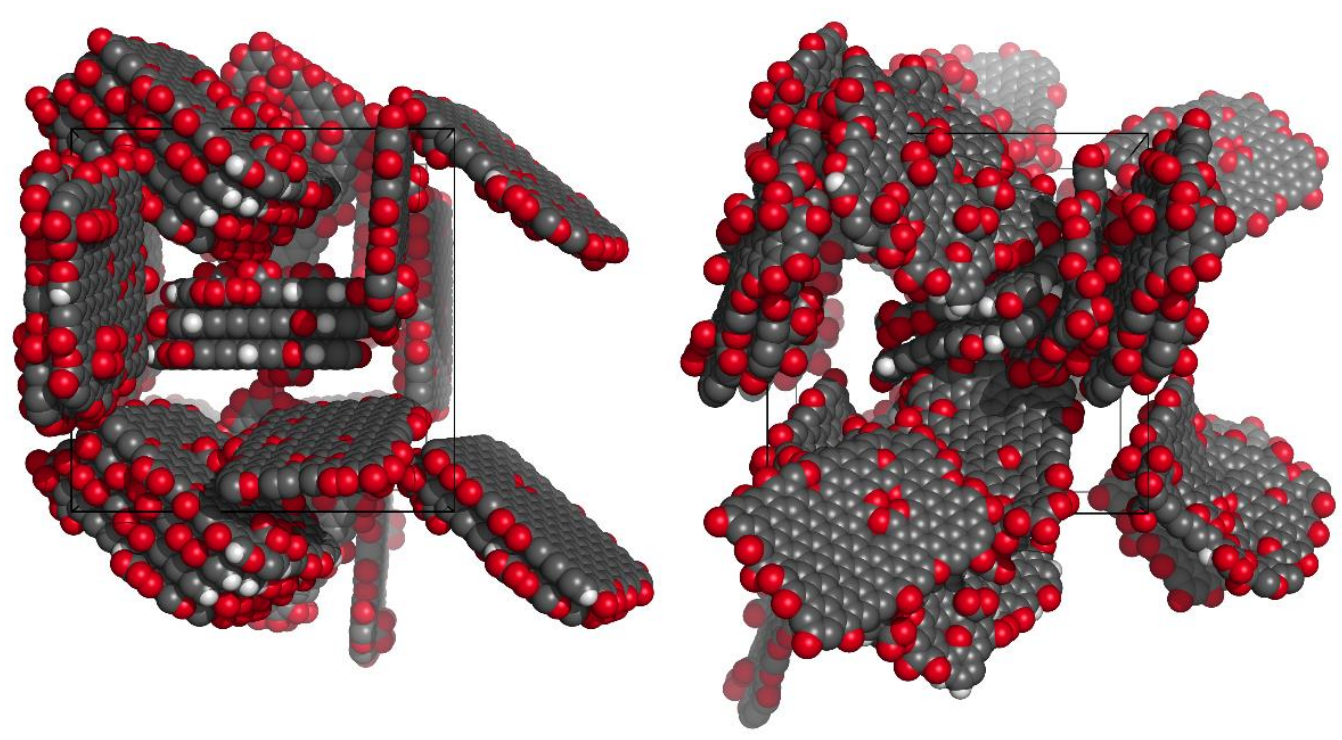

Fig. 23. Clustering process: Left - initial configuration; Right - Final carbon model; PBC conditions were considered for this illustration - all residues, and their periodic images, are represented as long as they have at least one atom inside the simulation box 
Three different residue libraries were built and used in the present work, each with different levels of oxygen content. A visual depiction of each model after the clustering process is displayed in Fig. 24. It is possible to verify that, with the increase in oxygen levels, the resulting microcrystallites progressively diverge from the initial planar form, and take a rougher structural shape, because the majority of the functional groups added during functionalization imply $\mathrm{sp}^{3}$ hybridization, therefore promoting loss of aromaticity of the carbon backbone and planarity of the microcrystallites.
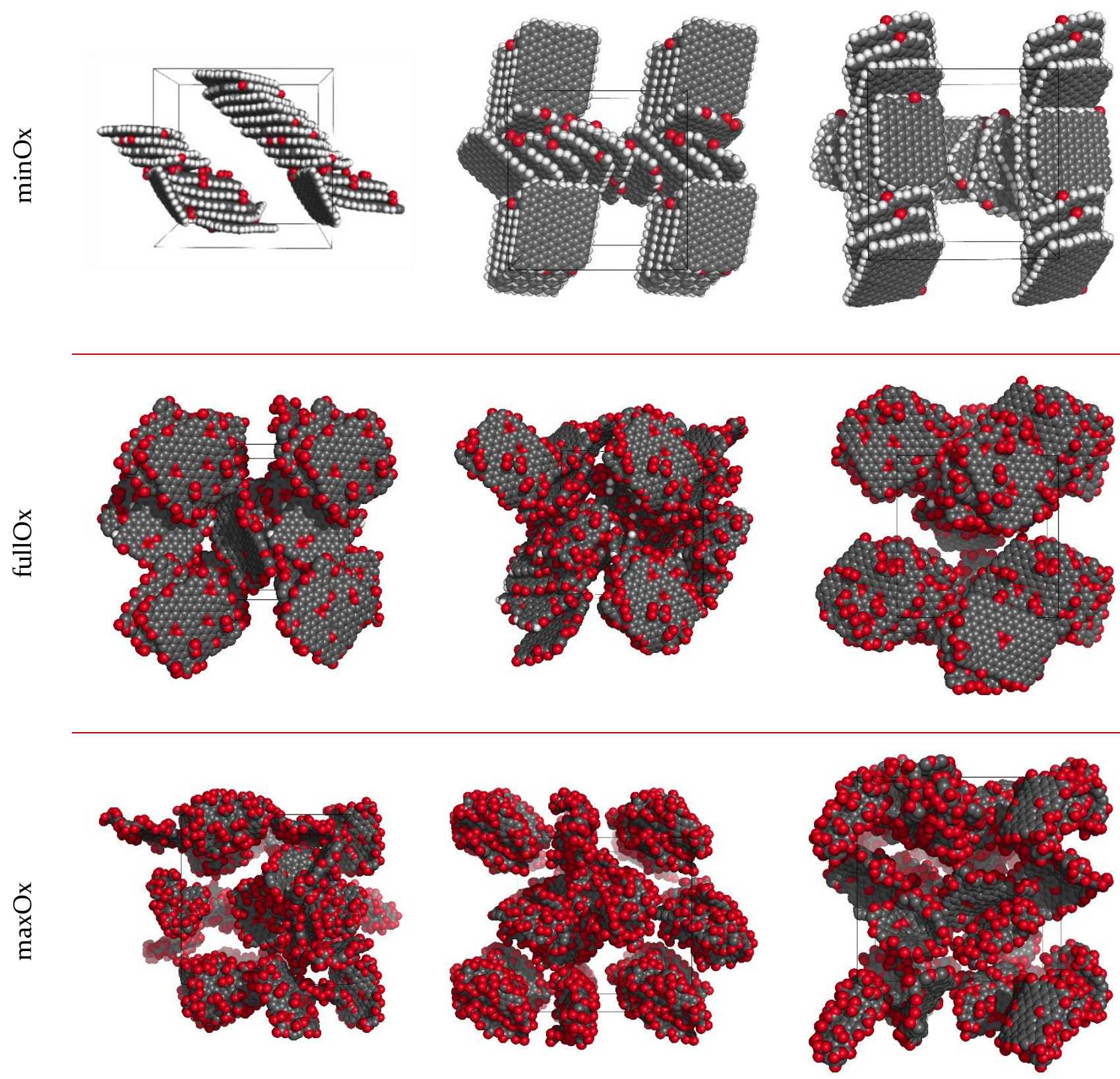

Fig. 24. Visual representation of different instances of the proposed AC model, for different oxygen levels: Top - minOx; Middle - fullOx; Bottom - maxOx 
The loss of planarity becomes evident when surface area is factored in, as show in Fig. 25. Further information regarding the characterization of the VPC models can be found in Table 8 . The increase in oxygen content augments the surface area of the corresponding AC model. Considering that the original experimental $\mathrm{AC}$ has a surface area of $1586 \mathrm{~m}^{2} \mathrm{~g}^{-1}$, the VPC model could still be optimized regarding this property $\left(2043 \pm 200 \mathrm{~m}^{2} \mathrm{~g}^{-1}\right)$. This lack of accordance between the real $\mathrm{AC}$ and the proposed model can be explained by:

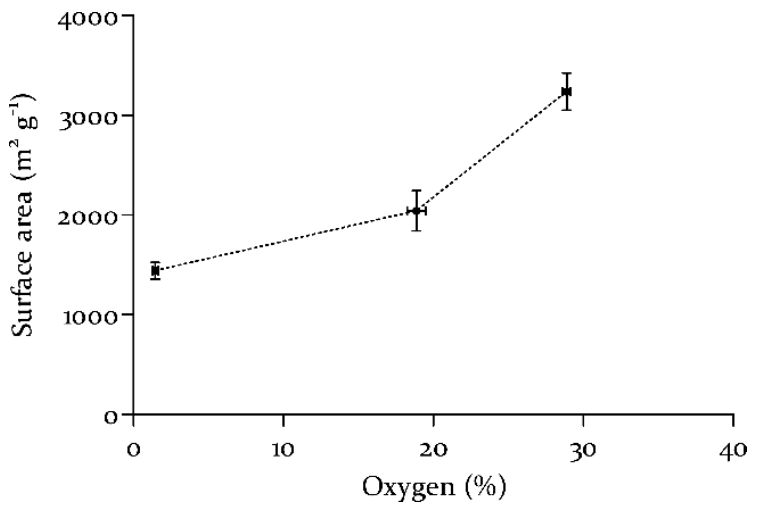

Fig. 25. Surface area evolution with oxygen content determined by Monte Carlo

- The residual existence of impurities, mainly carbonates, in the real sample which block access to smaller pores, thus reducing the $S_{\text {BET }}$.

- The existence of enclosed cavities in the AC, inaccessible to the probe molecule in experimental $S_{\mathrm{BET}}$ determination, but accounted for in the Monte Carlo method, described in section 2.

In terms of elemental and functional content composition, it is considered that the proposed model is in good accordance with the experimental data, as shown in Fig. 26. Furthermore, modulation of the oxygen content between model samples was achieved to the desired extent. However, $-\mathrm{C}-\mathrm{H}$ content differs between $\mathrm{PS} 800-\mathrm{K}_{2} \mathrm{CO}_{3}-\mathrm{HCl}$ and fullOx model. On the model, crown ethers and edge ethers in equal amount. The existence of edge ethers limits the appearance of $-\mathrm{C}-\mathrm{H}$ groups on the $\mathrm{AC}$ model. Therefore, it is expected that in $\mathrm{PS} 800-\mathrm{K}_{2} \mathrm{CO}_{3}-\mathrm{HCl}$ ethers appear mostly in internal ethers.
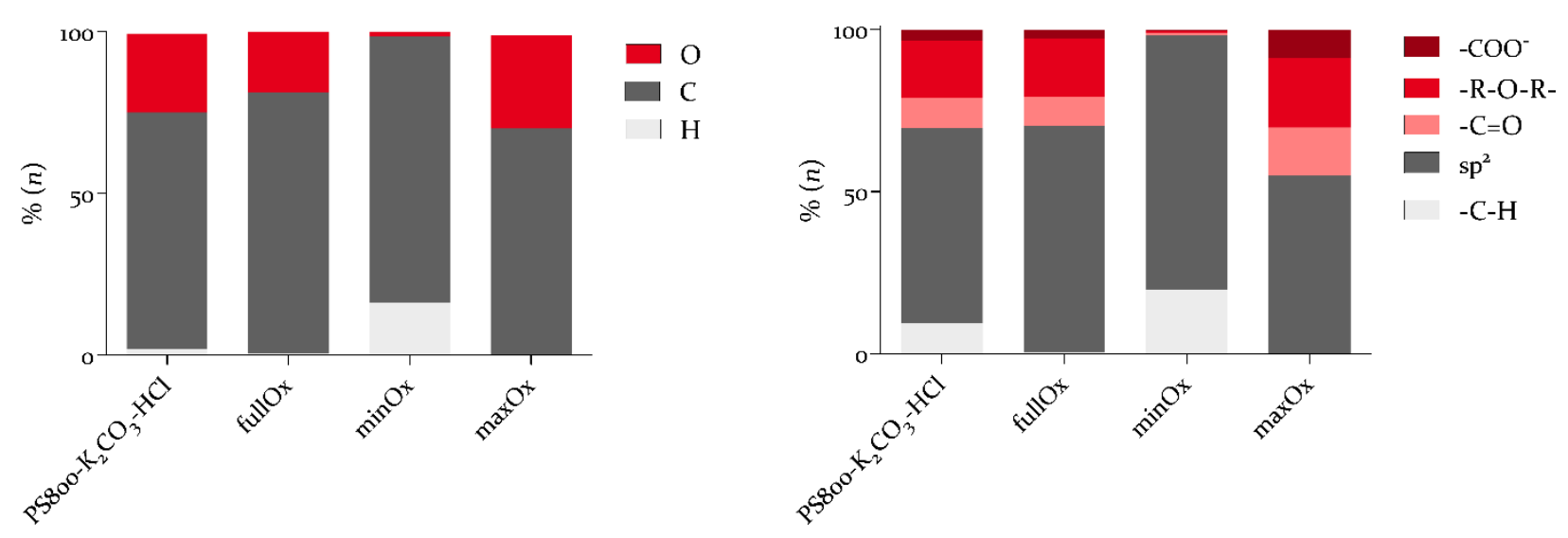

Fig. 26. Elemental and functional content comparison between models and experimental data: Left - Elemental composition; Right - Functional content 
Table 8. Characterization of the different models developed in comparison to PS800-K2CO3- $\mathrm{HCl}$ sample in terms of surface area, elemental composition, charged fraction and functional group content.

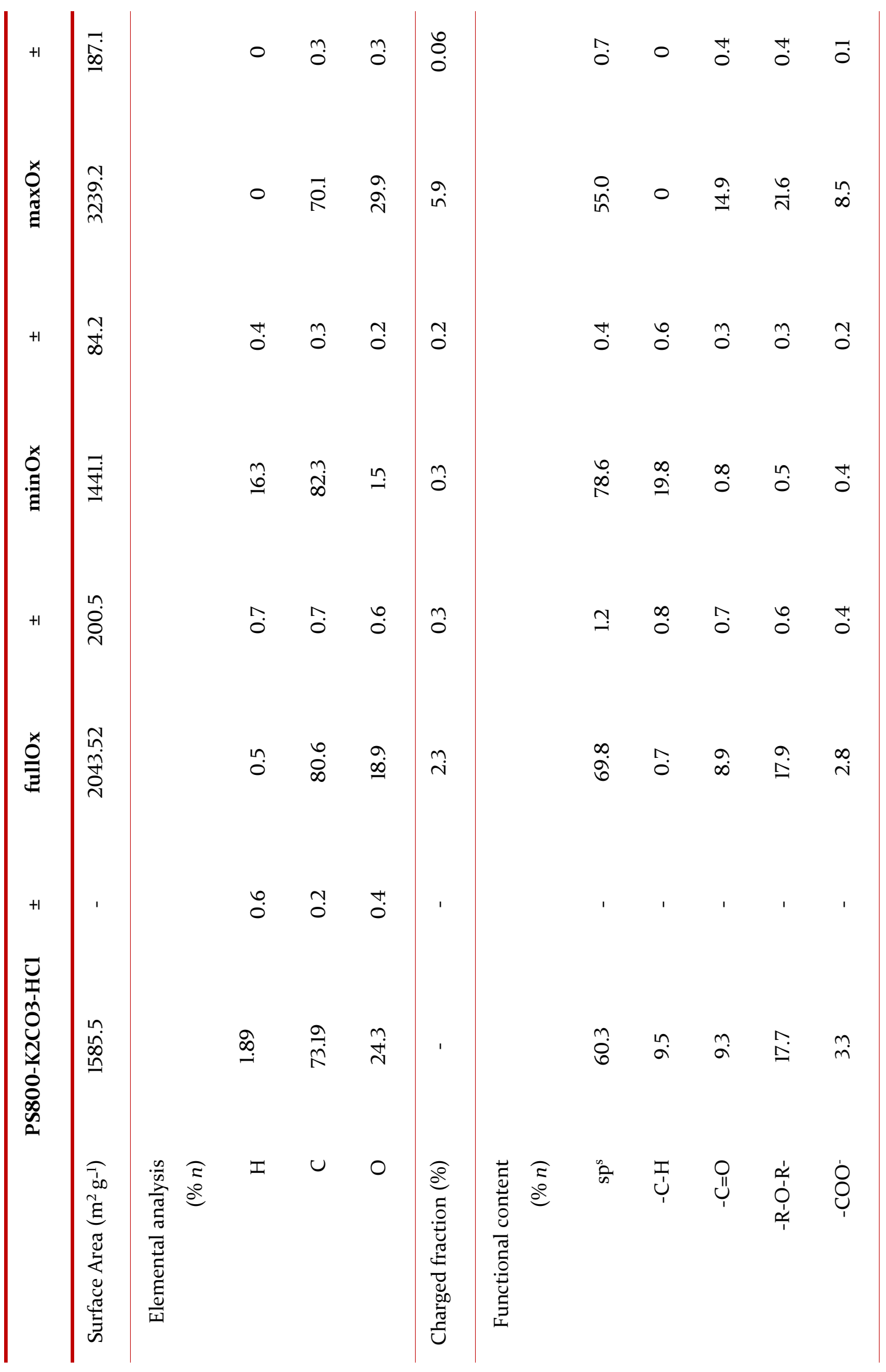




\subsection{3) Pore study}

MOLE 2.0 software was employed to study the formation and development of micropores in the proposed models. Delaunay triangulation/Voronoi diagrams were used in order to search for the shortest path between a starting point and the molecular surface (110). Pore structure has been appointed as an important factor in different applications, such as adsorption (117-119). Therefore, the proposed model in the present work should be able to develop an organized and viable micropore structure. Such challenge, although not trivial, is considered to be accomplished in the proposed AC models developed, as shown in Fig. 27. Both fullOx and maxOx models showed good pore development, but no micropores were displayed in minOx models.

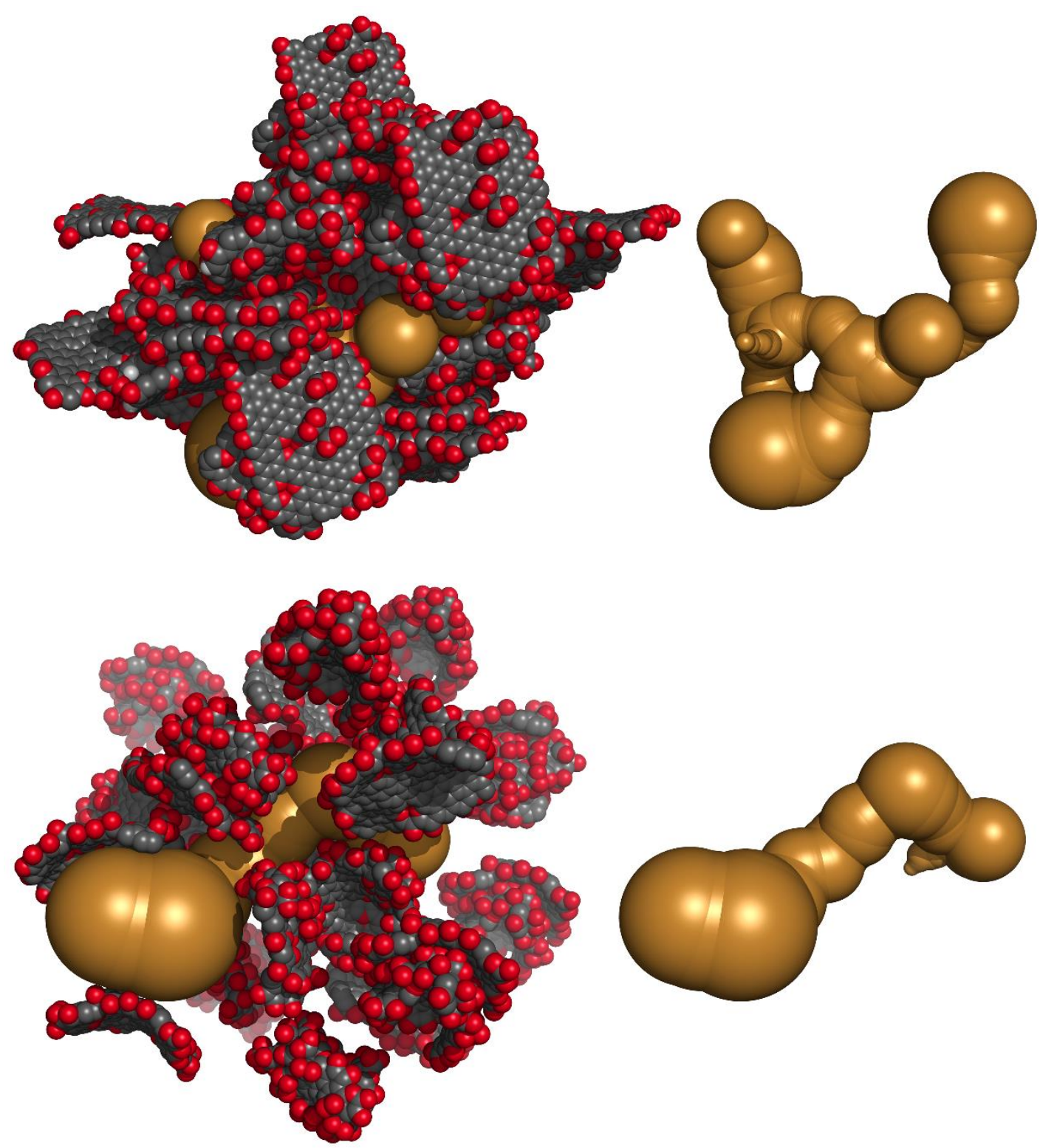

Fig. 27. Micropore structures in the proposed models: Top - fullOx; Bottom - maxOx; The corresponding structure in displayed in the right without the surrounding AC atoms, for visualization purposes. 


\subsection{4) Dipole moment visualization}

In order to understand certain behaviors to be discussed in the following topics, a visual representation of the involved molecules electrostatic potential maps emerges as a powerful tool. APBS was employed in the calculation of SMX and CBZ electrostatic potential maps, as illustrated in Fig. 28. It is possible to visualize that SMX has a stronger potential gradient than CBZ, as expected due to the negative charge.

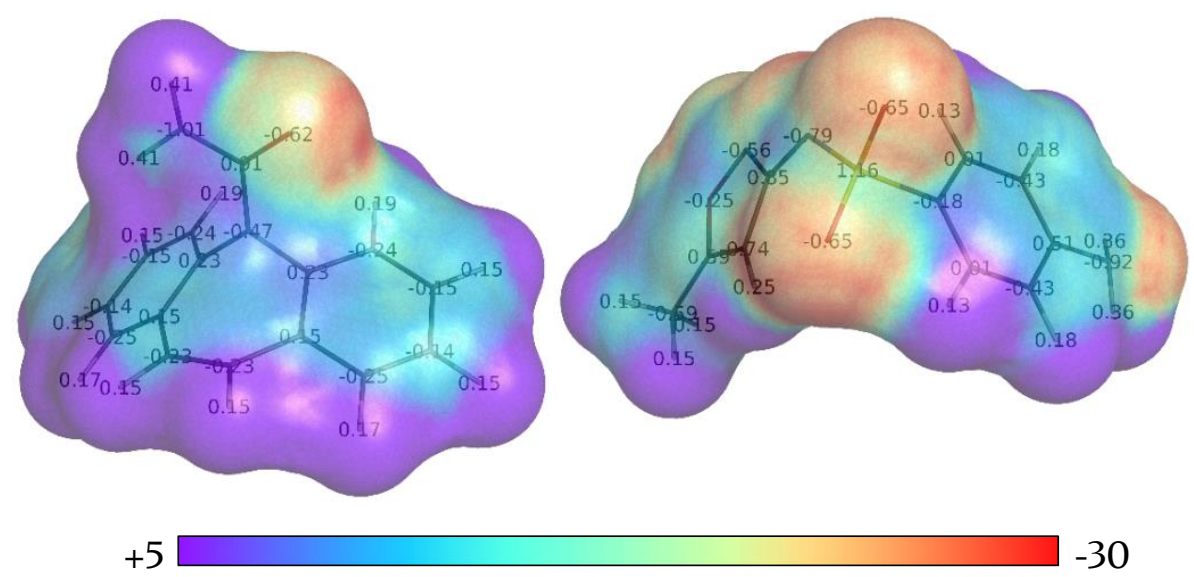

Fig. 28. Electrostatic potential maps (in $\mathrm{k}_{\mathrm{b}} \mathrm{T} / e$ ): Left - CBZ; Right - SMX. Atom partial charges are also displayed for visualization purposes.

Furthermore, a trajectory configuration result of competitive adsorption was also targeted in order to create the electrostatic potential of the involved species in equilibrium, as shown in Fig. 29. Negative electrostatic potentials are mainly caused by the presence of carboxyl groups and are often preferred sites for both SMX and CBZ adsorption.

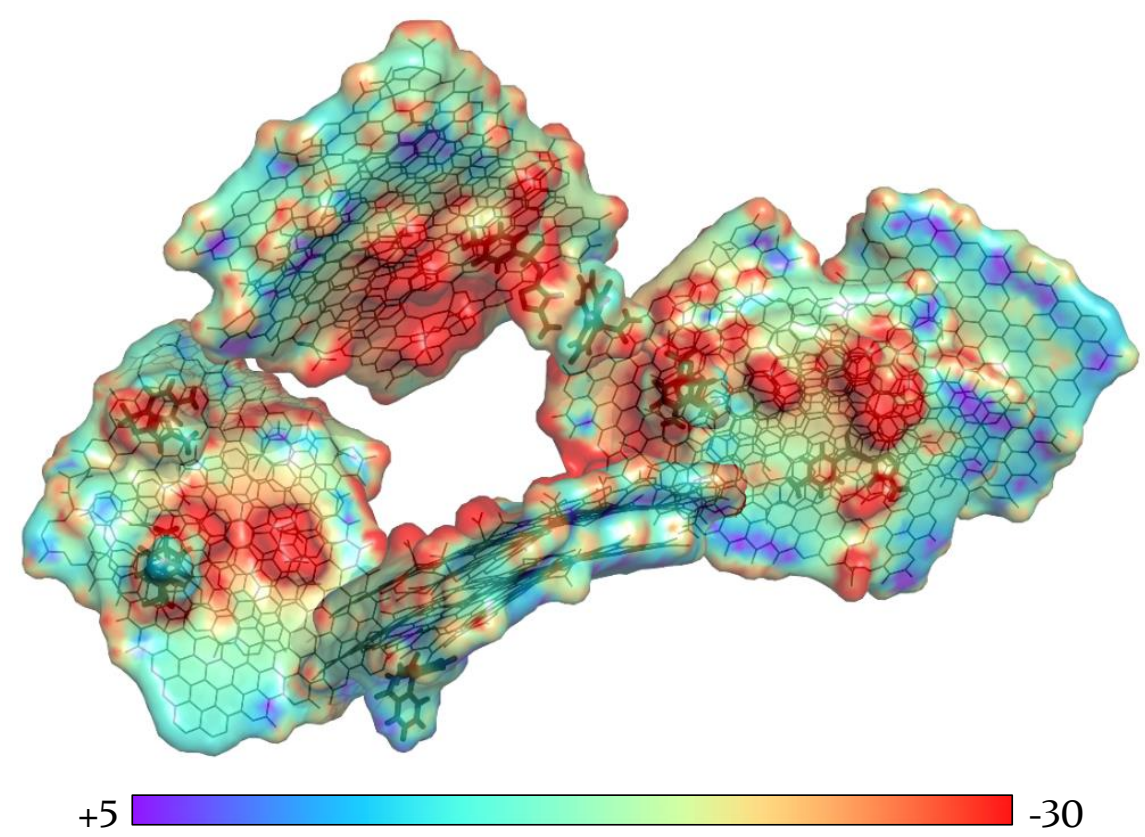

Fig. 29. Electrostatic potential map (in $\mathrm{k}_{\mathrm{b}} \mathrm{T} / e$ ) of the resulting $\mathrm{AC}$ model from MD simulation 


\subsection{4) GCMC essays}

GCMC ensemble simulations were employed to perform adsorption essays of CBZ and SMX onto the produced models. The present study targets two factors as modulators of adsorption: oxygen content and ionic strength on the wastewater. Several replicas for each residue library were produced, as previously described. 3 replica runs were performed for each carbon model, additionally, in order to evaluate both the inter- and intra-model variations. Maximum adsorption capacities were calculated for each library model (minOx, fullOx and maxOx), as described in Fig. 30. For each AC model, two modes of adsorption were considered: single component (SC - Only 1 pharmaceutical at a time) and competitive adsorption ( $\mathrm{C}$ - Both SMX and CBZ were added to the simulation simultaneously). This allows for the study of possible competitive or cooperative mechanics in the adsorption of this pharmaceuticals.

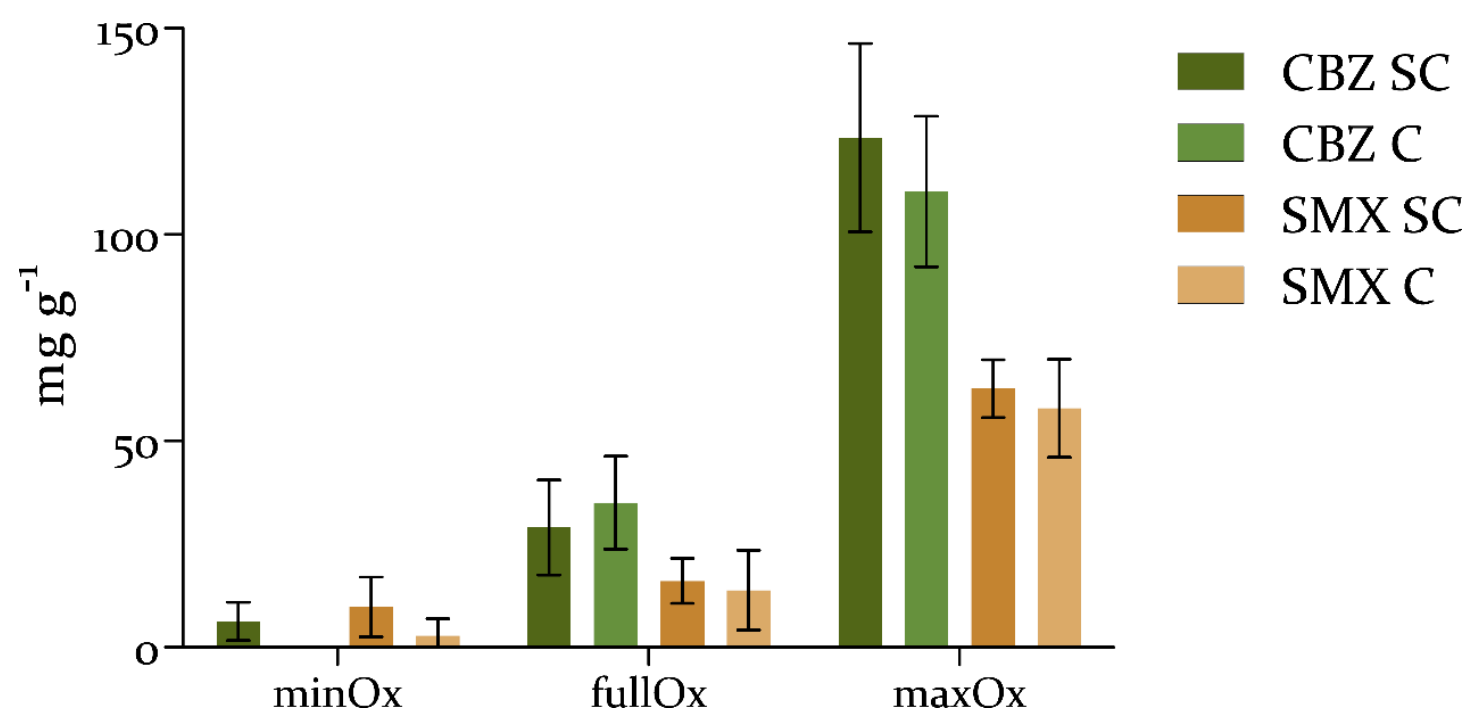

Fig. 30. GCMC adsorption results for different AC models, regarding CBZ and SMX in single component (SC) and competitive (C) modes

In a general way results suggest that pharmaceutical adsorption increases with increasing oxygen content $(\approx 20 \mathrm{x}$ and $6 \mathrm{x}$ increase for CBZ and SMX, respectively, in SC mode, from minOx to maxOx models). Competitive adsorption, overall, showed lower adsorption values for each pharmaceutical, as expected, but not in a meaningful manner or within the errors of the SC mode essay. This suggests the existence of some degree of cooperative adsorption or double layer effects, where a second pharmaceutical molecule 
is adsorbed to the surface of a first already adsorbed to the carbon surface. Finally, it is possible to observe a clear distinction between the adsorption of the two pharmaceuticals.

For the maxOx model, CBZ had an adsorption capacity ca. 2x superior to SMX. Since the simulations were carried at neutral $\mathrm{pH}$ of 7, both SMX and the AC are negatively charged and repulse each other. This does not apply to CBZ, which is neutral at pH 7.

As previously discussed, an increase in oxygen content of the AC models resulted in an equal increase in the surface area which, consequently, has positive repercussions in adsorption capacities. With this in mind, and analyzing Fig. 31, it is possible to infer that the increased SMX adsorption by carbons with oxygen content (and, therefore, charge) is caused by the increase in the AC surface area, while an increase in oxygen content has an additional positive effect in CBZ adsorption. Although being a neutral species at $\mathrm{pH} 7, \mathrm{CBZ}$ can have induced dipole moments (as discussed in the section above concerning the electrostatic potential maps) that interact with negatively charged functional groups of the AC. This result hints at the importance of functional groups and electrostatic interactions as modulators of adsorption and/or specificity in AC adsorbents.

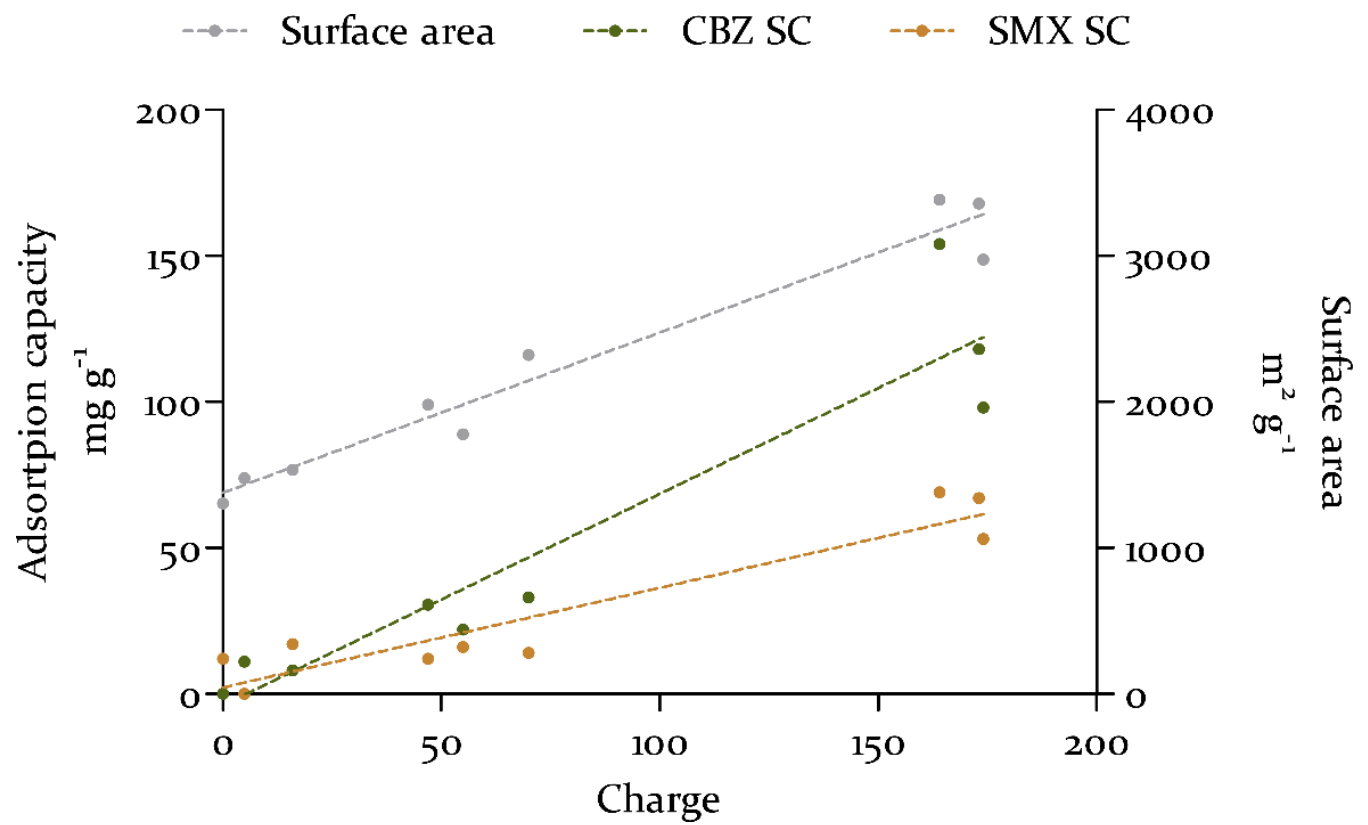

Fig. 31. Adsorption capacity and surface area evolution with the absolute value of charge $\left(e^{-1}\right)$ )in the AC model, for CBZ and SMX. Dashed lines represent the linear regression of that available data.

The effect of ionic strength on pharmaceutical adsorption was previously appointed as an important factor to take into account (120). In a real sample, ions ought 
to be naturally solvated in bulk water and away from the carbon surface, especially if the ion charge was equal to the dominant charge in the carbon surface Therefore, no ions were introduced in this simulation boxes. However, if a high enough ionic strength was introduced, by concentration increase, there would be a higher incidence of ions in the AC surface, and its influence in surface chemistry events, such as adsorption, should be considered. Sodium $\left(\mathrm{Na}^{+}\right)$was introduced in GCMC adsorption essays, in equimolar concentrations as the considered pharmaceuticals, and the results are exposed in Fig. 32. As expected, adsorption capacities increase with the increase in oxygen content. However, when $\mathrm{Na}^{+}$ions are added, both pharmaceuticals adsorption capacities in the AC increase (for maxOx model, an $\approx 1.25 \mathrm{x}$ and $5 \mathrm{x}$ increase is observed for CBZ and SMX adsorption, respectively, when compared to equivalent simulations with no ions added). SMX adsorption is predominantly affected. Two main mechanisms can be proposed:

- $\mathrm{Na}^{+}$ions screen the negative charge of both the AC and SMX, bridging the two species and allowing adsorption to the functional groups. This effect would allow for SMX to be predominantly adsorbed in the oxygen rich regions of the microcrystallites edges;

- $\mathrm{Na}^{+}$ions change the conformation of SMX to a more stable configuration, eventually promoting adsorption by weaker interactions ( $\pi-\pi$ stacking).

Although "salting out" effects are a possible explanation to the experimental observations described in literature (121), such effect was not considered in this work.

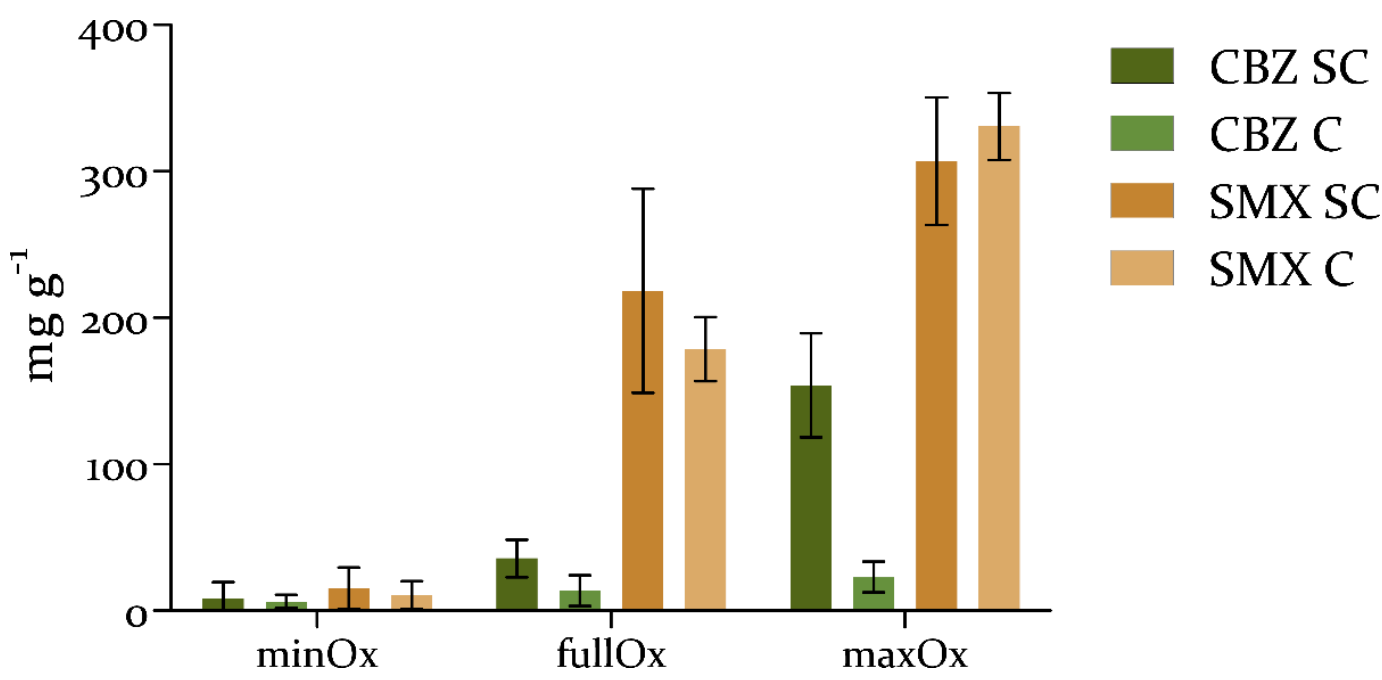

Fig. 32. GCMC adsorption results for different AC models, regarding CBZ and SMX in single component (SC) and competitive $(C)$ modes, when in presence of $\mathrm{Na}^{+}$ions 
Also, inspection of Fig. 33 suggests that, with a higher ionic strength, the previous behavior, in which SMX adsorption was fundamentally modulated by the increase in surface area, is no longer observed. In the presence of $\mathrm{Na}^{+}$, it is possible to infer that oxygen-rich functional groups have a positive effect on adsorption capacities of SMX besides the increase in surface area, while CBZ adsorption is not improved beyond the increase resulting from surface area expansion.

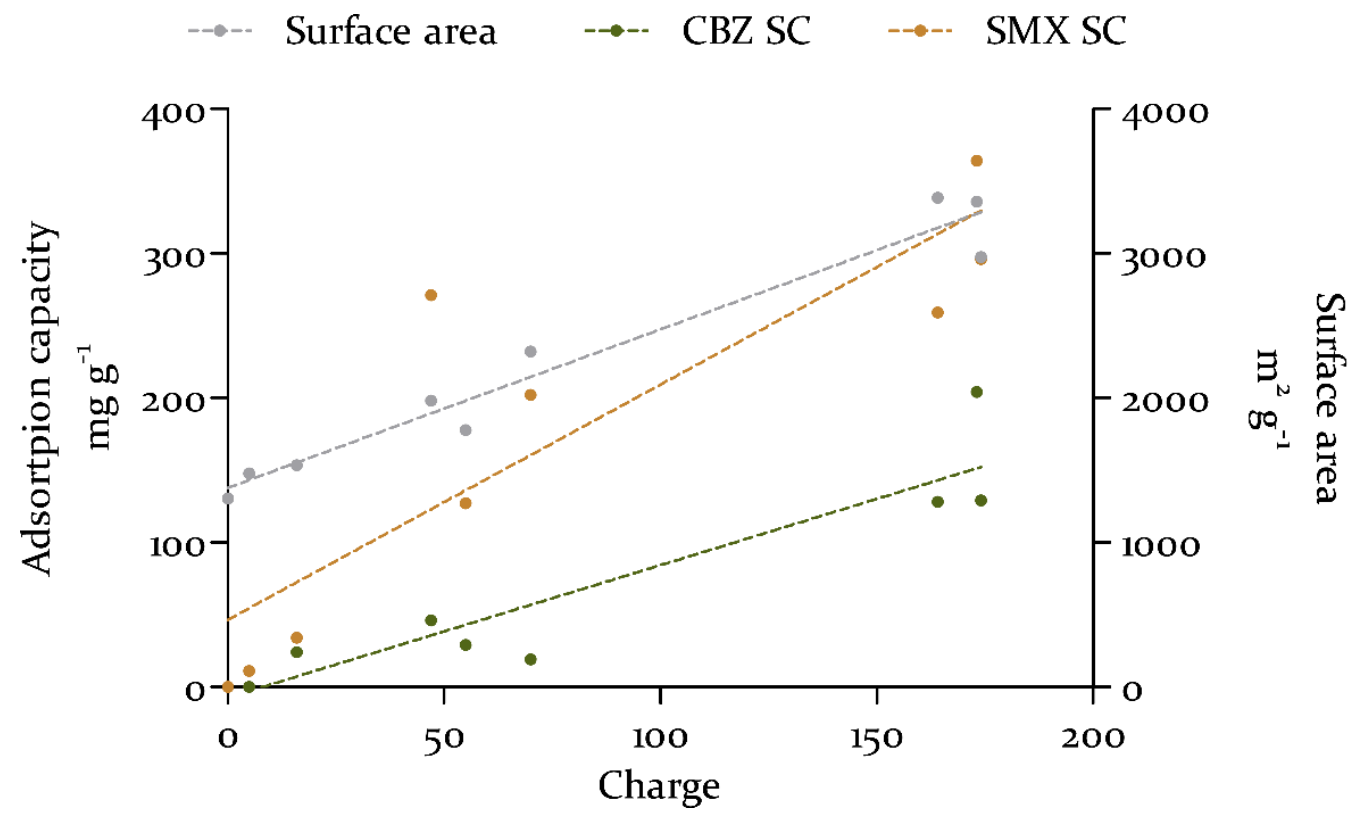

Fig. 33. Adsorption capacity and surface area evolution with the absolute value of charge $\left(e^{-1}\right)$ in the AC model, for CBZ and SMX in the presence of $\mathrm{Na}^{+}$. Dashed lines represent the linear regression on the available data points.

\subsection{5) Molecular dynamics}

Molecular dynamics simulations were carried out to highlight some of the proposed adsorption behaviors. Simulations were carried for $10 \mathrm{~ns}$ after minimization and equilibration. The presented behaviors were established relatively early ( 1 to 2 ns into the simulation) and remained stable. As an example, after adsorption on the carbon surface, no pharmaceutical molecule was desorbed. The following behaviors are transversal to all simulations performed and present in multiple replicas. 
- Double layer adsorption

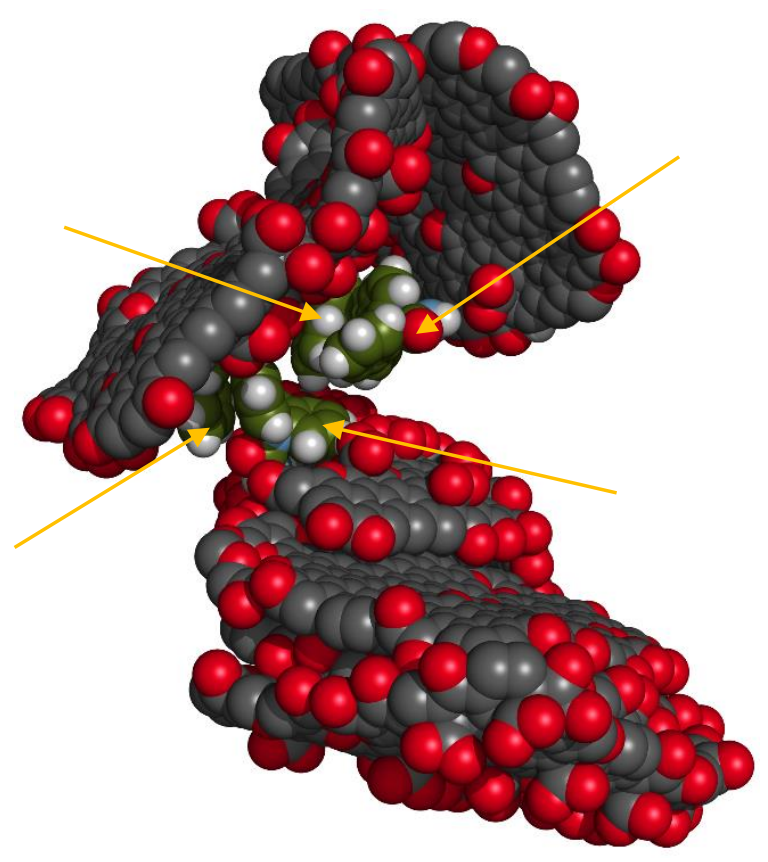

As shown in Fig. 34, four molecules of $\mathrm{CBZ}$ are tightly packed in a confined pore. The CBZ structure and neutral charge allows for the formation of double layers of adsorption, effectively increasing its adsorption capacities in normal circumstances, as previously highlighted in GCMC adsorption essays.

Fig. 34. Adsorbed CBZ in fullOx model. Excess microcrystallites and CBZ molecules were removed for visualization purposes. Yellow arrows point to CBZ molecules

\section{- SMX configurations}

Although multi conformation analysis showed that, in vacuum, SMX adopts a single "closed" conformation, MD studies showed that this molecule can adopt an "open" conformation that is stabilized on the surface of the AC upon adsorption, as illustrated in Fig. 35. Interestingly, when performing MD simulations with no $\mathrm{Na}^{+}$ions, $20 \%$ of the adsorbed SMX adopted the open structure, while simulations with $\mathrm{Na}^{+}$in solution showed that $40 \%$ of the SMX was in this configuration. Such results indicate that counter-ions balance the repulsive forces between the negatively charged groups in the pharmaceutical and AC, allowing the prevalence of $\pi-\pi$ stacking and hydrophobic interactions.
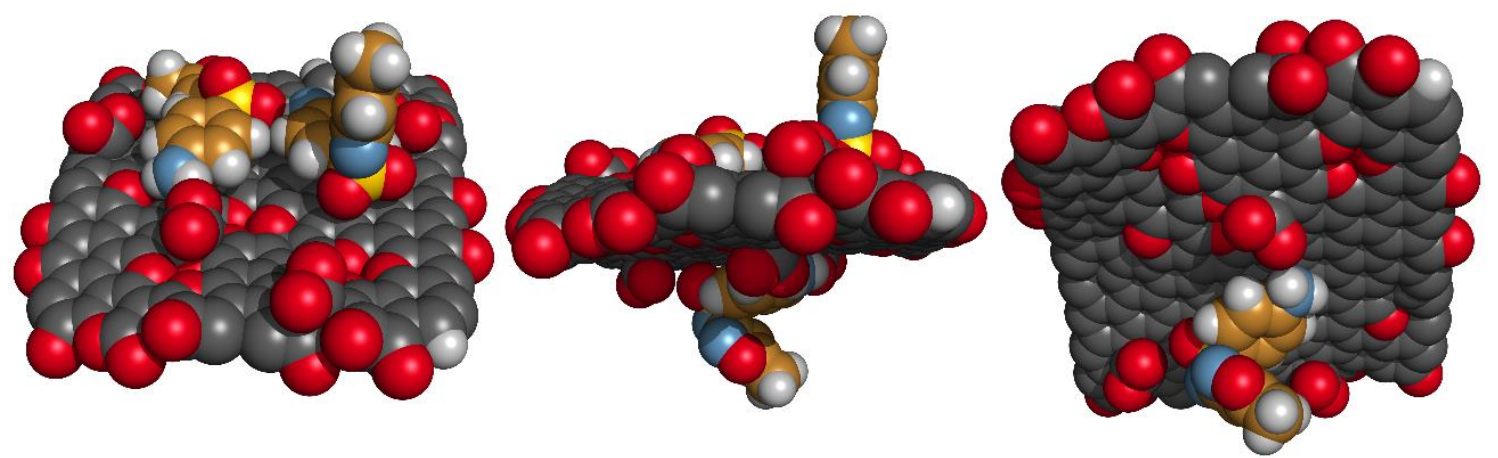

Fig. 35. Different configurations of SMX on a single microcrystallite, at different visualization angles 
- $\mathrm{Na}^{+}$complex with SMX

As illustrated in Fig. 36-Left, $\mathrm{Na}^{+}$ions interact with both the SMX and AC negative charged groups, screening the electrostatic repulsion and allowing for the establishment of $\pi-\pi$ stacking and hydrophobicity interactions. This effect allows SMX to be adsorbed onto the oxygen rich microcrystallites edges, as illustrated in Fig. 36-Right.

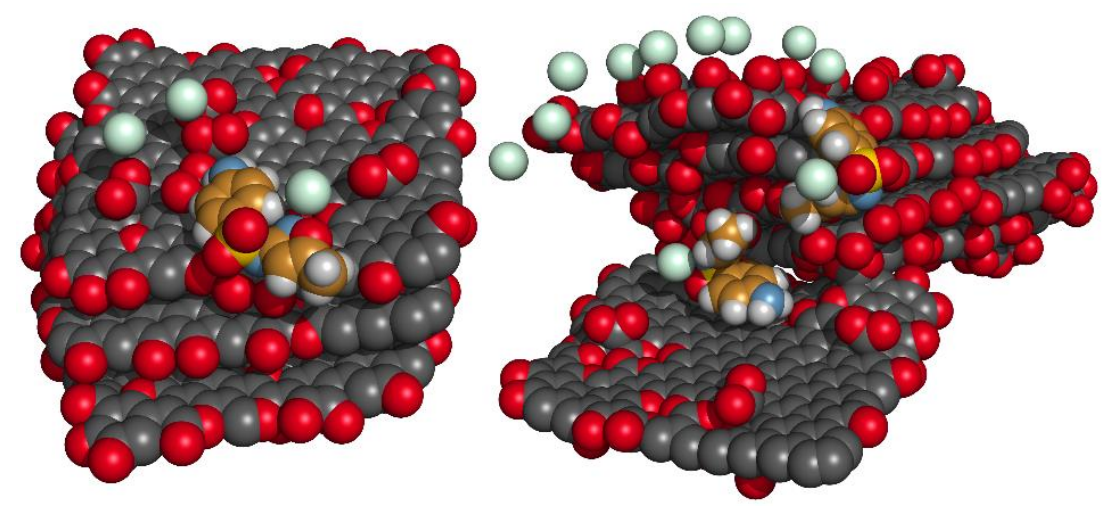

Fig. 36. $\mathrm{Na}+$ and SMX complexes with AC charged groups: Left - Na+ interaction allows the prevalence of "open" configurations; Right - Na+ allows for the interaction with microcrystallite's edges

- Competition effects

Competitive interactions were observed between $\mathrm{CBZ}$ and SMX in MD simulations, although not with great frequency, as illustrated in Fig. 37. Only 10 to $20 \%$ of the pharmaceutical molecules were in interaction with the one another. This indicates that, if present, cooperative adsorption mechanics are not relevant for this two specific pharmaceutical in a meaningful extent.

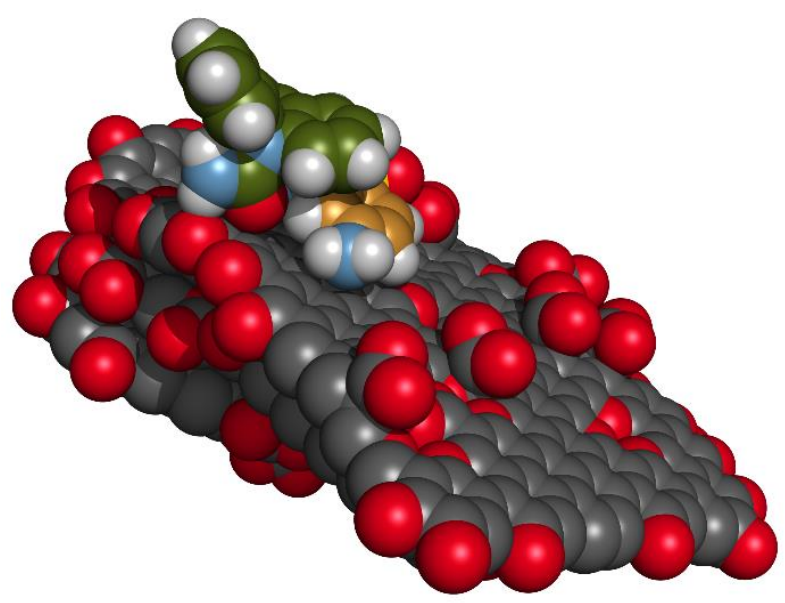

Fig. 37. Competitive adsorption interaction between SMX and CBZ. 



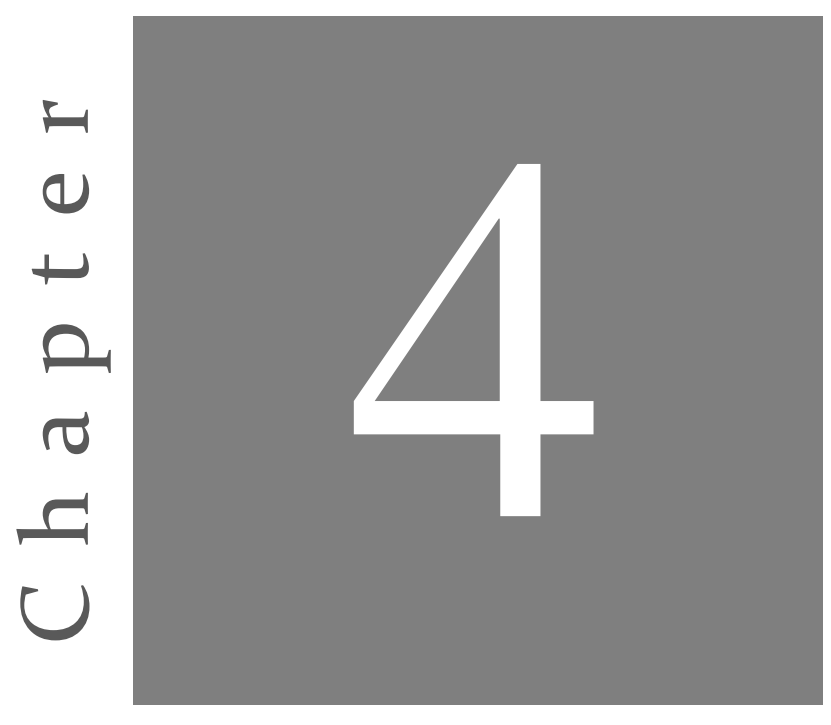

\section{Conclusion}

"There are some oddities in the perspective with which we see the world. The fact that we live at the bottom of a deep gravity well, on the surface of a gas covered planet going around a nuclear fireball 90 million miles away and think this to be normal is obviously some indication of how skewed our perspective tends to be, but we have done various things over intellectual history to slowly correct some of our misapprehensions."

- Douglas Adams, The Salmon of Doubt: Hitchhiking the Galaxy One Last Time, 2002 
To conclude the present study, an overall appreciation of the performed studies is presented, and some points are enumerated relative to possible future work in this subject.

The present project was essentially divided in three parts: experimental data gathering, AC model development and simulation results collection using the produced models. The primary objective was to produce a VPC model that would follow experimental data in a more accurate fashion in terms of elemental composition, functional group content, surface area and porous structure.

In terms of the first part of the present work, a total of 10 different techniques were explored to grant a thorough comprehension of the complexity of the carbon materials worked. Besides AC, non-activated materials were also produced and characterized to help understand the evolution of the adsorbent. Experimental data was used in the formulation of the AC model:

- $\quad \mathrm{PCZ}$ was used to define the AC charge at the simulated $\mathrm{pH}$;

- FTIR and XPS data information regarding the functional group content;

- EDS and Ultimate analysis data concerning elemental composition;

- S $_{\text {BET }}$ studies define the AC surface area;

- $\quad$ TEM and SEM imaging help to elucidate the pore structure.

Complementary techniques, such as Proximate analysis and TOC help in clarifying the composition of the AC samples in terms of fixed carbon, carbonaceous impurities and other aspects not covered in the computational model approximation.

Thus, AC model development had an experimental basis on top of which more accurate VPC models were built. It is shown that elemental composition, functional group content, surface area and pore structure are in good accordance to the gathered experimental data. This constitutes a validated computational model of the AC sample.

Such a model constitutes a workhorse for easily running simulations with the aim of gathering hints and evidence about the underlying mechanisms of adsorption of pharmaceuticals of interest from aqueous solutions. In the present work, CBZ and SMX were studied in more depth. MC and MD simulations were carried out, having the initial model tuned to reflect new conditions in the adsorption environment or changes in the material composition. It was demonstrated that surface area increases with oxygen 
content, inducing higher adsorption capacities. This effect is further enhanced for neutral substances such as CBZ. Also, when a high ionic strength is imposed to the system (in the form of addition of $\mathrm{Na}^{+}$ions), adsorption is greatly intensified. This effect is augmented in the adsorption of negatively charged molecules such as SMX. MD simulations reveal the formation of $\mathrm{AC}-\mathrm{Na}^{+}-\mathrm{SMX}$ complexes, in double layer and in microcrystallites edges, and showing good stability over time, reinforcing pharmaceutical adsorption and, therefore, constituting a possible modulating factor in SMX specific adsorption.

Although all simulations were carried at $\mathrm{pH} 7$, the $\mathrm{AC}$ model scripts, pharmaceutical definitions and simplified force fields were prepared with the notion of user-defined $\mathrm{pH}$. Therefore, $\mathrm{pH}$ effects on adsorption can be easily discussed and explored using the developed framework and made freely available to the scientific community. Furthermore, besides altering the total oxygen content of the AC model, the option to keep the oxygen composition while simply altering the functional group content was also implemented, and the study of the differences between the majority of functional groups can be readily explored. These two circumstances are appointed as possible future work regarding this specific AC. In terms of computational modelling, new pharmaceuticals of interest should also be explored.

In the experimental part of this project, and based on the information gathered, it is possible that increasing the oxygen content on the samples (in the form of functionalization) may result in higher adsorption capacities and surface areas, as suggested by the modelling results. In addition, experimentation with higher ionic strength media can be interesting as a way to modulate adsorption of certain species of pharmaceuticals.

In short, the present work required some approximations that, in future works, one should try to minimize or avoid, in order to increase the reliability of the gathered results, such as the fact that fugacity coefficients in GCMC simulations were extrapolated by approximation methods and, given time constrains, the number of replicas produced in GCMC essays was lower than desired.

However, given the scope of the project, it is considered that the conclusions gathered are reliable and of interest, and that the initially proposed objective was accomplished. 


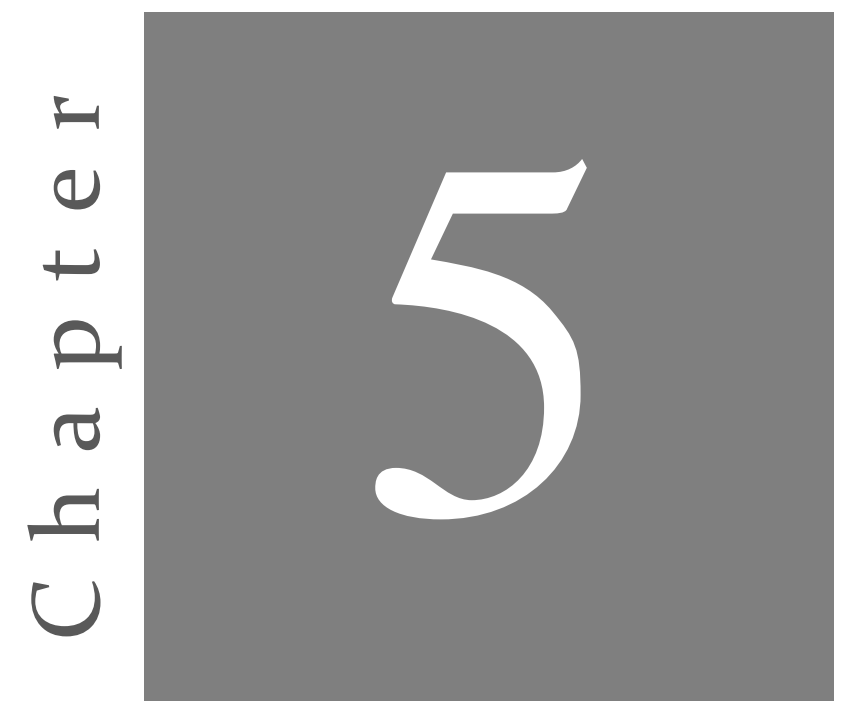

\section{Literature}

"Science and literature are not two things, but two sides of one thing."

- Thomas Henry Huxley, Aphorisms and Reflections from the Works of T.H. Huxley, 1907 
1. Escher BI, Baumgartner R, Lienert J, Fenner K. Predicting the ecotoxicological effects of transformation products. Handb Environ Chem Vol 2 React Process. 2009;2 P:205-44.

2. Boxall ABA, Sinclair CJ, Fenner K, Kolpin D, Maund SJ. Peer reviewed: When synthetic chemicals degrade in the environment. Environ Sci Technol. 2004;38(19):368A-375A.

3. Jelić A, Petrović M, Barceló D. Pharmaceuticals in Drinking Water. The Handbook of Environmental Chemistry. Springer Berlin Heidelberg; 2012. p. 1-24.

4. Hu X, Zhang H, Sun Z. Adsorption of low concentration ceftazidime from aqueous solutions using impregnated activated carbon promoted by Iron, Copper and Aluminum. Appl Surf Sci. 2016;392:332-41.

5. Tiwari B, Sellamuthu B, Ouarda Y, Drogui P, Tyagi RD, Buelna G. Review on fate and mechanism of removal of pharmaceutical pollutants from wastewater using biological approach. Bioresour Technol. 2017;224:1-12.

6. Sangion A, Gramatica P. Hazard of pharmaceuticals for aquatic environment: Prioritization by structural approaches and prediction of ecotoxicity. Environ Int. 2016;95:131-43.

7. Puckowski A, Mioduszewska K, Łukaszewicz P, Borecka M, Caban M, Maszkowska $\mathrm{J}$, et al. Bioaccumulation and analytics of pharmaceutical residues in the environment: A review. J Pharm Biomed Anal. 2016;127:232-55.

8. Jelić A, Petrović M, Barceló D. Pharmaceuticals in Drinking Water. The Handbook of Environmental Chemistry. Springer, Berlin, Heidelberg; 2012. p. 1-24.

9. Zwiener C, Frimmel FH. Oxidative treatment of pharmaceuticals in water. Water Res. 2000;34(6):1881-5.

10. Leal JE, Thompson AN, Brzezinski WA. Pharmaceuticals in drinking water: Local analysis of the problem and finding a solution through awareness. J Am Pharm Assoc. 2010;50(5):600-3.

11. Mirzaei A, Chen Z, Haghighat F, Yerushalmi L. Removal of pharmaceuticals from water by homo/heterogonous Fenton-type processes - A review. Chemosphere. 2017;174:665-88.

12. de Jongh CM, Kooij PJF, de Voogt P, ter Laak TL. Screening and human health risk assessment of pharmaceuticals and their transformation products in Dutch surface waters and drinking water. Sci Total Environ. 2012;427-428:70-7.

13. Evgenidou EN, Konstantinou IK, Lambropoulou DA. Occurrence and removal of transformation products of PPCPs and illicit drugs in wastewaters: A review. Sci Total Environ. 2015;505:905-26.

14. Escher BI, Fenner K. Recent Advances in Environmental Risk Assessment of Transformation Products. Environ Sci Technol. 2011;45(9):3835-47.

15. Calisto V, Domingues MRM, Erny GL, Esteves VI. Direct photodegradation of carbamazepine followed by micellar electrokinetic chromatography and mass spectrometry. Water Res. 2011;45(3):1095-104.

16. Jones OA, Lester JN, Voulvoulis N. Pharmaceuticals: A threat to drinking water? Vol. 23, Trends in Biotechnology. 2005. p. 163-7. 
17. Leal JE, Thompson AN, Brzezinski W a. Pharmaceuticals in drinking water: local analysis of the problem and finding a solution through awareness. J Am Pharm Assoc (2003). 2010;50(5):600-3.

18. Boxall $\mathrm{AB}$ a. The environmental side effects of medication. EMBO Rep. 2004;5(12):1110-6.

19. European Commision. $\operatorname{COM(2011)~876:~amending~Directives~2000/60/EC~and~}$ 2008/105/EC as regards priority substances in the field of water policy. Brussels; 2011.

20. Andreozzi R, Marotta R, Pinto G, Pollio A. Carbamazepine in water: Persistence in the environment, ozonation treatment and preliminary assessment on algal toxicity. Water Res. 2002;36(11):2869-77.

21. Johnson AC, Keller V, Dumont E, Sumpter JP. Assessing the concentrations and risks of toxicity from the antibiotics ciprofloxacin, sulfamethoxazole, trimethoprim and erythromycin in European rivers. Sci Total Environ. 2015;511:747-55.

22. Johnson AC, Jürgens MD, Nakada N, Hanamoto S, Singer AC, Tanaka H. Linking changes in antibiotic effluent concentrations to flow, removal and consumption in four different UK sewage treatment plants over four years. Environ Pollut. 2017;220:919-26.

23. Luo Y, Guo W, Ngo HH, Nghiem LD, Hai FI, Zhang J, et al. A review on the occurrence of micropollutants in the aquatic environment and their fate and removal during wastewater treatment. Vols. 473-474, Science of the Total Environment. 2014. p. 619-41.

24. ECOTOX. Proposals for Acute and Chronic Quality Standards. 2016.

25. Vieno N, Tuhkanen T, Kronberg L. Removal of pharmaceuticals in drinking water treatment: Effect of chemical coagulation. Environ Technol. 2006;27(2):183-92.

26. Calisto V, Ferreira CIA, Oliveira JABP, Otero M, Esteves VI. Adsorptive removal of pharmaceuticals from water by commercial and waste-based carbons. J Environ Manage. 2015;152:83-90.

27. Nghiem LD, Schäfer AI, Elimelech M. Pharmaceutical Retention Mechanisms by Nanofiltration Membranes. Environ Sci Technol. 2005;39(19):7698-705.

28. Hartig C, Storm T, Jekel M. Detection and identification of sulphonamide drugs in municipal waste water by liquid chromatography coupled with electrospray ionisation tandem mass spectrometry. In: Journal of Chromatography A. 1999. p. 163-73.

29. Andreozzi R, Marotta R, Paxéus N. Pharmaceuticals in STP effluents and their solar photodegradation in aquatic environment. Chemosphere. 2003;50(10):1319-30.

30. Wang Q, Dölle K, Tong J, Liu W-C. Pharmaceuticals in Surface Water and Waste Water Treatment Plant Effluent around the World - A Review. Asian J Environ Ecol AJEE. 2017;3(33):1-17.

31. Zhang Y, Geißen SU. Prediction of carbamazepine in sewage treatment plant effluents and its implications for control strategies of pharmaceutical aquatic contamination. Chemosphere. 2010;80(11):1345-52.

32. Zhou JL, Zhang ZL, Banks E, Grover D, Jiang JQ. Pharmaceutical residues in 
wastewater treatment works effluents and their impact on receiving river water. J Hazard Mater. 2009;166(2-3):655-61.

33. Ebele AJ, Abou-Elwafa Abdallah M, Harrad S. Pharmaceuticals and personal care products (PPCPs) in the freshwater aquatic environment. Vol. 3, Emerging Contaminants. Elsevier; 2017. p. 1-16.

34. Santos JL, Aparicio I, Alonso E. Occurrence and risk assessment of pharmaceutically active compounds in wastewater treatment plants. A case study: Seville city (Spain). Environ Int. 2007;33(4):596-601.

35. Ferrari B, Paxéus N, Giudice R Lo, Pollio A, Garric J. Ecotoxicological impact of pharmaceuticals found in treated wastewaters: Study of carbamazepine, clofibric acid, and diclofenac. Ecotoxicol Environ Saf. 2003;55(3):359-70.

36. Ternes TA. Occurrence of drugs in German sewage treatment plants and rivers. Water Res. 1998;32(11):3245-60.

37. Chu L, Wang J. Regeneration of sulfamethoxazole-saturated activated carbon using gamma irradiation. Radiat Phys Chem. 2017;130:391-6.

38. Tonucci MC, Gurgel LVA, Aquino SF de. Activated carbons from agricultural byproducts (pine tree and coconut shell), coal, and carbon nanotubes as adsorbents for removal of sulfamethoxazole from spiked aqueous solutions: Kinetic and thermodynamic studies. Ind Crops Prod. 2015;74:111-21.

39. Rodríguez-Escales P, Sanchez-Vila X. Fate of sulfamethoxazole in groundwater: Conceptualizing and modeling metabolite formation under different redox conditions. Water Res. 2016;105:540-50.

40. Alrashood ST. Carbamazepine. In: Profiles of Drug Substances, Excipients and Related Methodology. 2016. p. 133-321.

41. Ghattas AK, Fischer F, Wick A, Ternes TA. Anaerobic biodegradation of (emerging) organic contaminants in the aquatic environment. Vol. 116, Water Research. 2017. p. 268-95.

42. Bahlmann A, Brack W, Schneider RJ, Krauss M. Carbamazepine and its metabolites in wastewater: Analytical pitfalls and occurrence in Germany and Portugal. Water Res. 2014;57:104-14.

43. Bahlmann A, Carvalho JJ, Weller MG, Panne U, Schneider RJ. Immunoassays as high-throughput tools: Monitoring spatial and temporal variations of carbamazepine, caffeine and cetirizine in surface and wastewaters. Chemosphere. 2012;89(11):1278-86.

44. Calisto V, Bahlmann A, Schneider RJ, Esteves VI. Application of an ELISA to the quantification of carbamazepine in ground, surface and wastewaters and validation with LC-MS/MS. Chemosphere. 2011;84(11):1708-15.

45. Calisto V, Domingues MRM, Erny GL, Esteves VI. Direct photodegradation of carbamazepine followed by micellar electrokinetic chromatography and mass spectrometry. Water Res. 2011;45(3):1095-104.

46. Jaria G, Calisto V, Gil MV, Otero M, Esteves VI. Removal of fluoxetine from water by adsorbent materials produced from paper mill sludge. J Colloid Interface Sci. 2015;448:32-40. 
47. Kim I, Yamashita N, Tanaka H. Performance of UV and UV/H2O2 processes for the removal of pharmaceuticals detected in secondary effluent of a sewage treatment plant in Japan. J Hazard Mater. 2009;166(2-3):1134-40.

48. Ziylan A, Ince NH. The occurrence and fate of anti-inflammatory and analgesic pharmaceuticals in sewage and fresh water: Treatability by conventional and nonconventional processes. Vol. 187, Journal of Hazardous Materials. 2011. p. 24-36.

49. Rodriguez-Narvaez OM, Peralta-Hernandez JM, Goonetilleke A, Bandala ER. Treatment technologies for emerging contaminants in water: A review. Vol. 323, Chemical Engineering Journal. 2017. p. 361-80.

50. Adams C, Wang Y, Loftin K, Meyer M. Removal of Antibiotics from Surface and Distilled Water in Conventional Water Treatment Processes. J Environ Eng. 2002;128(3):253-60.

51. Thue PS, Adebayo MA, Lima EC, Sieliechi JM, Machado FM, Dotto GL, et al. Preparation, characterization and application of microwave-assisted activated carbons from wood chips for removal of phenol from aqueous solution. J Mol Liq. 2016;223:1067-80.

52. Ould-Idriss A, Stitou M, Cuerda-Correa EM, Fernández-González C, Macías-García A, Alexandre-Franco MF, et al. Preparation of activated carbons from olive-tree wood revisited. I. Chemical activation with H3PO4. Fuel Process Technol. 2011;92(2):261-5.

53. Thue PS, Lima EC, Sieliechi JM, Saucier C, Silvio LP, Vaghetti JCP, et al. Effects of first row transition metals and impregnation ratios on the physicochemical properties of microwave-assisted activated carbons from wood biomass. J Colloid Interface Sci. 2016;486:163-75.

54. Marsh H, Rodríguez-Reinoso F. Activated Carbon (Origins). Act Carbon. 1992;(1997):13-86.

55. Peláez-Cid A-A, Herrera-González A-M, Salazar-Villanueva M, Bautista-Hernández A. Elimination of textile dyes using activated carbons prepared from vegetable residues and their characterization. J Environ Manage. 2016;181:269-78.

56. Wakizaka H, Miyake H, Kawahara Y. Utilization of beer lees waste for the production of activated carbons: The influence of protein fractions on the activation reaction and surface properties. Sustain Mater Technol. 2016;8:1-4.

57. Brito MJP, Veloso CM, Bonomo RCF, Fontan R da CI, Santos LS, Monteiro KA. Activated carbons preparation from yellow mombin fruit stones for lipase immobilization. Fuel Process Technol. 2016;

58. Yakout SM, Sharaf El-Deen G. Characterization of activated carbon prepared by phosphoric acid activation of olive stones. Arab J Chem. 2016;9:S1155-62.

59. Maciá-Agulló JA, Moore BC, Cazorla-Amorós D, Linares-Solano A. Activation of coal tar pitch carbon fibres: Physical activation vs. chemical activation. Carbon $\mathrm{N}$ Y. 2004;42(7):1367-70.

60. Yahya MA, Al-Qodah Z, Ngah CWZ. Agricultural bio-waste materials as potential sustainable precursors used for activated carbon production: A review. Renew Sustain Energy Rev. 2015;46:218-35. 
61. Mestre AS, Bexiga AS, Proença M, Andrade M, Pinto ML, Matos I, et al. Activated carbons from sisal waste by chemical activation with $\mathrm{K} 2 \mathrm{CO} 3$ : Kinetics of paracetamol and ibuprofen removal from aqueous solution. Bioresour Technol. 2011;102(17):8253-60.

62. Viswanathan B, Neel P, Varadarajan T. Methods of activation and specific applications of carbon materials. Methods Act Specif Appl Carbon Mater. 2009;160.

63. Mestre AS, Pires RA, Aroso I, Fernandes EM, Pinto ML, Reis RL, et al. Activated carbons prepared from industrial pre-treated cork: Sustainable adsorbents for pharmaceutical compounds removal. Chem Eng J. 2014;253:408-17.

64. Sun Y, Wei J, Wang YS, Yang G, Zhang JP. Production of activated carbon by K2CO3 activation treatment of cornstalk lignin and its performance in removing phenol and subsequent bioregeneration. Environ Technol. 2010;31(1):53-61.

65. Laginhas C, Nabais JMV, Titirici MM. Activated carbons with high nitrogen content by a combination of hydrothermal carbonization with activation. Microporous Mesoporous Mater. 2016;226:125-32.

66. Hui T.S. \& Zaini M.A.A. Potassium hydroxide activation of activated carbon : a commentary. Carbon Lett. 2015;16(4):275-80.

67. Buczek B. Preparation of Active Carbon by Additional Activation with Potassium Hydroxide and Characterization of Their Properties. Adv Mater Sci Eng. 2016;2016:1-4.

68. Snyder SA, Adham S, Redding AM, Cannon FS, DeCarolis J, Oppenheimer J, et al. Role of membranes and activated carbon in the removal of endocrine disruptors and pharmaceuticals. Desalination. 2007;202(1-3):156-81.

69. Wong KT, Yoon Y, Snyder SA, Jang M. Phenyl-functionalized magnetic palm-based powdered activated carbon for the effective removal of selected pharmaceutical and endocrine-disruptive compounds. Chemosphere. 2016;152:71-80.

70. Sheng C, Nnanna AGA, Liu Y, Vargo JD. Removal of Trace Pharmaceuticals from Water using coagulation and powdered activated carbon as pretreatment to ultrafiltration membrane system. Sci Total Environ. 2016;550:1075-83.

71. Kyzas GZ, Deliyanni EA. Modified activated carbons from potato peels as green environmental-friendly adsorbents for the treatment of pharmaceutical effluents. Chem Eng Res Des. 2015;97:135-44.

72. Pardo B, Ferrer N, Sempere J, Gonzalez-Olmos R. A key parameter on the adsorption of diluted aniline solutions with activated carbons: The surface oxygen content. Chemosphere. 2016;162:181-8.

73. Cossarutto L, Zimny T, Kaczmarczyk J, Siemieniewska T, Bimer J, Weber J V. Transport and sorption of water vapour in activated carbons. Carbon N Y. 2001;39(15):2339-46.

74. Ngernyen Y, Tangsathitkulchai C, Tangsathitkulchai M. Porous properties of activated carbon produced from Eucalyptus and Wattle wood by carbon dioxide activation. Korean J Chem Eng. 2006;23(6):1046-54.

75. Sánchez AR, Elguézabal AA, De La Torre Saenz L. CO2 activation of char from Quercus agrifolia wood waste. Carbon N Y. 2001;39(9):1367-77. 
76. Giraldo L, Moreno-Piraján JC. Pb2+ adsorption from aqueous solutions on activated carbons obtained from lignocellulosic residues. Brazilian J Chem Eng. 2008;25(1):143-51.

77. Phan NH, Rio S, Faur C, Le Coq L, Le Cloirec P, Nguyen TH. Production of fibrous activated carbons from natural cellulose (jute, coconut) fibers for water treatment applications. Carbon N Y. 2006;44(12):2569-77.

78. Hu Z, Srinivasan MP, Ni Y. Novel activation process for preparing highly microporous and mesoporous activated carbons. Carbon N Y. 2001;39(6):877-86.

79. Aworn A, Thiravetyan P, Nakbanpote W. Preparation and characteristics of agricultural waste activated carbon by physical activation having micro- and mesopores. J Anal Appl Pyrolysis. 2008;82(2):279-85.

80. Rouquerol J, Avnir D, Fairbridge CW, Everett DH, Haynes JM, Pernicone N, et al. Recommendations for the characterization of porous solids (Technical Report). Pure Appl Chem. 1994;66(8):1739-58.

81. Areeprasert C, Scala F, Coppola A, Urciuolo M, Chirone R, Chanyavanich P, et al. Fluidized bed co-combustion of hydrothermally treated paper sludge with two coals of different rank. Fuel Process Technol. 2016;144:230-8.

82. Fang S, Yu Z, Lin Y, Hu S, Liao Y, Ma X. Thermogravimetric analysis of the copyrolysis of paper sludge and municipal solid waste. Energy Convers Manag. 2015;101:626-31.

83. Boshoff S, Gottumukkala LD, van Rensburg E, Görgens J. Paper sludge (PS) to bioethanol: Evaluation of virgin and recycle mill sludge for low enzyme, high-solids fermentation. Bioresour Technol. 2016;203:103-11.

84. Xu C, Lancaster J. Conversion of secondary pulp/paper sludge powder to liquid oil products for energy recovery by direct liquefaction in hot-compressed water. Water Res. 2008;42(6-7):1571-82.

85. Jaria G, Silva CP, Ferreira CIA, Otero M, Calisto V. Sludge from paper mill effluent treatment as raw material to produce carbon adsorbents: An alternative waste management strategy. J Environ Manage. 2017;188:203-11.

86. Calisto V, Ferreira CIA, Santos SM, Gil MV, Otero M, Esteves VI. Production of adsorbents by pyrolysis of paper mill sludge and application on the removal of citalopram from water. Bioresour Technol. 2014;166:335-44.

87. Ferreira CIA, Calisto V, Otero M, Nadais H, Esteves VI. Comparative adsorption evaluation of biochars from paper mill sludge with commercial activated carbon for the removal of fish anaesthetics from water in Recirculating Aquaculture Systems. Aquac Eng. 2016;74:76-83.

88. Ferreira CIA, Calisto V, Otero M, Nadais H, Esteves VI. Removal of tricaine methanesulfonate from aquaculture wastewater by adsorption onto pyrolysed paper mill sludge. Chemosphere. 2017;168:139-46.

89. Coimbra RN, Calisto V, Ferreira CIA, Esteves VI, Otero M. Removal of pharmaceuticals from municipal wastewater by adsorption onto pyrolyzed pulp mill sludge. Arabian Journal of Chemistry. 2015;

90. Khalili NR, Vyas JD, Weangkaew W, Westfall SJ, Parulekar SJ, Sherwood R. 
Synthesis and characterization of activated carbon and bioactive adsorbent produced from paper mill sludge. Sep Purif Technol. 2002;26(2-3):295-304.

91. Jambrina PG, Aldegunde J. Chapter 20 - Computational Tools for the Study of Biomolecules. In: Computer Aided Chemical Engineering. 2017. p. 583-648.

92. Schlick T. Pursuing Laplace's vision on modern computers. ... Approaches to Biomol Struct Dyn. 1996;1-20.

93. González MA. Force fields and molecular dynamics simulations. Collect SFN. 2011;12:169-200.

94. Vega LF. Chapter 5 Structural characterization of nano- and mesoporous materials by molecular simulations. Vol. 18, Theoretical and Computational Chemistry. 2008. $101-126 \mathrm{p}$.

95. Bahamon D, Carro L, Guri S, Vega LF. Computational study of ibuprofen removal from water by adsorption in realistic activated carbons. J Colloid Interface Sci. 2017;498:323-34.

96. Olivier JP. Improving the models used for calculating the size distribution of micropore volume of activated carbons from adsorption data. Carbon N Y. 1998;36(10):1469-72.

97. and VYG, James A. O’Brien* †. Prediction of Gas Mixture Adsorption on Activated Carbon Using Molecular Simulations. 1998;

98. Kaneko K, Ishii C, Ruike M, kuwabara H. Origin of superhigh surface area and microcrystalline graphitic structures of activated carbons. Carbon N Y. 1992;30(7):1075-88.

99. Biggs MJ, Buts A. Virtual porous carbons: what they are and what they can be used for. Mol Simul. 2006;32(7):579-93.

100. Liu JC, Monson PA. Monte Carlo simulation study of water adsorption in activated carbon. Ind Eng Chem Res. 2006;45(16):5649-56.

101. Di Biase E, Sarkisov L. Systematic development of predictive molecular models of high surface area activated carbons for adsorption applications. Carbon N Y. 2013;64:262-80.

102. Gonciaruk A, Siperstein FR. In silico designed microporous carbons. Carbon N Y. 2015;88:185-95.

103. Segarra EI, Glandt ED. Model microporous carbons: microstructure, surface polarity and gas adsorption. Chem Eng Sci. 1994;49(17):2953-65.

104. Wang J, Wolf RM, Caldwell JW, Kollman PA, Case DA. Development and testing of a general Amber force field. J Comput Chem. 2004;25(9):1157-74.

105. Hanwell MD, Curtis DE, Lonie DC, Vandermeerschd T, Zurek E, Hutchison GR. Avogadro: An advanced semantic chemical editor, visualization, and analysis platform. J Cheminform. 2012;4(8):17.

106. Frisch MJ, Trucks GW, Schlegel HB, Scuseria GE, Robb MA, Cheeseman JR, et al. Gaussian 09, Revision B.01. Gaussian 09, Revision B.01, Gaussian, Inc., Wallingford CT. 2009.

107. Wang J, Wang W, Kollman PA, Case DA. Automatic atom type and bond type 
perception in molecular mechanical calculations. J Mol Graph Model. 2006;25(2):247-60.

108. Abraham MJ, Murtola T, Schulz R, Páll S, Smith JC, Hess B, et al. Gromacs: High performance molecular simulations through multi-level parallelism from laptops to supercomputers. SoftwareX. 2015;1-2:19-25.

109. Jorgensen WL, Chandrasekhar J, Madura JD, Impey RW, Klein ML. Comparison of simple potential functions for simulating liquid water. J Chem Phys. 1983;79(2):926-35.

110. Sehnal D, Vařeková RS, Berka K, Pravda L, Navrátilová V, Banáš P, et al. MOLE 2.0: Advanced approach for analysis of biomacromolecular channels. J Cheminform. 2013;5(8):39.

111. Peng DY, Robinson DB. A New Two-Constant Equation of State. Ind Eng Chem Fundam. 1976;15(1):59-64.

112. Depci T, Sarikaya M, Prisbrey KA, Yucel A. Computational Chemistry Approach to Interpret the Crystal Violet Adsorption on Golbasi Lignite Activated Carbon. IOP Conf Ser Earth Environ Sci. 2016;44(5):52026.

113. Wang Q, Jia Q, Ma P. Prediction of the acentric factor of organic compounds with the positional distributive contribution method. J Chem Eng Data. 2012;57(1):16989.

114. Schrödinger, LLC. The $\{$ PyMOL $\}$ Molecular Graphics System, Version 1.8. 2015.

115. Baker NA, Sept D, Joseph S, Holst MJ, McCammon JA. Electrostatics of nanosystems: Application to microtubules and the ribosome. Proc Natl Acad Sci. 2001;98(18):10037-41.

116. Franklin RE. Crystallite Growth in Graphitizing and Non-Graphitizing Carbons. Proc R Soc A Math Phys Eng Sci. 1951;209(1097):196-218.

117. CZEPIRSKI L, SZCZUROWSKI J, BAŁYS M, CIESIŃSKA W, MAKOMASKI G, ZIELIŃSKI J. Pore structure of activated carbons from waste polymers. Inżynieria i Ochr Środowiska, t16, nr 3. 2013;(3):353-9.

118. Zhi M, Yang F, Meng F, Li M, Manivannan A, Wu N. Effects of Pore Structure on Performance of An Activated-Carbon Supercapacitor Electrode Recycled from Scrap Waste Tires. ACS Sustain Chem Eng. 2014;2(7):1592-8.

119. Inagaki M. Pores in carbon materials-Importance of their control. Xinxing Tan Cailiao/ New Carbon Mater. 2009;24(3):193-222.

120. Bui TX, Choi H. Influence of ionic strength, anions, cations, and natural organic matter on the adsorption of pharmaceuticals to silica. Chemosphere. 2010;80(7):681-6.

121. Wong KT, Yoon Y, Snyder SA, Jang M. Phenyl-functionalized magnetic palm-based powdered activated carbon for the effective removal of selected pharmaceutical and endocrine-disruptive compounds. Chemosphere. 2016;152:71-80. 